MASTER
LA-8042, Vol. II

UC-15 and UC-83

Issued: April 1980

\title{
Materials Management in an \\ Internationally Safeguarded \\ Fuels Reprocessing Plant
}

\author{
E. A. Hakkila \\ D. D. Cobb \\ E. A. Kern \\ H. A. Dayem \\ R. J. Dietz \\ J. T. Markin \\ J.P. Shipley \\ J.W. Barnes \\ L. Scheinman*
}

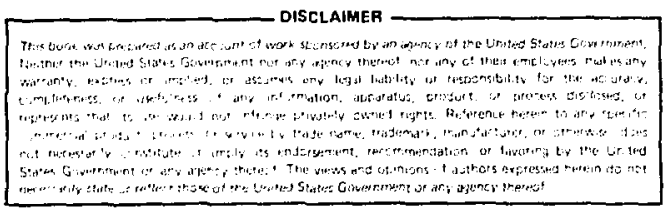

* LASL Consultant. Professor of Government, Cornell University, 628 Clark Hall, ithaca, NY 14853.

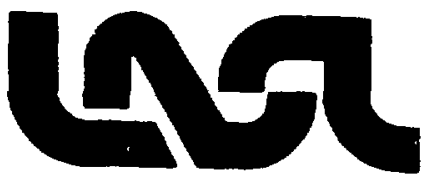


1. INTRODUCTION 2

A. Background of the Study 2

B. International Reprocessing Capabilities 4

C. Scope of the Study 5

D. Orqanization of the Report 8

II. THE REFERENCE FACILITIES 9

III. OPERATOR'S SAFEGUARDS SYSTEM: REQUIREMENTS AND STRUCTURE $\quad 11$

A. IAEA Requirements for States' Accounting Systems 11

1. Specific IAEA Guidance for Reprocessing Plants 12

2. Advanced Safeguards for Reprocessing Plants 14

B. Safeguards System Structure 16

$\begin{array}{ll}\text { C. Safequards System Security and Reliability } & 17\end{array}$

IV. OPERATOR'S SAFEGUARDS SYSTEM: MATERIALS

MEASUREMENT AND ACCOUNTING STRATEGJES

A. Introduction 19

B. Large Reference Facilities 19

1. Conventional Materials Accouricing 19

a. MBA 1--Fuel Receiving, Storage, Chop, and Leach 20

b. MBA 2--Chemical Separations Process 26

c. MBA 3--Uranyl Nitrate Product 32

d. MBA 4--Plutonium Nitrate Product Storage 33

e. MBA 5--Conversion Process 34

f. MBA 6--Plutonium Oxide Storage 34

2. Dynamic Materials Accounting 34

a. Chemical Separations Process Area 35

(1) UPAA 1 2--Chemical Separations Process 36

(2) UPAA 1--Codecontamination-Partitioning 36

(3) UPAA 2--Plutonium Purification Process 41

b. Canversiori Pracess 41

(1) UPAA 34 5--Canversion Process Area 41

(2) UPAA 3, UPAA 4, UPAA 5--Conversion
Process Lines

(3) UPAA 3A, UPAA 4A, UPAA 5A--Feed-Adjust/ Precipitation Processes 43

(4) UPAA 3B, UPAA 4B, UPAA 5B--

Calcination/Product Loadout Processes $\quad 44$

C. Small Reprocessing Plant 44

1. The Japan Atomic Energy Research Institute
(JAERI) Study

2. Conventional Materials Accounting 46

3. Dynamic Materials Accounting 49 
CONTENTS (cont)

V. OPERATOR'S SAFEGUARDS SYSTEM: EFFECTIVENESS OF THE MATERIALS MEASUREMENT AND ACCOUNTING SYSTEM 52

A. Introduction 52

B. Modeling, Simulation, and Analysis Techniques 52

1. Mode ling and Simulation Approach 52

a. Process Model 53

b. Measurement Models 53

c. Materials Balances 53

2. Data Analysis Techniques 54

a. Shewhart Chart 55

b. Cusums 55

c. Uniform Diversion Test 55

d. Sequential $V$ ariance Test 56

e. Smoothed Materials Balance Test 57

f. Wilcoxon Rank Sum Test 57

3. Data Analysis Graphic Aids 58

a. Alarm Charts 58

b. Examples 59

4. Systerns Performance Analysis 63

a. Performance Surfaces 63

b. Cusum Performance Surfaces 63

c. Examples 64

C. Large Reference Facility 66

1. Conventional Materials Accounting 66

a. MBA ?--Chemical Separations Process 66

b. MBA 5--Conversion Process 67

2. Dynamic Materials Accounting 67

a. Chemical Separations Are? 68

(1) UPAA I 2--Chemical Separations 68

(2) UPAA 1--Codecontamination-Partitioning 69

(3) UPAA 2--Plutonium Purification 71

b. Conversion Process Area 73

(1) UPAA 34 5--Conversion Process Area 73

(2) UPAA 3, 4, and 5--Conversion Process Lines 77

D. Materials Accounting in a Small Plant 79

1. Conventional Materials Accounting 79

2. Dynamic Materials Accounting 80

VI. INTERNATIONAL VERIFICATION 83

A. Introduction 83

B. Diversion Possibilities 87

1. Possible Diversion Locations 87

2. Possible Diversion Patterns 88

3. Mode of Physical Removal 88

4. Concealment Activities 88

a. Diversion Hidden by Measurement Uncertainties 89

b. Falsification 89 
CONTENTS (cont)

C. Verification Activities--General 90

1. Inspections 91

2. Measures 91

3. Containment and Surveillance 92

4. Materials Accounting 93

a. Data Analysis 94

b. Materials Balance Methods 97

(1) Cleanout Physical Inventory Taking 98

(2) Draindown Physical Inventory Taking 98

(3) Running Physical Inventory Taking 98

(4) Running Rook Inventory Taking 98

D. Verification Activities--Sperific 99

1. MBA l--Fuel Receiving, Storage, Chop, and Leach 99

a. Fuel Receiving and Storage 99

b. Fuel Chop, Leach, and Input Accountability 100

2. MBA 2--Chemical Separations Process 101

a. UPAA 1--Codecontamination-Partitioning Process

102

b. UPAA 2--Plutonium Purification Process 103

c. UPAA 12 2--Chemical Separations Process 104

3. MPA 4--Plutonium-Nitrate Product Storage 104

4. MBA 5--Conversion Process 105

VII. INSTITUTIONAL ARRANGEMENTS 107

A. Introduction 107

B. Historical Evolution of International Safeguards 107

C. Basis for International Safeguards Arrangements 108

D. Institutional Issues Concerning Near-Real-Time
Accounting

1. Operator Acceptance 110

2. IAEA Verification 111

E. International Management Strategies $\quad 114$

1. International Plutonium Storage 116

2. Multinational Ownership 118

3. International Fuel-Cycle Centers 119

VIII. RESULTS, RECOMMENDATIONS, CONCLUSIONS 123

A. International Safeguards Requirements 123

]. Agency Requirements $1 ? 3$

2. The State's Requirements 124

3. Institutional Arrangemerits 124

B. The Operator's Safeguards System 125

l. Safequards System Structure 125

2. The Materials Measurement and Accounting System 125

3. Effectiveness of the MMAS 126 


\section{CONTENTS (cont)}

C. Design Criteria and Identified Problem Areas

1. NDA on Spent Fuel

2. Input Accountability

3. Solvent-Extraction Contactors

4. Codecontamination Cycle

5. Process Tanks

6. Process Buffer Tanks

7. Product Concentration

130

8. Process Stream Measurements 130

9. Instrument Accessibility

130

10. Redundant Instrumentation 130

11. Computer Data Handling 130

D. Recommendations and Conclusions 130

1. Institutional Arrangements 130

2. Process Design 130

3. Materials Accounting 131

4. Reactor-Reprocessing Plant Correlations 131

5. Verification 131

6. Integration of Materials Accounting with 132

7. Demonstration 132

$\begin{array}{ll}\text { ACKNOMLEDGMENTS } & 133\end{array}$

$\begin{array}{ll}\text { REFERENCES } & 134\end{array}$ 
TABLES

I Worldwide Commercial LWR Reprocessing Plants 5

II Other Commercial Fuel Reprocessing Plants 6

III Operator's Precision and Frequency of Conventional

$\begin{array}{ll}\text { Materials Balance Accounting } & 13\end{array}$

IV Quantities of Safeguards Significance $\quad 14$

V Estimated Material Conversion Times 15

VI Flow Key Measurement Points for Conventional Materials $\begin{array}{ll}\text { Accounting in the Reference Facilities } & 21\end{array}$

VII Inventory Key Measurement Points for Conventional Materials Accounting in the Reference Facilities

VIII Remote Samplers to SAC 4 29

IX Remote Samplers to SAC $8 \quad 30$

$\times \quad$ Remote Samplers to Uranium Glovebox 30

XI Remote Samplers to Plutonium Glovebox 31

XII Local Samplers to HCLA 31

XIII Analytical Methods Used in Reference Plants 32

XIV Quantities of Plutonium in Daily Samples 33

XV Measurements Added for Dynamic Accountability
in the Chemical Separations Process

XVI Measurements Added for Dynamic Accountability
in the Conversion Process

XVII Measurement Points in the Reference Small
Chemical Separations Plant

$\begin{array}{ll}\text { XVIII } & \text { Flow and Inventory Key Measurement Points for } \\ \text { Conventional Materials Accounting at Tokai-mura } & 49\end{array}$

XIX Measurements Added for Dynamic Accountability
at Tokai-mura

XX Alarm Classification for the Alarm-Sequence Chart 58 
TABLES (cont)

XXI MBA 2--Chemical Separations Conventional Materials Accounting

XXII MBA 5--Conversion Process Conventional Materials Accounting

XXIII UPAA 12 --Chemical Separations Dynamic Materials Accounting

XXIV UPAA I--Codecontamination-Partitioning Dynamic Materials Accounting

XXV UPAA 2--Plutonium Purification Dynamic Materials Accounting, 8-h Balances

XXVI UPAA 2--Plutonium Purification Dynamic Materials Accounting, l-h Balances

XXVII UPAA 34 5--Conversion Dynamic Materials Accounting

XXVIII UPAA 3, UPAA 4, UPAA 5--Conversion Process Lines Dynamic Materials Accounting

XXIX Small Chemical Separations Plant Conventional Materials Accounting

XXX Small Chemical Separations Plant Dynamic Materials Accounting

XXXI Uranium-235 Materials Accounting in the Reference Facilities

XXXII Plutonium Materials Accounting in the Reference Facilities 


\section{FIGURES}

1 Power reactor nuclear-fuel cycle 3

2 Structure of the safeguards system 17

3 MBAs in the reference facilities 20

4 UPAAs in the chemical separations process area 35

5 Dissolution-coseparation process 37

$6 \quad$ Plutonium purification process 38

7 Conversion process block diagram 42

8 UPAAs in the conversion process 43

$9 \quad$ Tokai codecontamination-partitioning process 47

10 Tokai plutonium purification process 48

11 UPAAs in the reference small chemical separations facility 51

12 Shewhart and alarm charts 60

13 Cusum and alarm charts 61

14 UDT and alarm charts 62

15 Three-dimensional space of performance surfaces 64

1.6 Cusum performance surfaces for two accounting cases;
worst (upper), best (lower)

17 UPAA 12 --Cusum performance surfaces; Case 1 (upper), Case 2 (lower) 70

18 UPAA 2--Performance surfaces; Cusum (upper), UDT (lower) 74

19 UPAA 2--Performance surfaces detection probability difference 75

20 UDT-Cusum detection sensitivities 76

21 Conversion process area Cusum performance surfaces;
Case 1 (upper), Case 2 (lower)

Small plant performance surfaces; Case 1 (upper),
Case 2 (lower)

23 Structure of the international safeguards system 84

24 The Bonded Crucial Facility (BCF) 121 


\section{GLOSSARY}

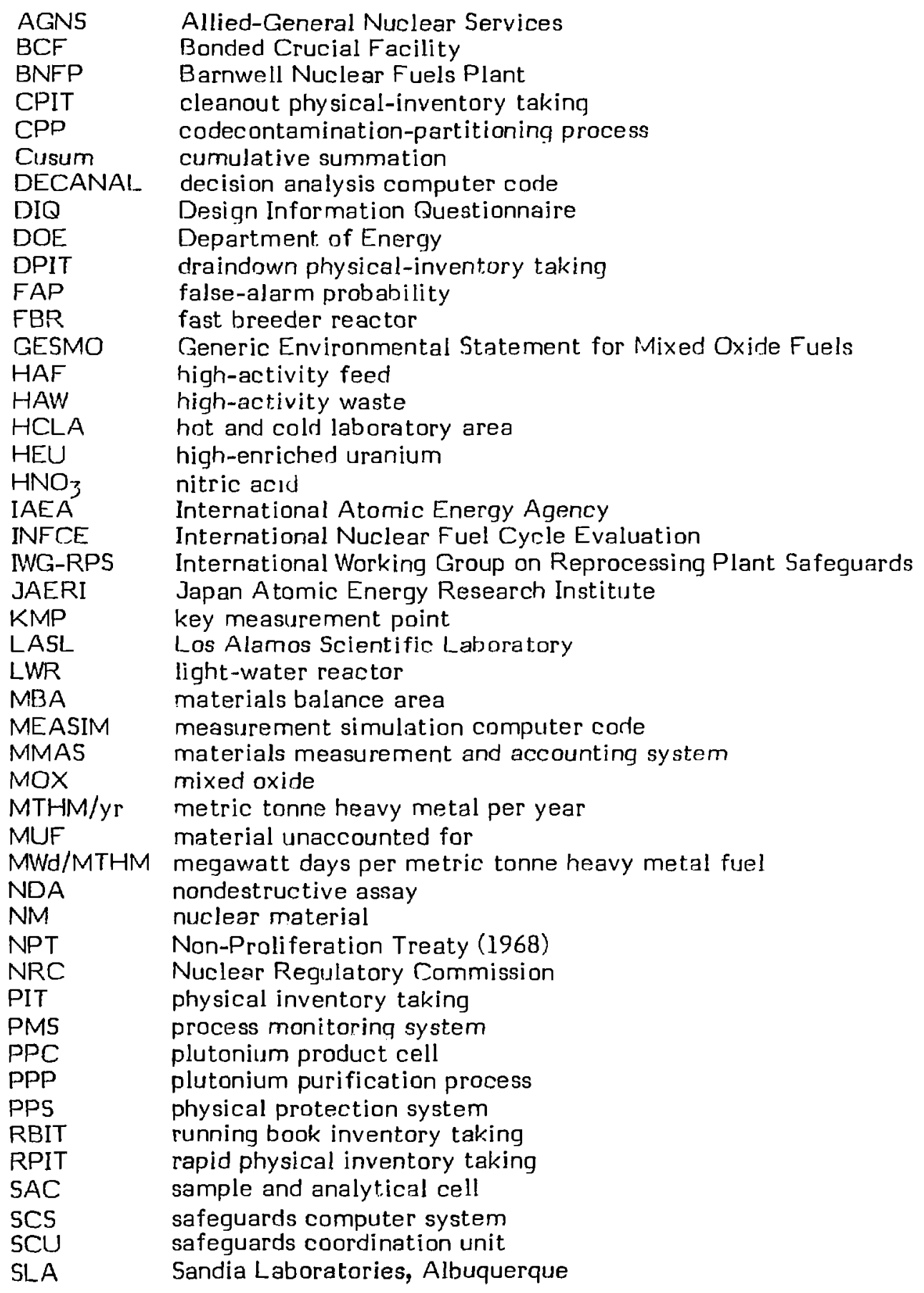




$\begin{array}{ll}\text { SMBT } & \text { smoothed materials balance test } \\ \text { S/R } & \text { shipper/receiver } \\ \text { SRL } & \text { Savannah River Laboratory } \\ \text { SRP } & \text { Savannah River Plant } \\ \text { SVT } & \text { sequential variance test } \\ \text { UDT } & \text { uniform diversion test } \\ \text { UPAA } & \text { unit process accounting areas }\end{array}$

\section{Purex Process Identifiers}

Contactors

A extraction-scrub for U-Pu or Pu alone

B U-Pu partition or Fu strip

C U-Pu strip

D extraction-scrub for Pu alone

$H$ preparation columns or streams

$\begin{array}{cl}\text { Stream } & \\ \text { A } & \text { aqueous } \\ F & \text { feed } \\ \text { IS } & \text { intermediate scrub } \\ O & \text { ornanic } \\ P & \text { product containing } \mathrm{Pu} \text { or } \mathrm{Pu}+\cup \\ R & \text { raffinate (no appreciable } \mathrm{U} \text { or } \mathrm{Pu} \text { ) } \\ \mathrm{S} & \text { scrub } \\ U & \text { product containing only } U \\ W & \text { waste (no appreciable } U \text { or } \mathrm{Pu} \text { ) } \\ X & \text { extractant }\end{array}$




\title{
MATERIALS MANAGEMENT IN AN INTERNATIONALLY SAFEGUARDED FUELS REPROCESSING PLANT
}

\author{
Volume II
}

\author{
by \\ E. A. Hakkila, D. D. Cobb, H. A. Dayem, R. J. Dietz, \\ E. A. Kern, J. T. Markin, and J. P. Shipley \\ LASL Safeguards Systems Staff (Q-4) \\ J. W. Barnes \\ LASL Engineering Design Staff (WX-4) \\ L. Scheinman \\ Cornell University
}

\begin{abstract}
The first volume of this report summarizes the results and conclusions for this study of conventional and advanced nucleas materials accounting systems applicable for both large (1500 MTHM/yr) and small (210 MTHM/yr) spent-fuel reprocessing facilities subject to international verification. The second volume describes the requirements and functions of materials measuremerit and accounting systems (MMAS) and conceptual designs for an MMAS incorporating both conventional and near-real-time (dynamic) measurement and accounting techniques. Effectiveness evaluations, based on recently developed modeling, simulation, and analysis procedures, show that conventional accountability can meet IAEA goal quantities and detection times in these reference facilities only for lowenriched uranium. Dynamic materials accounting may meet IAEA goals for detecting the abrupt (1-3 wk) diversion of $8 \mathrm{~kg}$ of plutonium. Current materials accounting techniques probably cannot meet the $I-y_{r}$ protracted-diversion goal of $8 \mathrm{~kg}$ for plutonium. Supporting information, including detailed facility and process descriptions, and details of the design and analysis procedure are given in a third volume (Appendixes).
\end{abstract}




\section{INTRODUCTION}

The nuclear fuel cycle consists of a series of unit operations beginning with the mining of uranium ore and ending with the interment of radioactive waste (Fig. 1). The spent-fuel reprocessing operation for light-water reactor (LWR) fuels recycle, including recovery of plutonium and conversion of plutonium nitrate to oxide, involves handling plutonium in its most attractive form for diversion from the commercial fuel cycle. Nuclear materials (NM) accountability is of fundamental importance in ensuring that NM recovered from the reprocessing operations are retained in the nuclear fuel cycle. Safeguards concepts inust address domestic materials management requirements and international verification.

\section{A. Background of the Study}

Conceptual designs of advanced domestic materials management systems for safeguarding NM in the three major components of the back end of the uranium-plutonium fuel cycle (chemical separation, ${ }^{1}$ plutonium nitrate-to-oxide conversion, ${ }^{2}$ and mixedoxide (MOX) fuel fabrication ${ }^{3}$ were developed and evaluated previously by the Safeguards Systems Group of the Los Alamos Scientific Laboratory (LASL). Some of the problems associated with extending these concepts to international safeguards and integrating the materials accounting system with the containment and surveillance systern also were addressed. ${ }^{4}$ Reference 4 presents concepts for the development of an advanced materials accounting system and the concomitant International Atomic Energy Agency (IAEA) verification that would be necessary for internationally safeguarded high-throughput reprocessing and conversion facilities. The present study continues the development of concepts described in Ref. 4 and is being performed in conjunction with a parallel effort by the Sandia Laboratories, Albuquerque (SLA) to develop internationally acceptable containment/surveillance techniques.

In these studies the 1500-metric-tonne heavy metal per year (MTHM/yr) Allied-General Nuclear Services (AGNS) plant at Barnwell, South Carolina, is used as the reference reprocessing facility, ${ }^{5}$ and a 30-MT/yr (plutonium) conversion plant that is based on a Savannah River Laboratory (SRL) design is the reference conversion facility. 6,7 The conversion plant uses plutonium (III) oxalate precipitation with subsequent calcining to produce reactor-quality $\mathrm{PuO}_{2}$. These plants are typical of plants that could be on-stream in the 1990s. In addition, a small (210-MTHM/yr) 


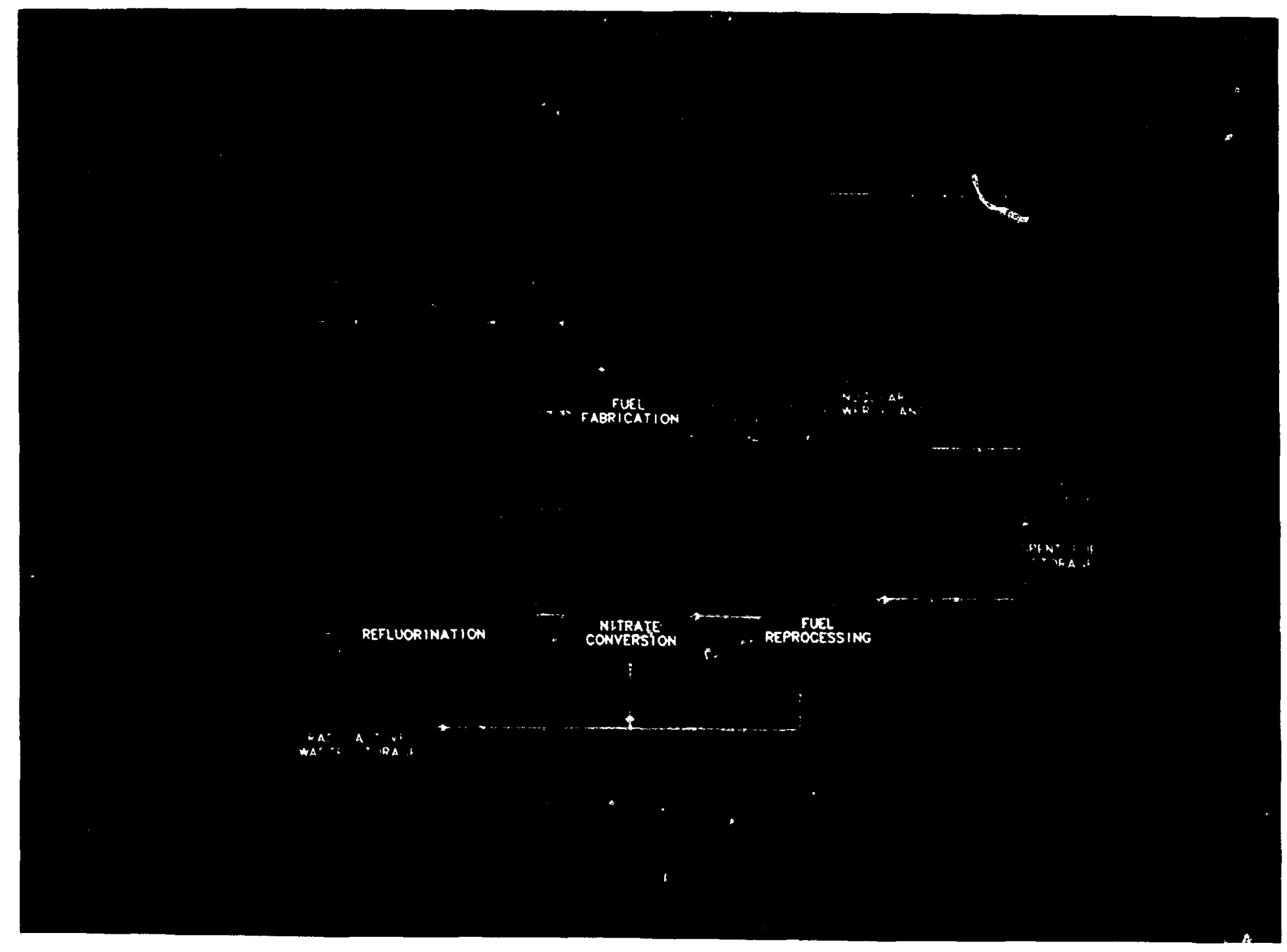

Fig. 1. Power reactor nuclear-fuel cycle. 
reprocessirg plant was studied, using the Japanese plant at Tokai-Mura as the reference facility. The Tokai plant is considered typical of existing facilities.

In this study, We rely heavily on previously developed concepts for dynamic materials accounting in the State's safeguards system, $1,2,3,8$ and attempt to modify those concepts to accommodate the IAEA verification required by existing international agreements. ${ }^{9,10}$ The study also incorporates concepts published by members of the IAEA staff ${ }^{11,12}$ and the results of discussions arising from International Nuclear Fuel Cycle Evaluation (INFCE) and the IAEA-sponsored International Working Group on Reprocessing Plant Safeguards (MG-RPS).

\section{B. International Reprocessing Capabilities}

The capability for reprocessing commercial LWR fuels to recover the fissile value of their contained uranium and plutonium has existed in the US, Europe, and Asia since the 1960s, mostly on a pilot-plant scale (plant capacities < $300 \mathrm{MTHM} / \mathrm{yr}$ ). On the basis of the experience gajined from these plants, larger plants with capacities to $1500 \mathrm{MTHM} / \mathrm{yr}$ have been built or designed. (Table 1 summarizes present and planned reprocessing capacities for the nations outside the centrally planned economies.) In addition, the EXXON Company recently filed a preliminary safety analysis report for a $2.100-M T H M / y r$ reprocessing plant at Oak Ridge, Tennessee, ${ }^{27}$ but withdrew its construction application pending the results of the INFCE and the US Generic Environmental Statement for Mixed Oxide (GESMO). Pakistan has contracted for construction of a small reprocessing plant to be built by France. After providing $95 \%$ of the design effort and commencing construction, the French cancelled the agreement and offered instead to construct a coprocessing plant. The offer was rejected by Pakistan. ${ }^{28}$ China also offered to build the Pakistani plant, ${ }^{29}$ but the status of the plant is still in doubt.

Spain, Brazil, and South Korea have shown interest in having their own indigenous reprocessing capability.

Commercial plants to reprocess uranium-thorium, fast-breeder reactor (FBR), and low-enriched uranium metal fuels also exist or are fianned. Most of them (Table II) are of pilot-plant size to study Purex reprocessing techniques, but could be adapted to reprocessing commercial reactor fuel.

Worldwide reprocessing requirements projected to 1990 have been summarized by the IAEA. ${ }^{34}$ The accumulated quantity of discharged fuel is estimated to be in the range $65-95 \times 10^{3} \mathrm{MTHM}$. Existing reprocessing plants have an estimated capacity to reprocess $18 \times 10^{3}$ MTHM. 
TABLE I

WORLDWIDE COMMERCIAL LWR REPROCESSING PLANTS

\begin{tabular}{|c|c|c|c|c|c|}
\hline Nation & Plant & $\begin{array}{l}\text { Capacity } \\
(\mathrm{MT} / \mathrm{Yr}) \\
\end{array}$ & Comments & Status & Ref. \\
\hline USA & NFS & 300 & $\begin{array}{l}\text { Operated 1966-1972; processed } \\
630 \text { HT fuel; pulsed columns }\end{array}$ & Shutdown indefinitely & 13 \\
\hline USA & Barnwe11 & 1500 & $\begin{array}{l}\text { Centrifugal contactor; pulsr } 3 \\
\text { columns }\end{array}$ & $\begin{array}{l}\text { In cold check-out; } \\
\text { startup deferred }\end{array}$ & 5,14 \\
\hline USA & GE-Mor $\mathrm{r}$ is & 300 & $\begin{array}{l}\text { Aqua-fluor; plant completed } \\
\text { but rever operated }\end{array}$ & Indef initely gostponed & \\
\hline uk & Windscale-1 & 400 & $\begin{array}{l}\text { Mixer-settler: headend of } \\
\text { Pu production reprocessing } \\
\text { plant modifled for LWR fuel }\end{array}$ & $\begin{array}{l}\text { Operational } 1980 \text {; limited } \\
\text { to } 150 \mathrm{MT} / \mathrm{yr} \text { by metal fuel } \\
\text { reprocessing requirements }\end{array}$ & 16 \\
\hline $\mathrm{ux}$ & $\begin{array}{l}\text { Windscale-2 } \\
\text { (THORP) }\end{array}$ & 1200 & Pulsed columns & $\begin{array}{l}\text { Scheduled for completion } \\
\text { in } 1986\end{array}$ & 16 \\
\hline FRG & $\begin{array}{l}\text { Kar lsruhe- } \\
\text { WAK }\end{array}$ & 35 & Mixer-settler: pilot plant & Operational since 1971 & 17 \\
\hline FRG & Gor leben & 1400 & $\begin{array}{l}\text { Pulsed columns, } 2 \text { parallel } \\
\text { lines; part of integrated } \\
\text { fuel cycle center }\end{array}$ & Indefinitely deferred & 18 \\
\hline Japan & Tokai-1 & 210 & Mixer-settler; pilot plant & Operational since 1977 & 19,20 \\
\hline Japan & $?$ & 1500 & Pulsed column & $\begin{array}{l}\text { Planned for } 1990 \text { s opera- } \\
\text { tion; second } 1500-\text { MT plant } \\
\text { possible }\end{array}$ & 21 \\
\hline rrance & LaHague-1 & $\begin{array}{l}400(1978) \\
800(1980)\end{array}$ & $\begin{array}{l}\text { Mixer-zettler; headend } \\
\text { can accept most types of } \\
\text { Fuel; higher capacity for } \\
\text { metalilic fuels }\end{array}$ & Comnercial reprocessing & 22 \\
\hline France & $\begin{array}{l}\text { LaHague- } \\
\text { UP } 3-A \text {. } \\
\text { UP } 3-B\end{array}$ & 800 each & In design stage & $\begin{array}{l}\text { UP }_{3-A} \text { expected to be } \\
\text { operational } 21985\end{array}$ & 22 \\
\hline Italy & Saluggia & 30 & $\begin{array}{l}\text { Originally designed for } \\
\text { MTR fuels; modified in } \\
1975 \text { for LWR fuels }\end{array}$ & Operational since 1970 & 23 \\
\hline India & Trombay & 60 & $\begin{array}{l}\text { Pulsed columns-anion } \\
\text { exchange; pilot plant }\end{array}$ & Operational 1964-1977? & 24,25 \\
\hline India & Tar apur & 100 & $\begin{array}{l}\text { Pulsed columns; Np recovery; } \\
\text { oxalate conversion process }\end{array}$ & $\begin{array}{l}\text { Operational (cold } \\
\text { check-out in 1977) }\end{array}$ & 25 \\
\hline Belgium & Mol & 60 & & $\begin{array}{l}\text { Operated by Eurochemic } \\
\text { from } 1966-1976 ; \text { taken over } \\
\text { for experimental purposes } \\
\text { by Belgonucleaire }\end{array}$ & 26 \\
\hline
\end{tabular}

\section{Scope of the Study}

The immediate prospect of introducing reprocessing and conversion facilities into the commercial nuclear fuel cycle underscores a concern that material produced in such a facility might be used for nuclear explosives, either through the diversion of fissile material being processed at the plant or through clandestine use of the facility to process fissile material from undeclared feed. Traditional safeguards methods, which depend primarily upon materials balancing by periodic shutdown, cleanout, and physical inventory, may provide adequate safeguards for small-scale demonstration and pilot plants only if 
TABLE I I

OTHER COMMERCIAL FUFL REPROCESSING PLANTS

\begin{tabular}{|c|c|c|c|c|c|}
\hline Nation & Plant & $\begin{array}{l}\text { Capacity } \\
\text { (MT/yr) }\end{array}$ & Comments & Status & Ref. \\
\hline Italy & $\begin{array}{l}\text { ITREC } \\
\text { (Matera) }\end{array}$ & $?$ & $\begin{array}{l}\text { Th-u fuels; pilot plant } \\
\text { eventually will be modified } \\
\text { to process Italian FBR fuels }\end{array}$ & Hot operation since 1975 & 23 \\
\hline FRG & Julich & 0.6 & $\begin{array}{l}\text { Th-U fuels; pilot experimental } \\
\text { plant; mixer-settlers }\end{array}$ & Operational in 1980 & 30 \\
\hline UK & Dounreay & $\begin{array}{l}\text { Pilot: } \\
\text { plant }\end{array}$ & FBR fuel; mini mixer-settlers & Operational in 1977 & 31 \\
\hline UK & Dounreay & 300 & FBR fuel & In design stage & 31 \\
\hline France & Marcoule & $900-1200$ & $\begin{array}{l}\text { Pulsed columns; for natural } \\
\text { U, MTA fuels }\end{array}$ & $\begin{array}{l}\text { Used since } 1958 \text { for } \\
\text { military fuels }\end{array}$ & 32 \\
\hline ISA & $\begin{array}{l}\text { HEF, Oak } \\
\text { Ridge }\end{array}$ & 150 & $\begin{array}{l}\text { In design stage; for } T h-U \\
\text { and FBR fuels }\end{array}$ & $\begin{array}{l}\text { Tentatively scheduled for } \\
\text { 19B6-198B }\end{array}$ & 33 \\
\hline
\end{tabular}

in-process inventory is measured for each campaign ( $1-2$ wk). Large-scale reprocessing and conversion plants require improved safequards measures to detect the diversion of relatively small but weapons-significant quantities of NM that might be obscured by the statistical and measurement uncertainties inherent in high-throughput facilities. Such improved measures include dynamic materials measurement and accounting to yield more sensitive and timely measurement information than does conventional accounting and modern containment and surveillance techniques to assure that the facility is not being deliberately misoperated and that information gathered by the materials measurement and accounting system (MMAS) reflects the true status of NM within the facility.

The basis for most current international safeguards arrangements is the Treaty on the Nun-Proliferation of Nuclear Weapons, ${ }^{10}$ agreed to by over 100 signatory nations since 1970. The detailed terms and conditions under which specific facilities are safeguarded under the Non-Proliferation Treaty (NPT) are negotiated with the IAEA, in accord with the general conditions of Article III of the NPT, set forth in IAEA document INFCIRC/153. ${ }^{9}$

The objective of international safeguards, as declared by these documents, is the "...timely detection of diversion of significant quantities of nuclear material from peaceful muclear activities..., and deterrence of such diversion by the risk of early detection." The emphasis is on "...the use of materials accountancy as a safeguards measure of fundamental importance, with containment and surveillance as important complementary measures.....$^{9}$ The manner and frequency of inspections for compliance are negotiated between the IAEA and the host nation on a case-by-case basis and are documented in the so-called "Subsidiary Arrangements and Facility Attachments." 
The specific objective of the international safeguards system is the independent verification of the facility-generated reports and statements submitted by the State to the IAEA. The independently verified data are the basis for a conclusion on nondiversion or diversion of NM. The inspector's verification activities include the independent measurement of materials and audits of the operator's records, as wel! as independent observations on the integrity of the containment. The provision for independent verification of the facility data is indispensable in the design of a State-operated system that is consistent with the objectives of the IAE.A. Provisions to facilitate independent verification are called out in the design information of the facility attachment.

INFCIRC/153, para. 43, stipulates that the design information shall include "description of the existing and proposed procedures at the facility for nuclear material accountancy and control, with special reference to materials balance areas (MBAs) established by the operator, measurements of flow and procedures for physical inventory taking."

Furthermore, para. 47 states that "...the Agreement should provide that design information sha!l be reexamined in the light of changes in operating conditions, of developments in safeguards technology or of experience in the application of verification procedures, with a view to modifying the action the Agency has taken pursuant to (examination of design information)." Thus, although Agency verification of accountability data is based on design information filed with the Agency, provision is made to upgrade State's accounting and Agency verification techniques as improvements in safeguards technology become available.

The IAEA criteria for safeguarding NM are specified in INFCIRC/66 35 for non-NPT states and INFCIRC $/ 153^{9}$ for NPT states. To base safeguards standards on quantitative rather than qualitative factors, the Agency is attempting to defire and establish goals for significant quantities of $N M$ and conversion times. The significant quantity is understood to be the approximate quantity of fissionable material required for a single nuclear explosive device; conversion time is defined as the minimum time required to convert different forms of $N M$ to the metallic components of a nuclear explosive device. Values for significant quantity and conversion time have not been adopted by the IAEA; however, values of $8 \mathrm{~kg}$ of plutonium with a detection time of 1-3 wk for unirradiated material are being considered. 36 These are discussed in more detail in Sec. IV. 


\section{Organization of the Report}

This stud; is intended to provide the design concepts necessary for a modern NM measurement and accounting system and to assess its effectiveness in enhancing the safeguards system for a chemical separations-plutonium nitrate conversion plant. The large reference facility chosen for this study is typical of one that might be built in the 1980 s and is based an the AGNS-BNJFP (Barnwell Nuclear Fuels Plant) design for reprocessing and SRL-SRP (Savannah River Plant) design for conversion. The MMAS that has been superimposed on the model plant uses current technology and hardware that could be made available in the appropriate time frame. The safeguards system has been applied to the existing process with minimal operational impact and equipment modification.

The model large reprocessing facility was originally designed in the 1960 s to meet the (then) existing US domestic regulatory and safeguards requirements. As a commercial facility it was optimized for maximum throughput and economic recovery and not as an experimental facility or a state-of-the-art safeguards demonstration. For these reasons, access to the process for measurement modification is difficult. Nevertheless, near-real-time materials accounting concepts are being evaluated by AGNS personnel to determine the feasibility of incorporating additional measurement instruments.

Application of near-real-time accounting to an existing small plant also has been considered, based largely on the 0.7-MTHM/day-throughput Tokai plant. 19,20,37,38

The conversion process selected is based on a reference design provided by SRL. The process uses demonstrated technology, developed at LASL, and was selected for maximum ease of process control, product flexibility, and production scaling.

Section 1 of this report discusses the basis for the study. Section II describes the reference facilities used in this study. The structure and capabilities of the operator's (State's) accounting system are reviewed in Secs. III-V. The structure of interr.ational safeguards systems is described in Sec. VI. Institutional problems relating to application of improved NM accountability are discussed in Sec. VII. The results of the study, including recommendations for improved safeguards, are summarized in Sec. VIII.

The appendices discuss in detail the reference facilities and process chemistry; suggest methods to improve NM accounting through improvements in design and operation; and review basic methodology used in developing and assessing improved materials accounting systems. 


\section{THE REFERENCE FACILITIES}

The reference large fuel-reprocessing plant for this study is based on the AGNS chemical separations facility coupled to an oxalate conversion facility designed by SRL.-SRP. The AGNS plant uses conventional Purex technology to process $1500 \mathrm{MTHM} / \mathrm{yr}$ of nuclear fuel, recovering $15 \mathrm{MT} / \mathrm{yr}$ of plutonium as the nitrate solution. ${ }^{1,5}$ The conversion plant can convert $30 \mathrm{MT} / \mathrm{yr}$ of plutonium from the nitrate solution to $\mathrm{PuO}_{2}$ using plutonium (III) oxalate precipitation. In this study the facility throughput was sizer to match the sutput of the reprocessing facility. These designs were selected as typical of plants that will be required in the 1990 s to support a mature nuclear industry.

The reference small fuel-reprocessing plant is based on the 210-MTHM/yr facility operated at Tokai-mura, Japan. ${ }^{19,20,38}$ The facility can recover up to $2100 \mathrm{~kg}$ of plutonium annually as the nitrate solution. A conversion process has not been selected, and the product is stored for future use.

Both reprocessing plants are designed to reprocess LWR reactor fuel having a burnup not exceeding $40000 \mathrm{MWd} / \mathrm{MTHM}$ (megawatt days per metric tonne of heavy metal) after a decay time of at least 160 days. Nominal plutonium concentration of $\sim 1 \%$ is assumed in the fuel. The plutonium nitrate product in both facilities is concentrated to $\sim 250 \mathrm{~g} / \mathrm{L}$. The following differences in process design or operation could be important for materials accounting.

- The AGNSS plant uses a centrifugal contactor for initial fission-product decontamination with pulsed columns for all subsequent extraction, scrub, and strip operations. The Tokai facility employs mixer-settlers throughout.

- The centrifuge for solids removal (fission-product metallic ingots, Zircaloy fines) is located between the accountability tank and process feed tank at AGNS and between the dissolver and accountability tank at Tokai.

- An additional scrub section in the Tokai plant between the fission-product decontamination and the uranium-plutonium partition steps provides an additional 10- to 100-fold improvement in fission-product decontamination before the plutonium purification cycle.

- Buffer tanks are included between the decontamination and partition cycles and between the partition and plutonium purification cycles in the Tokai design.

- Two plutonium purification cycles are used in the AGNS facility; the Tokai facility uses one purification cycle. 
The SRL-SRP design was selected as the conversion facility for the large reference plant because detailed design information is available ${ }^{2,6,7}$ and because LASL and SRP have extensive experience with the process. The process consistently produces a readily filterable precipitate with low losses and is controlled easily at room temperature.

The processes are described in App. A; detailed design information on the reference facilities is available in App. B. Process and design considerations that may improve materials accountability for safeguards in plants to be designed in the future are described in App. $C$. 


\section{OPERATOR'S SAFEGUARDS SYSTEM: REQUIREMENTS AND STRUCTURE}

The overall structure of the operator's safeguards system is developed in this Section. Application of these techniques and the development of the unit process accounting structure is described in Sec. IV. The effectiveness of the operator's MMAS is described in Sec. $V$.

\section{A. IAEA Requirements for States' Accounting Systems}

International safeguards agreements generally provide that the State's safeguards system must be adequate for the Agency to discharge its obligations. Agreements under INFCIRC/66/Rev. $2^{35}$ require that accounting and operating records be maintained for each facility under international safeguards. The State must provide routine accounting reports at specified intervals and special reports in unusual circumstances where losses of NM may be involved.

The State's safeguards obligations are exparided significantly under NPT agreements, as outlined in the model agreement INFCIRC/153. ${ }^{9}$ The State must maintain a system of accounting for and control of all NM subject to safeguards. ${ }^{9,11,39,40}$ Furthermore, the State's system must enable the Agency to verify the State's findings. For its part, the Agency must make full use of the State's system and avoid unnecessary duplication.

The State's accounting system must be based on a structure of MBAs, defined as areas for which each transfer of NM and the physical inventory, when necessary, can be determined. For each MBA, the difference between the book inventory and the physical inventory and its limits of error must be determined at specified intervals.

Subsidiary arrangements negotiated pursuant to the basic agreement include provisions for:

- Measurements of transfer and inventory quantities;

- Evaluation of measurement uncertainty, both precision and accuracy;

- Evaluation of shipper/receiver (S/R) differences;

- Physical inventory procedures;

- Evaluation of accounting data; and

- A system of records and reports.

Accounting and operating records must be maintained for each MBA. Inventory changes are reported every 30 days. The materials balance is reported within 30 days after a physical inventory. For accounting purposes, the NM is apportioned in batches for which the composition and quantity are defined by a single set of specifications or measurements. 
1. Specific IAEA Guidance for Reprocessing Plants. Requirements are negotiated separately for each facility (or class of facilities) under safeguards and are specified in attachments to the basic agreement. The Agency, primarily through expert advisory groups, has proposed guidelines for the operator's safeguards system in various types of facilities, including reprocessing plants. ${ }^{12,41,42}$ The complexity of high-throughput reprocessing facilities and the concomitant verification effort is recognized by providing for a continuous inspection effort. $9,12,35$

Normally, reprocessing plants should be divided into three functionally defined MBAs: spent-fuel receiving and storage, the chemical separations process area, and the product storage area. There may be separate product storage areas for uranium and plutonium. Collocated facilities for conversion of the uranium and plutonium nitrate products would be placed in separate MBAs.

The boundary between the first and second MBAs should be defined functionally so that only S/R differences need be determined for the first MBA. Shipper's values currently are based on the calculated fissile contents of spent-fuel assemblies at the reactor, while receiver's values are based on measurements at the input accountability tank that are adjusted for losses in hulls (and feed-clarification sludge where applicable) and additions from recycled acid and dissolver solution.

The boundary between the second and third MBAs generally should also be defined so that oniy $S / R$ differences need be determined for the third MBA, with shipper's values measured at the product accountability tank and receiver's values determined, for example, at the input to the conversion plant. However, this is not always true. For example, the third MBA of the Tokai facility is a materials unaccounted for (MUF) MBA even though it is defined as a plutonium nitrate storage area. ${ }^{43}$

Thus, the second (process) MBA is a so-called "pure MUF" MBA where materials balances based on transfer and inventory measurements must be determined at specified intervals. Table III gives the expected precision and frequency of conventional materials balance accounting in the separations area of a reprocessing plant and in conversion plants. Estimates are compared from three sources: two IAEA papers (Ref. 11, Part A; Ref. 36), US Nuclear Regulatory Commission (NRC) regulations, ${ }^{44}$ and a projection of the state of the art in conventional US accounting practice. ${ }^{45}$ The IAEA precisions are suggested minimum international standards, and the suggested frequency of physical inventories applies to the relatively small plants ( $<300 \mathrm{MTHM} / \mathrm{yr}$ throughput) currently under Agency safeguards. The NRC rules for plutonium processing have been suspended pending a decision concerning commercial reprocessing in the US. Estimates in Ref. 45 
TABLE III

OPERATOR'S PRECISION AND FREQUENCY OF CONVENTIONAL MATERIALS BALANCE ACCOUNTING

\begin{tabular}{|c|c|c|c|c|c|c|}
\hline \multirow[b]{2}{*}{ Facility } & \multicolumn{2}{|c|}{ IAEA 11,36} & \multicolumn{2}{|c|}{ US $\mathrm{NRC}^{46}$} & \multicolumn{2}{|c|}{ McSweeney et al. 47} \\
\hline & Precision $^{a}$ & Frequency ${ }^{b}$ & Precision $^{a}$ & Frequency & Precision $^{a}$ & Frequency $^{b}$ \\
\hline $\begin{array}{l}\text { Chemical } \\
\text { separations }\end{array}$ & & & & & & \\
\hline $235 U$ & 0.8 & $2-4$ & 0.35 & 2 & - & - \\
\hline $\mathrm{Pu}$ & 1 & $2-4$ & 0.5 & 2 & 0.36 & 2 \\
\hline
\end{tabular}

Nitrate

conversion

$235_{U}$

0.3

$1-2$

0.25

$2-4$

0.25

0.19

6

ane materials balance standard deviation expressed as a percentage of throughput.

$b_{\text {Number }}$ of physical inventories per year.

are based on assumed in-plant measurement capabilities projected from US experience. $^{46}$

Stringent international safeguards effectiveness criteria were proposed recently on the basis of expert advisory group recommendations (Ref. 11, Part A; Refs. 12, 36, 42). The proposed criteria for reprocessing plants include detection of an abrupt (short-term) diversion of a significant quantity $(B \mathrm{~kg})$ of plutonium within days to weeks and detection of the protracted (long-term) diversion of a significant quantity during one year. Corresponding proposed values for $<20 \%$ enriched uranium are $75 \mathrm{~kg}$ of contained $235 \mathrm{U}$ during one year. The recommended false-alarm and detection probabilities are 5\% and 95\%, respectively. Proposed significant quantities and the estimated time to convert various material forms to metal are summarized in Tables IV and $V .36$ Presumably, the detection time should correspond to the conversion time.

In current practice, the operator's safeguards system may need to surpass these goals, because the detection sensitivity of the two-step process (operator's accounting plus Agency verification) generally may be less than that of the operator's system alone. Because criteria for safeguards effectiveness are the subject of international debate, they must be established through negotiations on a case-by-case basis. 
TABLE IV

QUANTITIES OF SAFEGUARDS SIGNIFICANCE

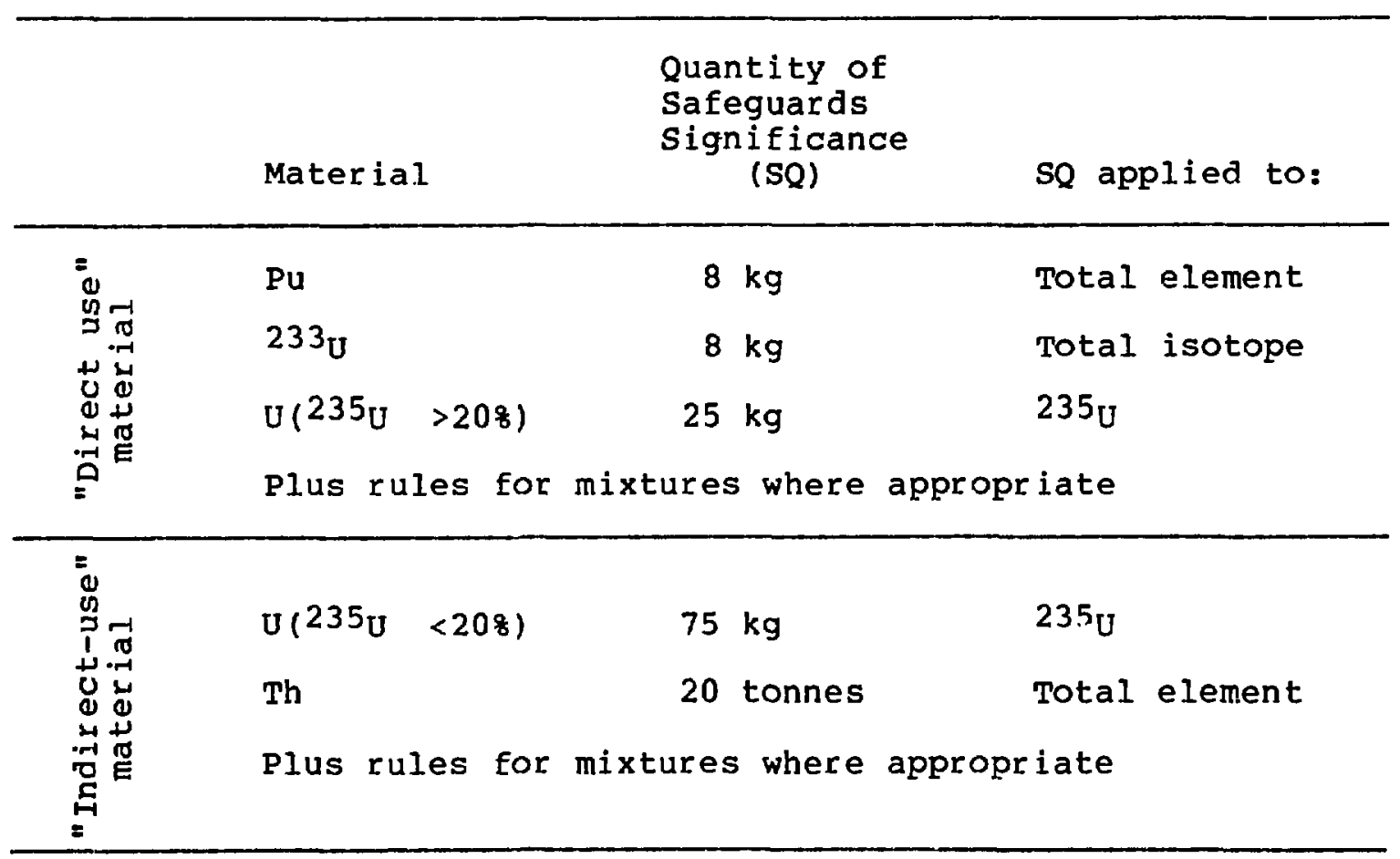

Although the physical protection of NM is the exclusive responsibility of the State, the IAEA through various advisory groups has also promoted the establishment of internationally accepted standards for the States' physical protection systems. The standards are outlined in INFCIRC/225/Rev. $10^{47}$ Certain containment and surveillance measures applied by the State, for example, during the transportation of spent fuel, may bear directly on the application of international safeguards. In such cases, the Agency must be able to verify the State's containment and surveillance system. ${ }^{48}$

2. Advanced Safeguards for Reprocessing Plants. Although large (1000 MTHM/yr) reprocessing plants wil! not come under international safeguards for several years, the IAEA is promoting the development of advanced safeguards concepts for such plants by sponsoring international working groups and by participating in the safeguards research and development activities of Member States. It is generally accepted by the IAEA that 


\begin{tabular}{|c|c|c|c|}
\hline $\begin{array}{c}\text { Material } \\
\text { Classification } \\
\end{array}$ & Beginning Material Form & End Process Form & $\begin{array}{c}\text { Estimated } \\
\text { Conversion } \\
\text { Time } \\
\end{array}$ \\
\hline 1 & $\begin{array}{l}\text { Pu, high-enriched uranium } \\
\text { (HEU), or U-233 Metal }\end{array}$ & $\begin{array}{l}\text { Finished plutonium } \\
\text { or uranium metal } \\
\text { components }\end{array}$ & $\begin{array}{l}\text { Order of } \\
\text { days }(7-10)\end{array}$ \\
\hline 2 & $\begin{array}{l}\mathrm{PuO}_{2}, \mathrm{Pu}\left(\mathrm{NO}_{3}\right) 4 \text {, or } \\
\text { other pure cOmpounds. HEU, } \\
\mathrm{U}-233 \text { oxide, or other pure } \\
\text { compounds. }\end{array}$ & $"$ & $\begin{array}{l}\text { Order of } \\
\text { weeks }(1-3)\end{array}$ \\
\hline 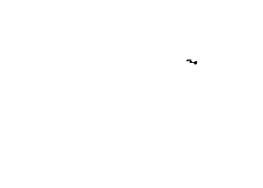 & $\begin{array}{l}\text { MOX or other nonirradiated } \\
\text { pure mixtures of Pu or } \\
\text { U (U-233 }+U-235) \geq 208 \text {. } \\
\text { Pu, HEU and/or U-233 in scrap } \\
\text { or other miscellaneous impure } \\
\text { compounds. }\end{array}$ & $"$ & $\begin{array}{l}\text { Order of } \\
\text { weeks }(1-3)\end{array}$ \\
\hline 3 & $\begin{array}{l}\text { Plutonium, HEU, or U-233 in } \\
\text { irradiated fuels }(\geq 105 \mathrm{Ci} / \mathrm{kg} \\
\text { HEU or } U-233 \text { or plutonium) }\end{array}$ & $"$ & $\begin{array}{l}\text { Order of } \\
\text { months }(1-3)\end{array}$ \\
\hline 4 & $\begin{array}{l}\text { Uranium containing } \leq 208 \quad U-235 \\
\text { and } U-233 ; \text { thor ium }\end{array}$ & $"$ & Order of $1 \mathrm{yr}$ \\
\hline
\end{tabular}

current safeguards measures must be upgraded substantially to meet the stringent safeguards-effectiveness criteria proposed for large reprocessing plants. Some upgrading of safeguards also may be required for small plants if they are to meet the proposed critieria.

Advanced safeguards concepts incorporate various combinations of near-real-time (dynamic) accounting measures with complementary containment and surveillance measures. $1,2,12,49-53$ Rapid nondestructive assay (NDA) measurement techniques with automated data a:equisition and analysis capabilities are common features of the proposed systems. Materials flows and major components of the in-process inventory are monitored by upgraded process-control and on-line accountability instruments. The "process-grade" measurements are frequently backed up by more precise and accurate (but slower) wet chemical analyses. Materials balances are drawn as often as practicable around selected portions of the process, and flow and inventory measurements are correlated throughout the process. Conventional physical inventories are performed infrequently to "recalibrate" the real-time system. Containment and surveillance measures are applied to ensure the validity of the accounting data and the declared operation of the process. $^{48,54}$ 
The advanced accounting systems for reprocessing and conversion plants described here are based on detailed conceptual design studies performed under sponsorship of the Department of Energy (DOE). $1,2,53$ The US nuclear industry has actively participated in the development of these domestic operator's safeguards systems. Many US government contractors and private industrial groups are developing and testing subsystems and components, and the feasibility of dynamic accounting is being demonstrated in small as well as in large reprocessing plants. ${ }^{54,55}$ For example, a computerized NM accounting system using on-line measurements is being developed at the BNFP, and the applicability of dynamic accounting in the plutonium purification process is being studied.

\section{B. Safequards System Structure}

A comprehensive operator's in-plant safeguards strategy includes four functions:

- Exclusion of all unauthorized persons from the facility and selective exclusion of others from sensitive areas within the plant;

- Monitoring of all activities involving NM to determine whether each activity is consistent with safeguards requirements and with normal, expected facility operation;

- Accounting for all NM in the facility to determine whether correct amounts of all materials are present in their proper locations; and

- Response to and reporting of the facility's safeguards status.

At the same time, the safeguards system is bounded by the following constraints:

- It must be economical;

- It must be based on demonstrated technology;

- It must not disrupt process operations unnecessarily; and

- It must not compromise public health, safety, and environmental requirements or unnecessarily infringe upon employee rights and working conditions.

These constraints support the principle that the fundamental purpose of any nuclear fuel-cycle facility is to process NM. Safeguards are vitally important, but relationships among sometimes conflicting objectives must be kept in perspective.

A basic management, control, and coordination structure of operator's safeguards systems for domestic nuclear fuel-cycle facilities was proposed in earlier reports. ${ }^{1-3,8,56-60}$ A block diagram of a facility and its safeguards system is shown in Fig. 2. Functions directly related to the process are enclosed in the doubly outlined box. The safeguards system (1) provides timely, accurate reports on the safeguards status of the facility, (2) implements safeguards requirements imposed by the regulatory 


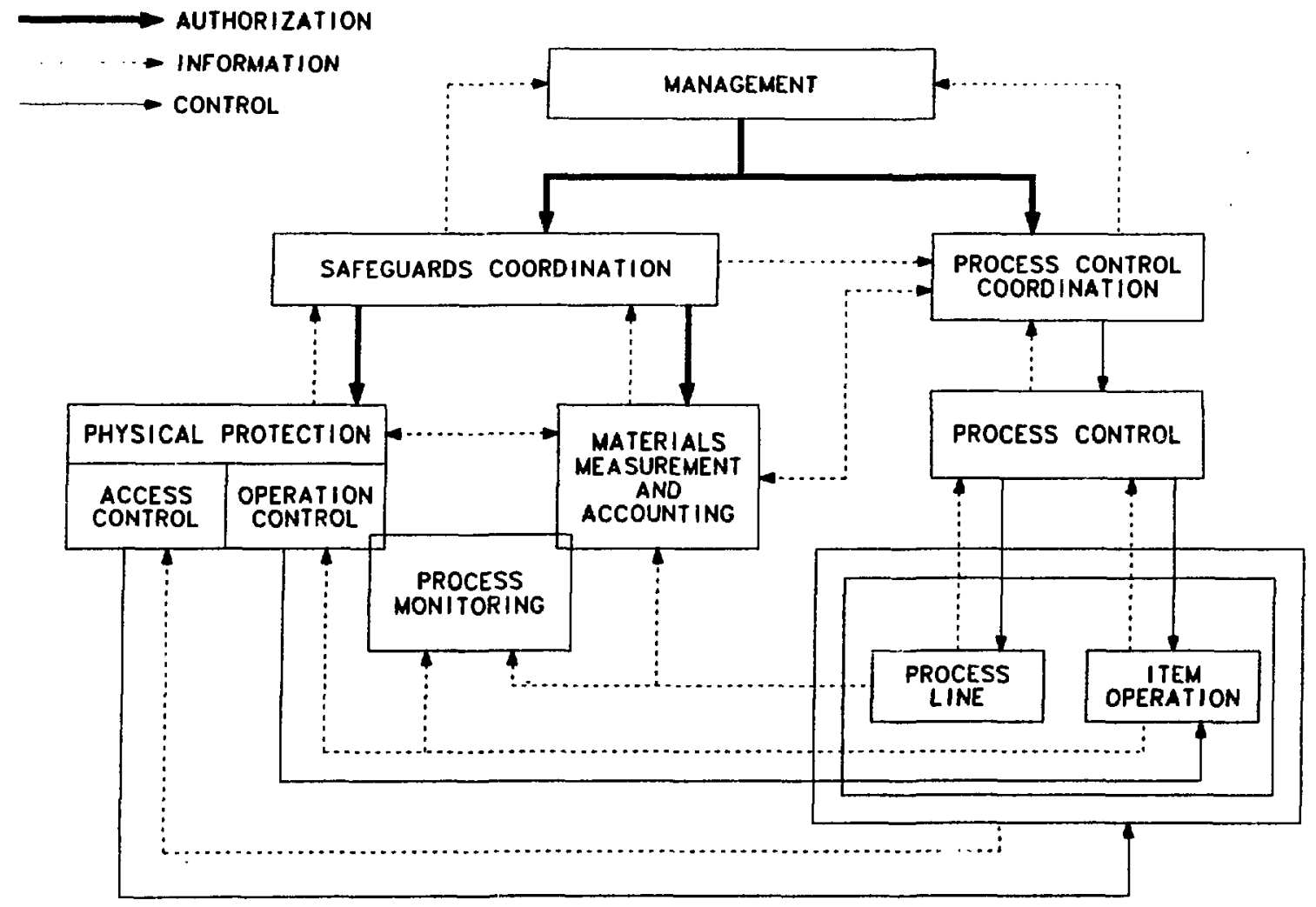

Fig. 2. Structure of the safequards system.

authorities, and (3) initiates and coordinates external responses to possible safeguards breaches. The system comprises several subsystems, including (1) the safeguards coordination unit (SCU), (2) the physical protection system (PPS), (3) the MMAS, (4) the process monitoring system (PMS), and (5) the safeguards computer system (SCS). These subsystems and the related functions of process control and plant management are discussed in App. D.

C. Safeguards System Security and Reliability

Advanced safeguards systems will rely heavily on computerized data acquisition and analysis. This is driven by the desire for increased speed in data processing and improved timeliness and accuracy of the data base and the output documents generated. Computerized information systems also offer greater opportunities for flexiblity in manipulating data to detect meaningful trends. 
Current technology provides the means to ensure that valid security controls for safeguards information are in effect for computerized systems. Software procedures such as personnel identification tests at LOGIN and file-access points protect safeguards data base integrity, and recent developments in encryption and data-authentication techniques are applicable to securing information transmission from data collection points to the safeguards information center. Proper use of such security measures ensures that the safeguards system can detect in a timely manner safeguards violation at the national and subnational level with high confidence.

Computer network reliability analyses consider network component reliability, use of redundant components, and variations in system architecture to arrive at a reliable network that is tolerant of individual component failures. For example, additional memory units allow the system to continue gathering and storing safeguards data until a failed main computer has been repaired. If the failure is corrected before the backup memory is filled, then no real interruption of information has occurred. Through such considerations, the reliability of the system is increased beyond that calculated by simply combining component reliabilities.

Reliability calculations are made for the instrumentation in each unit process accounting area (UPAA). Key measurement points (KMPs) are identified and availability requirements are chosen to avoid interference of instrument failures with normal process flow and to ensure timely safeguards information. These requirements consider those process characteristics allowing flexibility in tanks that allow the process to continue although all instruments are not operational. Further, the presence of multiple UPAAs allows one to combine two UPAAs if, for example, the transfer measurement between them is not available, so that a materials balance is drawn despite a failed instrument. Through use of redundant instrumentation and contingency planning that exploits the systems flexibility, the instrumentation reliability is raised to the required level.

The safeguards system security and reliability are discussed in more detail in App. I. 


\section{OPERATOR'S SAFEGUARDS SYSTEM: MATERIALS MEASUREMENT AND ACCOUNTING STRATEGIES}

\section{A. Introduction}

The operator's MMAS combines conventional and near-real-time materials accounting and is based on the reference facility designs described in Sec. II and App. B.

The MMAS for the large reference facility, including both chemical separations and conversion processes, is described first. The description of the conventional accounting subsystem is followed by that of the near-real-time subsystem. Detailed design and process information for the chemical separations facility is available in the open literature, ${ }^{1,5}$ from which an MMAS that includes such details as sampling points and sampling frequencies can be developed. The reference conversion process is based on a preliminary design; ${ }^{2,6,7}$ however, similar processes have been operated (for example, at LASL and SRP), and much information has been acquired from design and process personnel. ${ }^{61}$ Therefore, while the conversion process portion of the MMAS developed below is detailed, it is not as well characterized as the chemical separations portion.

The MMAS for the small reference facility includes only a chemical separations process and is based on the Tokai plant. At this time, only limited design and process information is available. ${ }^{19,20,37,38}$ From that information, an MMAS can be developed for the small reference chemical separations facilty but not at the same level of detail as that for the large chemical separations facility.

Model reference processes based on the descriptions in App. B are described in App. $F$. The reader is encouraged to refer to those descriptions because process design and logic frequently dictate the MMAS design features, especially in the near-real-time materials accounting system.

\section{B. Large Reference Facilities}

1. Conventional Materials Accounting. Conventional materials accounting relies on discrete-item counting and materials-balance closure following periodic shutdown and cleanout physical inventory. For this study, the base-line facilities are divided into six MBAs. An MBA is generally a physical area for which the quantity of NM moving into or out of the area can be measured. The input, output, and inventory measurement points for the six MBAs are called KMPs.

The six MBAs are identified in Fig. 3. MBAs 1, 3, 4, and 6 are S/R MBAs; MBAs 2 and 5 are process MBAs. The flow and inventory KMPs for the reference facilities are 


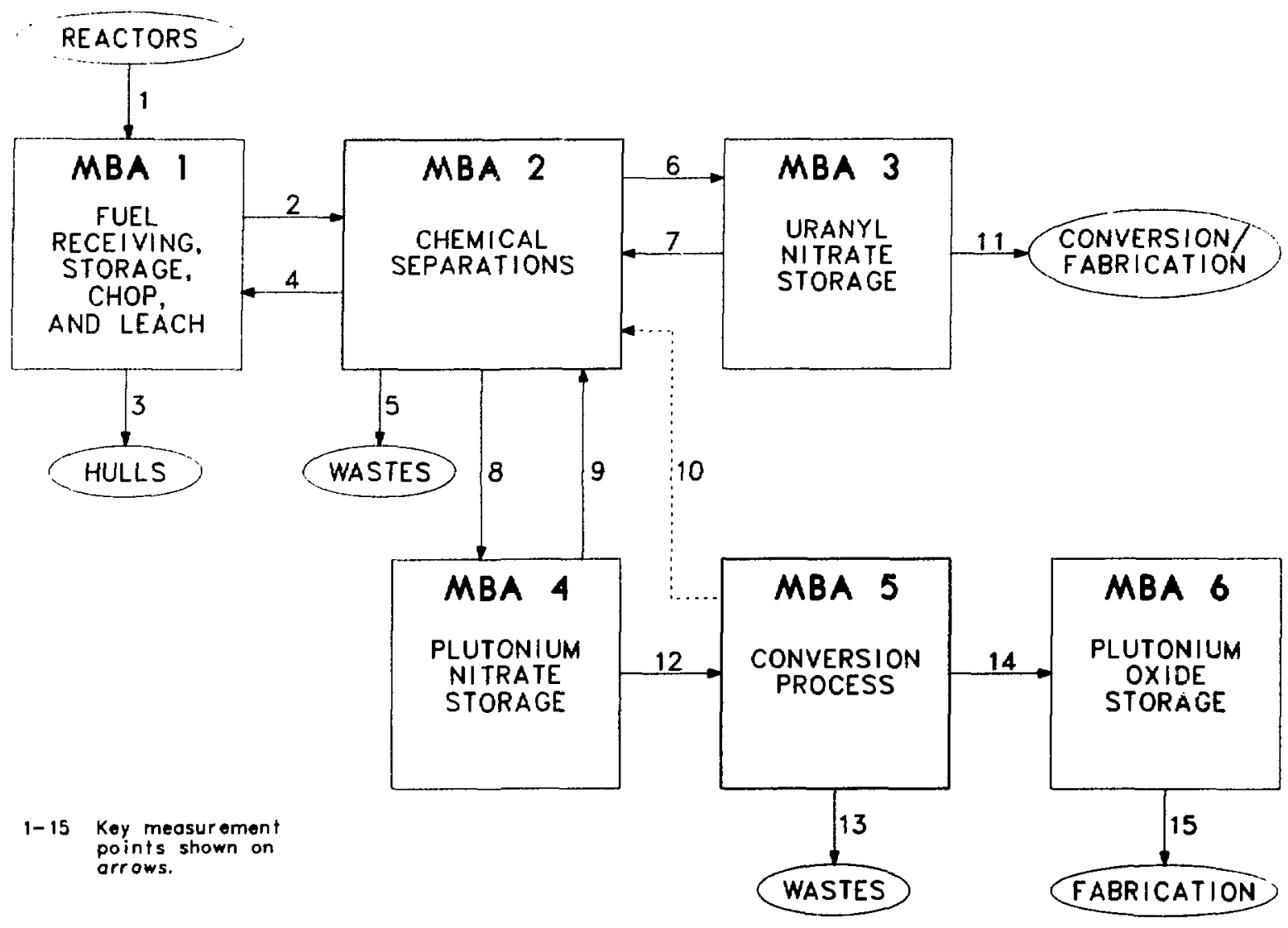

Fig. 3. MBAs in the reference facilities.

given in Tables VI and VII. Measurement methods for conventional materials accounting are described in App. K. Each MBA is described below.

a. MBA 1--Fuel Receiving, Storage, Chop, and Leach. MBA 1 includes the cask-unloading and spent-fuel pools, the shearing operation, and the dissolution process. The flow KMPs are:

KMP 1: receipt of irradiated fuel,

KMP 2: transfers from MBA 1 to MBA 2

(chemical separations MBA),

KMP 3: measured discards (hulls), and

KMP 4: recycle from MBA 2.

The inventory KMP, KMP A, is located in the spent-fuel pool. 
FLOW KEY MEASUREMENT POINTS FOR CONVENTIONAL MATERIALS ACCOUNTING

IN THF. REFERENCE FACILITIES

\begin{tabular}{|c|c|c|c|c|c|}
\hline$\underline{\text { KMP }}$ & Measurement Point & Material Description & Measurement Type & $\begin{array}{l}\text { Instrument } \\
\text { Precision } \\
(8,10) \\
\end{array}$ & $\begin{array}{c}\text { Calibration } \\
\text { Error } \\
(8 \text { lu }) \\
\end{array}$ \\
\hline 1 & Cask-unloading pool & $\begin{array}{l}\text { Irradiated fuel assemblies } \\
218 \mathrm{U}-235,218 \mathrm{Pu}\end{array}$ & See App. I & -- & \\
\hline $2 \mathbf{a}$ & Accountability tank & $\begin{array}{l}\text { Dissolver solution } \\
300 \mathrm{~g} \mathrm{U/L} \\
3 \mathrm{~g} \mathrm{Pu} / \mathrm{L}\end{array}$ & $\begin{array}{l}\text { Volume } \\
\text { Mass spectrometry } \\
\text { Mass spectrometry }\end{array}$ & $\begin{array}{l}0.3 \\
1 \\
1\end{array}$ & $\begin{array}{l}0.1 \\
0.2 \\
0.3\end{array}$ \\
\hline $2 b$ & MBA 1 laboratory samples & U, PU, FP in $\mathrm{HNO}_{3}$ & Chemical analysis & -- & \\
\hline 3 & Leached hull basket & $\begin{array}{l}\text { S.S., Zr } \\
\text { Traces of U, Pu, FP }\end{array}$ & NDA & -- & \\
\hline 4 & Dissolver acid surge tank & $\begin{array}{l}\mathrm{HNO}_{3} \text { (Recycle Acid) } \\
\text { Trace of } U\end{array}$ & $\begin{array}{l}\text { Volume: } \\
\text { Fluor imetry or } \\
\text { spectrophotometry }\end{array}$ & $\begin{array}{r}2 \\
20\end{array}$ & $\begin{array}{r}3 \\
10\end{array}$ \\
\hline & & Trace of Pu & NDA， $\propto$ & 10 & 5 \\
\hline $5 a$ & HLW sample tank & $\begin{array}{l}\text { Concentrated high-level waste } \\
3 \mathrm{~g} \mathrm{U} / \mathrm{L} \\
0.1 \mathrm{~g} \mathrm{Pu} / \mathrm{L}\end{array}$ & $\begin{array}{l}\text { Volume; } \\
\text { Mass spectrometry } \\
\text { Mass spectrometry }\end{array}$ & $\begin{array}{l}5 \\
1 \\
1\end{array}$ & $\begin{array}{l}3 \\
0.5 \\
0.5\end{array}$ \\
\hline $5 b$ & $\begin{array}{l}\text { General process waste } \\
\text { check tank }\end{array}$ & $\begin{array}{l}\text { Concentrated low-level waste } \\
13 \mathrm{~g} \mathrm{U} / \mathrm{L} \\
\text { Trace of Pu }\end{array}$ & $\begin{array}{l}\text { Volume; } \\
\text { Mass spectrometry } \\
\text { Mass spectrometry }\end{array}$ & $\begin{array}{l}5 \\
1 \\
1\end{array}$ & $\begin{array}{l}0.5 \\
0.5 \\
0.5\end{array}$ \\
\hline $5 c$ & Solid-waste drums & $\begin{array}{l}\text { Very low-level solid waste } \\
\text { Traces of } U, \text { Pu }\end{array}$ & NDA $\gamma, \mathrm{n}$ & 50 & 10 \\
\hline $5 d$ & Solvent-burner feed tank & $\begin{array}{l}\text { Waste solvent } \\
\text { Trace of } U\end{array}$ & $\begin{array}{l}\text { Volume } \\
\text { Fluorimetry or } \\
\text { spectrophotometry }\end{array}$ & $\begin{array}{r}1 \\
20\end{array}$ & $10^{0.5}$ \\
\hline & & Trace of Pu & NDA, $\alpha$ & 10 & 5 \\
\hline $5 e$ & Central stack & $\begin{array}{l}\text { Off-gas } \\
\text { Traces of } U, P u\end{array}$ & $\begin{array}{l}\text { Volume } \\
\text { NDA? }\end{array}$ & $\begin{array}{l}20 \\
40\end{array}$ & $\begin{array}{l}10 \\
20\end{array}$ \\
\hline 6 & U product sample tank & $\begin{array}{l}\text { Uranyl nitrate } \\
370 \mathrm{~g} / \mathrm{L}\end{array}$ & $\begin{array}{l}\text { Volume } \\
\text { Gravimetry }\end{array}$ & $\begin{array}{l}0.3 \\
0.25\end{array}$ & $\begin{array}{l}0.1 \\
0.1\end{array}$ \\
\hline $7 a$ & II Iework tank & $\begin{array}{l}\text { Uranyl nitrate } \\
3709 \mathrm{U} / \mathrm{L}\end{array}$ & $\begin{array}{l}\text { Volume } \\
\text { Gravimetry }\end{array}$ & $\begin{array}{l}0.5 \\
0.25\end{array}$ & $\begin{array}{l}0.5 \\
0.1\end{array}$ \\
\hline $7 \mathrm{~b}$ & Laboratory samples & Uranyl nitrate & Chemical analysis. & $\cdots$ & \\
\hline
\end{tabular}




\begin{tabular}{|c|c|c|c|c|c|}
\hline$\underline{\text { KMP }}$ & Measurement Point & Material Description & Measurement Type & $\begin{array}{l}\text { Instrument } \\
\text { Precision } \\
(810) \\
\end{array}$ & $\begin{array}{c}\text { Calibration } \\
\text { Error } \\
(810) \\
\end{array}$ \\
\hline 8 & Pu product sample tank & $\begin{array}{l}\text { Plutonium nitrate } \\
250 \mathrm{~g} \mathrm{Pu} / \mathrm{L}\end{array}$ & $\begin{array}{l}\text { Volume } \\
\text { Amperometry or } \\
\text { coulometry }\end{array}$ & $\begin{array}{l}1 \\
0.2\end{array}$ & $\begin{array}{l}0.5 \\
0.1\end{array}$ \\
\hline 8 & $\begin{array}{l}\text { Pu product interim } \\
\text { storage tanks (3) }\end{array}$ & $\begin{array}{l}\text { Plutonium nitrate } \\
250 \mathrm{~g} \mathrm{Pu} / \mathrm{L}\end{array}$ & $\begin{array}{l}\text { Volume } \\
\text { Amperometry or } \\
\text { coulometry }\end{array}$ & $\begin{array}{l}0.3 \\
0.2\end{array}$ & $\begin{array}{l}0.1 \\
0.1\end{array}$ \\
\hline $9 a$ & Pu rework tank & $\begin{array}{l}\text { Plut nium nitrate } \\
250 \text { y } \mathrm{Pu} / \mathrm{L}\end{array}$ & $\begin{array}{l}\text { Volume } \\
\text { Amperometry or } \\
\text { coulometry }\end{array}$ & $\begin{array}{l}1 \\
0.2\end{array}$ & $\begin{array}{l}0.5 \\
0.1\end{array}$ \\
\hline $9 b$ & Laboratory samples & plutonium nitrate & Chemical analysis & -- & \\
\hline $10 \mathrm{a}$ & Pu rework tank & Plutonium nitrate & $\begin{array}{l}\text { Volume } \\
\text { Amperometry or } \\
\text { coulometry }\end{array}$ & $\frac{1}{0.2}$ & $\begin{array}{l}0.5 \\
0.1\end{array}$ \\
\hline 11 & $\begin{array}{l}\text { U nitrate accountability } \\
\text { tank }\end{array}$ & Uranyl nitrate & $\begin{array}{l}\text { Volume } \\
\text { Gravimetry }\end{array}$ & $\begin{array}{l}0.3 \\
0.25\end{array}$ & $\begin{array}{l}0.1 \\
0.1\end{array}$ \\
\hline 12 & Receipt tanks & plutonium nitrate & $\begin{array}{l}\text { Volume } \\
\text { Amperometry or } \\
\text { coulometry }\end{array}$ & $\begin{array}{l}0.2 \\
0.2\end{array}$ & $\begin{array}{l}0.1 \\
0.1\end{array}$ \\
\hline $13 \mathbf{a}$ & Haste $r$ un tank & $\begin{array}{l}\text { Intermediate-level waste } \\
\text { Trace of } \mathrm{Pu}\end{array}$ & $\begin{array}{l}\text { Volume } \\
\text { NDA, a }\end{array}$ & $\begin{array}{r}5 \\
10\end{array}$ & $\begin{array}{l}2 \\
5\end{array}$ \\
\hline $13 b$ & Solid-waste drums & Trace of Pu & NDA $\gamma, n$ & 50 & 10 \\
\hline 14 & Product can & Plutonium oxide & $\begin{array}{l}\text { Mass } \\
\text { Amperometry or } \\
\text { coulometry }\end{array}$ & $\begin{array}{l}0.1 \\
0.2\end{array}$ & $\begin{array}{l}0.05 \\
0.1\end{array}$ \\
\hline 15 & Product can & Plutonium oxide & $\begin{array}{l}\text { Mass } \\
\text { Amper ometry or } \\
\text { coulometry }\end{array}$ & $\begin{array}{l}0.1 \\
0.2\end{array}$ & $\begin{array}{l}0.05 \\
0.1\end{array}$ \\
\hline
\end{tabular}

FP = fission products

s.s. = stainless steel. 
INVENTORY KEY MEASUREMENT POINTS FOR CONVENTIONAL MATERIALS ACCOUNTING IN THE REFERENCE FACILITIES

\begin{tabular}{|c|c|c|c|c|c|}
\hline$\underline{\mathbf{K M P}}$ & Measurement Point & Material Description & Measurement Tyee & $\begin{array}{l}\text { Instrument } \\
\text { Precision } \\
\begin{array}{l}(810) \\
\end{array}\end{array}$ & $\begin{array}{c}\text { Calibration } \\
\text { Error } \\
(8 \text { lo }) \\
\end{array}$ \\
\hline A & Spent-fuel pool & Irradiated fuel assemblies & See Sec. IV.B.I.a & -- & \\
\hline Bl & Feed-adjust tanks (2) & $\begin{array}{l}\mathrm{U}, \mathrm{Pu}, \mathrm{FP} \text { in } \mathrm{HNO}_{3} \\
30 \mathrm{~g} \mathrm{~V} / \mathrm{L} \\
3 \mathrm{~g} \mathrm{Pu} / \mathrm{L}\end{array}$ & $\begin{array}{l}\text { Volume } \\
\text { Mass spectrometry } \\
\text { Mass spectrometry }\end{array}$ & $\begin{array}{l}1 \\
1 \\
1\end{array}$ & $\begin{array}{l}0.5 \\
0.2 \\
0.3\end{array}$ \\
\hline B2 & lBP surge tank & $\begin{array}{l}\mathrm{U}, \mathrm{Pu}, \text { residual } \mathrm{FP} \text { in } \mathrm{HNO}_{3} \\
10 \mathrm{~g} \mathrm{U/L} \\
5 \mathrm{~g} \mathrm{Pu} / \mathrm{L}\end{array}$ & $\begin{array}{l}\text { Volume } \\
\text { Amperometry or } \\
\text { coulometry }\end{array}$ & $\begin{array}{l}1 \\
1\end{array}$ & $\begin{array}{l}0.5 \\
0.25\end{array}$ \\
\hline B3 & off-spec product tank & $\begin{array}{l}\text { off-spec uranyl nitrate } \\
370 \mathrm{~g} \mathrm{U} / \mathrm{L}\end{array}$ & $\begin{array}{l}\text { Volume } \\
\text { Gravimetry }\end{array}$ & $\begin{array}{l}0.5 \\
0.25\end{array}$ & $\begin{array}{l}0.5 \\
0.1\end{array}$ \\
\hline B4 & Pu rework tank & $\begin{array}{l}\text { off-spec plutonium nitrate } \\
250 \mathrm{~g} \mathrm{pu} / \mathrm{L}\end{array}$ & $\begin{array}{l}\text { Volume } \\
\text { Amperometry or } \\
\text { coulometry }\end{array}$ & $\begin{array}{l}1 \\
0.2\end{array}$ & $\begin{array}{l}0.5 \\
0.1\end{array}$ \\
\hline B5 & J.SF tank & $\begin{array}{l}\text { Miscelianeous solutions } \\
\text { Trace of } \mathrm{U} \\
\text { Trace of } \mathrm{Pu}\end{array}$ & $\begin{array}{l}\text { Volume } \\
\text { Mass spectrometry; } \\
\text { Mass spectrometry }\end{array}$ & $\begin{array}{l}1 \\
1 \\
1\end{array}$ & $\begin{array}{l}0.5 \\
0.1 \\
0.25\end{array}$ \\
\hline B6 & LAWB check & $\begin{array}{l}\text { The following tanks contain } \\
\text { negligible quantities of } U\end{array}$ & Volume & $1-5$ & $0.5-3$ \\
\hline B-7 & Recovered-acid storage & $\begin{array}{l}\text { and } \mathrm{Pu} \text { in recovered acid, } \\
\text { solvent, and miscellaneous } \\
\text { solutions. }\end{array}$ & $\begin{array}{l}\text { Traces of } U \text { by } \\
\text { fluor imetry or } \\
\text { spectrophotometry }\end{array}$ & $1-40$ & $0.5-20$ \\
\hline B8 & Solvent-system feed (2) & & $\begin{array}{l}\text { Traces of Pu by } \\
\text { NDA, } \alpha\end{array}$ & 10 & 5 \\
\hline B9 & Solvent-batch strip & & & & \\
\hline $\mathbf{B} 10$ & Service-concentrator feed & & & & \\
\hline B11 & Service-concentrator check & & & & \\
\hline B12 & Sump collection & & & & \\
\hline C & Laboratory & Assorted samples & See Sec. IV.B.1.b & & \\
\hline
\end{tabular}




\begin{tabular}{|c|c|c|c|c|c|}
\hline$\underline{\mathbf{K M P}}$ & Measurement Point & Material Description & Measurement Type & $\begin{array}{l}\text { Instrument } \\
\text { Precision } \\
\begin{array}{l}(810) \\
\end{array}\end{array}$ & $\begin{array}{c}\text { Calibration } \\
\text { Error } \\
(810) \\
\end{array}$ \\
\hline D & $\begin{array}{l}\text { Oranium nitrate storage } \\
\text { tank }\end{array}$ & Uranium nitrate & $\begin{array}{l}\text { Volume } \\
\text { Gravimetry }\end{array}$ & $\begin{array}{l}0.5 \\
0.25\end{array}$ & $\begin{array}{l}0.5 \\
0.1\end{array}$ \\
\hline $\mathbf{E}$ & $\begin{array}{l}\text { Plutonium nitrate storage } \\
\text { tank }\end{array}$ & $\begin{array}{l}\text { Plutonium nitrate } \\
250 \mathrm{~g} \mathrm{Pu/L}\end{array}$ & $\begin{array}{l}\text { Volume } \\
\text { Amperometry or } \\
\text { coulometry }\end{array}$ & $\begin{array}{l}0.5 \\
0.2\end{array}$ & $\begin{array}{l}0.2 \\
0.1\end{array}$ \\
\hline F2 & Sweeping cans & Plutonium oxide & $\begin{array}{l}\text { Mass } \\
\text { Anperometry or } \\
\text { coulometry }\end{array}$ & $\begin{array}{l}5 \\
0.2\end{array}$ & $\begin{array}{l}2 \\
0.1\end{array}$ \\
\hline F3 & $\begin{array}{l}\text { Anion exchange product } \\
\text { tank }\end{array}$ & Plutonium nitrate & $\begin{array}{l}\text { Volume } \\
\text { Amperometry or } \\
\text { coulometry }\end{array}$ & $\begin{array}{l}0.5 \\
0.2\end{array}$ & $\begin{array}{l}0.5 \\
0.1\end{array}$ \\
\hline G & storage vault & Plutonium oxide & $\begin{array}{l}\text { Item verification } \\
\text { NDA }\end{array}$ & -- & \\
\hline
\end{tabular}

$\overline{\text { FP }}=$ fission products. 
All irradiated fuel received passes through KMP 1. A single assembly is a typical batch for KMP 1. The serial number of each fuel assembly is identified visually and is checked against the accompanying shipping papers. The shipping papers also include the following data for each fuel assembly: $:^{12}$

(a) Shipper identification;

(b) Date of transfer;

(c) Fabricator's data (before irradiation)--chemical composition, total and fissile weight of uranium and plutonium;

(d) Shipper's data (after irradiation)--burnup, isotopic composition, total and fissile weight of uranium and plutonium.

The fabricator's data are based on chemical analysis of the fuel material and NDA of the fuel rods. The shipper's data are based on the reactor power history that, along with the fabricator's data, are used to calculate the isotopic composition, including fissile uranium and plutonium content. At present, verification of the shipper's data is difficult because it requires verification of the fabricator's data, the shipper's reactor power history, and the shipper's isotopic generation and depletion calculational methods. NDA methods for verifying declared burnup and cooling time and for assaying fissile content of spent fuel are being developed and may be available soon ${ }^{62}$ (see App. N). If such measurements do become available, the MBA structure could be modified by making the shearing and dissolution processes into a separate process MBA, instead of including those processes in the S/R MBA.

All transfers of NM from MBA 1 to MBA 2 pass through KMP 2. Two types of transfers pass through KMP 2: transfer of dissolved NM, and transfer of samples to the analytical laboratory that is within MBA 2. One filling of the accountability tank that corresponds to a number of similar fuel assemblies or a set of sample vials from the dissolution of those assemblies are typical batches for KMP 2. The amount of dissolved NM transferred in one batch is determined in the accountability tank by measuring the volume of the solution with an electromanometer and by measuring uranium and plutonium concentrations and isstopic compositions by isotope-dilution mass spectrometry. On the average, two and one-half accountability batches are transferred daily; each batch contains $\sim 6700 \mathrm{~L}$ at $\sim 297 \mathrm{~g} \mathrm{U} / \mathrm{L}$ and $\sim 3 \mathrm{~g} P \mathrm{u} / \mathrm{L}$.

The following data are recorded for each laboratory sample: ${ }^{12}$

(a) Sample-vial identification,

(b) Dissolution batch identification,

(c) Date and time of sampling,

(d) Volume and density of solution, 
(e) Concentration of uranium and plutonium and isotopic compositions,

(f) Method of analysis, and

(g) Precision and accuracy of the analysis method.

For KMP 3, one dissolver basket of leached hulls is a typical batch. The batch is identified by the corresponding dissolved assembly identification numbers, the corresponding dissolution batch identification number, and by the total and fissile weight of uranium and plutonium contained in the leached hulls. In cases where no measurement. of the hulls is available, one assumes that $0.01 \%$ of the input is discarded. ${ }^{12}$ Methods for measuring the amount of residual uranium and plutonium in leached hulls are being developed $^{63}$ (see App. K). Batches that are transferred through KMP 3 are considered to be measured discards.

Recycled acid from MBA 2 is batch-transferred to MBA 1 through KMP 4. Uranium and plutonium content of the recycled acid is determined in the dissolver and surge tank fram volume determinations and either fluorimetric or spectrophotometric measurements.

An S/R difference can be closed about MBA I after each campaign (approximately every 5 days) when the dissolver tanks, hull-rinse tanks, and associated piping are drained and flushed into the accountability tank. This flush-out between batches from different customers results in a more accurate S/R difference because it eliminates contamination from previous customer batches. The S/R difference is obtained by adding the shipper's values for a number of fuel assemblies (KMP 1) to the corresponding number of batches of recycled acid (KMP 4) and subtracting the accountability tank and laboratory vial batches (KMP 2) and the leached-hull batches (KMP 3). Isotope correlation techniques may be useful in verifying irradiation history (App. $M$ ).

At present, inventory verification in MBA 1 is based on piece count and identification of the fuel assembly fabrication serial numbers. Nondestructive measurement systems are being developed to measure passive gamma-ray, Cerenkov, and neutron signatures from spent-fuel assemblies. ${ }^{62}$ These signatures may be useful in verifying the burnup and cooling time of irradiated fuel elements.

b. MBA 2--Chemical Separations Process. This MBA includes the solventextraction operations from the accountability tank to the uranyl nitrate and plutonium nitrate product sample tanks. The flow KMPs are:

$$
\begin{array}{lll}
\text { KMP 2: } & \text { transfers to MBA } 2 \text { from MBA 1, } \\
\text { KMP 4: } & \text { recycle to MBA 1, } \\
\text { KMP 5: } & \text { measured discards and retained waste, }
\end{array}
$$




$$
\begin{array}{ll}
\text { KMP 6: } & \begin{array}{l}
\text { transfers from MBA } 2 \text { to MBA } 3 \\
\text { (uranyl nitrate storage), }
\end{array} \\
\text { KMP 7: } & \text { recycle from MBA 3, } \\
\text { KMP 8: } & \begin{array}{l}
\text { transfers from MBA } 2 \text { to MBA } 4 \\
\text { (plutonium nitrate storage), }
\end{array} \\
\text { KMP 9: } & \text { recycle from MBA 4, and } \\
\text { KMP 10: } & \text { transfers to MBA 2 from MBA } 5 \\
& \text { (conversion process). }
\end{array}
$$

The inventory KMPs are (1) those tanks in which reliable volume measurements can be made when the process is drained and flushed (KMP B) and (2) the analytical laboratory (KMP C).

The flow KMPs required for conventional materials accounting in the reference facilities are given in Table Vl. KMPs 2 and 4 are common with MBA 1 and are discussed in Sec. IV.B.l.a. All discards and retained wastes are transferred out of MBA 2 through $K M P$ 5. Concentrated liquid wastes are sampled and volumes are measured in sample or check tanks before transfer to on-site storage. NM content in solid-waste drums is checked by NDA techniques. Gaseous wastes are filtered, then checked for NM content before venting.

Uranyl nitrate product solution is transferred out of MBA 2 through KMP 6. Product batches $(\sim 4460 \mathrm{~L}, \sim 374 \mathrm{~g} \mathrm{U} / \mathrm{L})$ are transferred approximately every $8 \mathrm{~h}$. The volume of each batch is measured in the uranium sample tank and samples are taken for chemical analysis (gravimetry).

Plutonium nitrate product is transferred out of MBA 2 through KMP 8. Product batches $(2394 \mathrm{~L}, \sim 250 \mathrm{~g} \mathrm{Pu} / \mathrm{L})$ are transferred to the plutonium nitrate storage facility from one of three interim product storage tanks. The batch volume is measured in the interim storage tanks and samples are taken for chemical analysis of plutonium concentration and isotopics (amperometry or coulometry, mass spectrometry).

Uranyl nitrate or plutonium nitrate product batches that are off specification are transferred to their respective rework tanks for recycle within MBA 2.

Uranyl nitrate solutions that are off specification in the $\mathrm{UF}_{6}$ conversion facility are transferred back to MBA 2 for recycle through KMP 7.

Plutonium nitrate solutions that are off specification in the plutonium nitrate storage area (because of americium buildup, for example) can be transferred to MBA 2 through KMP 9. The solution volume is measured in the plutonium rework tank, and samples are taken for chemical analysis of material concentrations and isotopics. 
Recycle solutions and laboratory samples can be transferred to MBA 2 from the conversion process (MBA 5) through KMP 10. This transfer provision is made because in an integrated fuel-cycle facility it may be desirable to recycle the filtrate, flush, and dissolved solids solutions to MBA 2 rather than to have an independent recycling process within the conversion facility. A centralized analy tical laboratory also is desirable.

An analytical sampling plan is incorporated into each operational run plan for each campaign. The following guidelines are used to develop the sampling plan.

- Batch-type vessels shall be sampled once per batch.

- Streams and surge vessels shall be sampled at a frequency that will provide sufficient information to permit safe, efficient, and economic operation of the facility.

- Samples shall be used as a backup to safety-related and quality-assurance instrumentation when the instrumentation is not in service and to verify accuracy during service.

Samples are obtained for chemical analysis by either remote or local samplers. Local samplers installed in some waste tanks obtain samples after air-sparging. Needle-block samplers are located in the sample and analytical cell (SAC) for radioactive samples and in the plutonium product cell (PPC) glovebox for samples free of fission products. Samples are transmitted by pneumatic tube to the hot and cold analytical laboratory area (HCLA) for analysis.

Remote samplers of the dry-jet, air-lift type continuously circulate air-liquid mixture from remote sample points. Samples are taken into bottles of $w 10-\mathrm{mL}$ capacity that are attached to the needle blocks. The needle blocks are designed to allow $\sim 70 \%$ of the air-liquid mixtures to bypass the sample bottles, thereby providing a faster recirculation time. Locations of remote samplers and the purpose of the analyses are summarized in Tables VIII to XII.

Some of the analytical methods used for various sampling points are summarized in Table XIII and are discussed in detail in App. K.

The daily quantities of plutonium removed to the SLCA from process streams are summarized in Table XIV.

A physical inventory in MBA 2 includes a shutdown and flushout of the separations process area (KMP B) and a cleanout of extraneous samples and a piece-count verification of remaining materials in the laboratory (KMP C). The process line is drained and flushed into 226 primary accountability tanks that have been calibrated so that reliable volume measurements can be made and samples can be taken for analysis. Some of these tanks 
TABLE VIII

REMOTE SAMPLERS TO SAC 4

\begin{tabular}{|c|c|c|c|}
\hline Iine or Tank Samples & Purpose & $\begin{array}{l}\text { Nominal } \\
\text { Frequency }\end{array}$ & Analyses \\
\hline Accountability tank & A, $P C$ & $3 /$ day $a$ & $\begin{array}{l}\mathrm{H}^{+}, \mathrm{Sp} . \mathrm{gr} ., \mathrm{U}, \mathrm{U} \text { iso., } \\
\mathrm{Pu}, \mathrm{Pu} \text { iso., Np }\end{array}$ \\
\hline No. 1 feed adjustment tank & PC & 3/day & 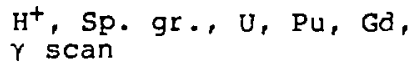 \\
\hline HAW surge tank & PC & $6 /$ day ${ }^{a}$ & $\mathrm{Sp} . \mathrm{gr}, \mathrm{Pu}$ \\
\hline LAW concentrator feed tank & PC & NR & $\mathrm{H}^{+}, \mathrm{U}, \mathrm{Pu}$ \\
\hline $\begin{array}{l}\text { General purpose concentrator } \\
\text { feed tank }\end{array}$ & PC & $3 /$ day & $\mathrm{H}^{+}$ \\
\hline HWW sample tank & PC, A & $1 /$ daya & $\begin{array}{l}\mathrm{H}^{+}, \mathrm{Sp} . \mathrm{gr}, \mathrm{U}, \mathrm{U} \text { iso., } \\
\mathrm{Pu} \text { iso.. Np, Na }\end{array}$ \\
\hline Hull-rinse surge tank & PC & 1/day & $\mathrm{H}^{+}, \mathrm{U}, \mathrm{Sp} . \mathrm{gr}$ \\
\hline Sump collection tank & PC & $1 /$ day & $\mathrm{H}^{+}, \mathrm{Sp} \cdot \mathrm{gr} ., \mathrm{U}, \mathrm{Pu}$ \\
\hline LAWB check tank & PC & $1 /$ day & $H^{+}$, sp. gr., U, Pu \\
\hline 2DW line & PC, I & $3 /$ day & $\mathrm{U}$ \\
\hline Dissolver-acid surge tank & I & $2 /$ week & $\mathrm{H}^{+}, \mathrm{Sp}, \mathrm{gr} ., \mathrm{Gd}$ \\
\hline Dissolver-flush accumulator & PC & $1 /$ day & $\mathrm{H}^{+}, \mathrm{U}, \mathrm{sp}, \mathrm{gr}$ \\
\hline No. 2 feed adjustment tank & $\mathrm{PC}$ & $3 /$ day $^{a}$ & $\begin{array}{l}\mathrm{H}^{+}, \mathrm{Sp}, \mathrm{gr} ., \mathrm{U}, \mathrm{Pu}, \mathrm{Gd}, \\
\gamma \text { scan }\end{array}$ \\
\hline $\begin{array}{l}\text { No. } 1 \text { dissolver transfer } \\
\text { tank }\end{array}$ & PC & NR & $\mathrm{H}^{+}, \mathrm{U}$ \\
\hline $\begin{array}{l}\text { No. } 2 \text { dissolver transfer } \\
\text { tank }\end{array}$ & $\mathrm{PC}$ & NR & $\mathrm{H}^{+}, \mathrm{U}$ \\
\hline $\begin{array}{l}\text { No. } 3 \text { dissolver transfer } \\
\text { tank }\end{array}$ & PC & NR & $\mathrm{H}^{+}, \mathrm{U}$ \\
\hline $\begin{array}{l}\text { No. } 4 \text { dissolver transfer } \\
\text { tank }\end{array}$ & $\mathrm{PC}$ & $\mathrm{NR}$ & $\mathrm{H}^{+}, \mathrm{U}$ \\
\hline Feed surge tank & PC & NR & $\begin{array}{l}H^{+}, \text {Sp. gr., U, U iso., } \\
\text { Pu, Pu iso. }\end{array}$ \\
\hline
\end{tabular}

actual frequency may vary from that indicated, but each batch is sampled.

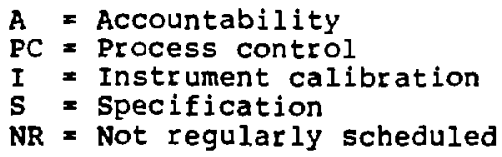


TABLE IX

REMOTE SAMPLERS TO SAC 8

\begin{tabular}{|c|c|c|c|}
\hline Line or Tank Sampled & Purpose & $\begin{array}{l}\text { Nominal } \\
\text { Frequency }\end{array}$ & Analyses \\
\hline $\begin{array}{l}\text { No. } 1 \text { solvent-system feed } \\
\text { tank }\end{array}$ & PC & $2 / w k$ & $Y$ scan, TBP \\
\hline Carbonate diversion tank & PC & NR & $\mathrm{U}, \mathrm{Pu}, \mathrm{Alk}$ \\
\hline 10w-10K line & $\mathrm{PC}$ & L/day & $U, P u, A l k, \gamma \operatorname{scan}$ \\
\hline $1 R W-1 R R$ line & $\mathrm{PC}$ & 1/day & Sp. gr., Alk \\
\hline $\begin{array}{l}\text { General purpose concentrator } \\
\text { check tank }\end{array}$ & $P C, A$ & $1 /$ a ay & $\begin{array}{l}\mathrm{H}^{+}, \mathrm{U}, \mathrm{U} \\
\mathrm{Pu} \text { iso., }\end{array}$ \\
\hline lPO line & $\mathrm{PC}$ & 1/day & $\mathrm{H}^{+}$ \\
\hline IBX anolyte feed tank & $\mathrm{PC}$ & 1/day & $\alpha$ \\
\hline lBP line & PC, I & $3 /$ aby & $\begin{array}{l}\mathrm{H}^{+}, \mathrm{So}, \mathrm{gr}, \mathrm{U}, \mathrm{N}_{2} \mathrm{H}_{4}, \mathrm{Pu} \\
\mathrm{Zr}, \mathrm{Ru}, \mathrm{Nb}, \mathrm{S}, \mathrm{Scan}\end{array}$ \\
\hline IBU recycle tank & $p c$ & 3/day & $\mathrm{V}, \mathrm{NO}_{2}, a$ \\
\hline lCU line & PC, I & 3/day & sp. gr.. $\alpha, \gamma \operatorname{scan}$ \\
\hline lCW line & $\mathrm{PC}$ & $3 / d a y$ & $U, \gamma \operatorname{scan}$ \\
\hline HSP Iine & PC, I & $3 /$ day & $\mathrm{NO}_{2}, r$ scan \\
\hline IBP surge tank & PC, I & $3 /$ day & $\mathrm{H}^{+}, \mathrm{Sp}, \mathrm{gi}, \mathrm{NO}_{2}, \alpha$ \\
\hline ISF tank & $\mathrm{PC}, \mathrm{I}$ & 1/day & $\mathrm{H}^{+}, \mathrm{u}, \mathrm{\gamma}, \mathrm{NO}_{2}$ \\
\hline ISW line & PC, I & 3/oay & $\alpha$ \\
\hline
\end{tabular}

TABLE X

REMOTE SAMPLERS TO URANIUM GLOVEBOX

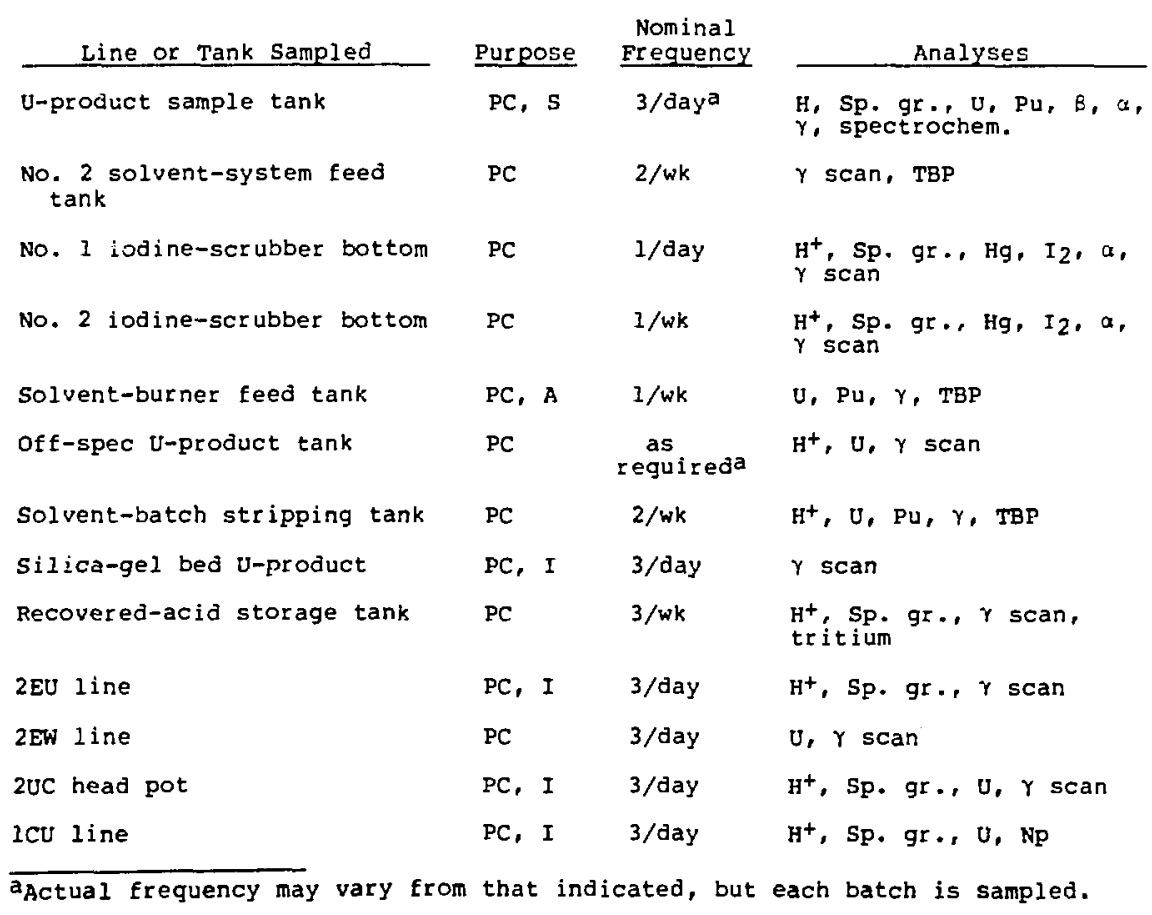


TABLE XI

REMOTE SAMPLERS TO PLUTONIUM GLOVEBOX

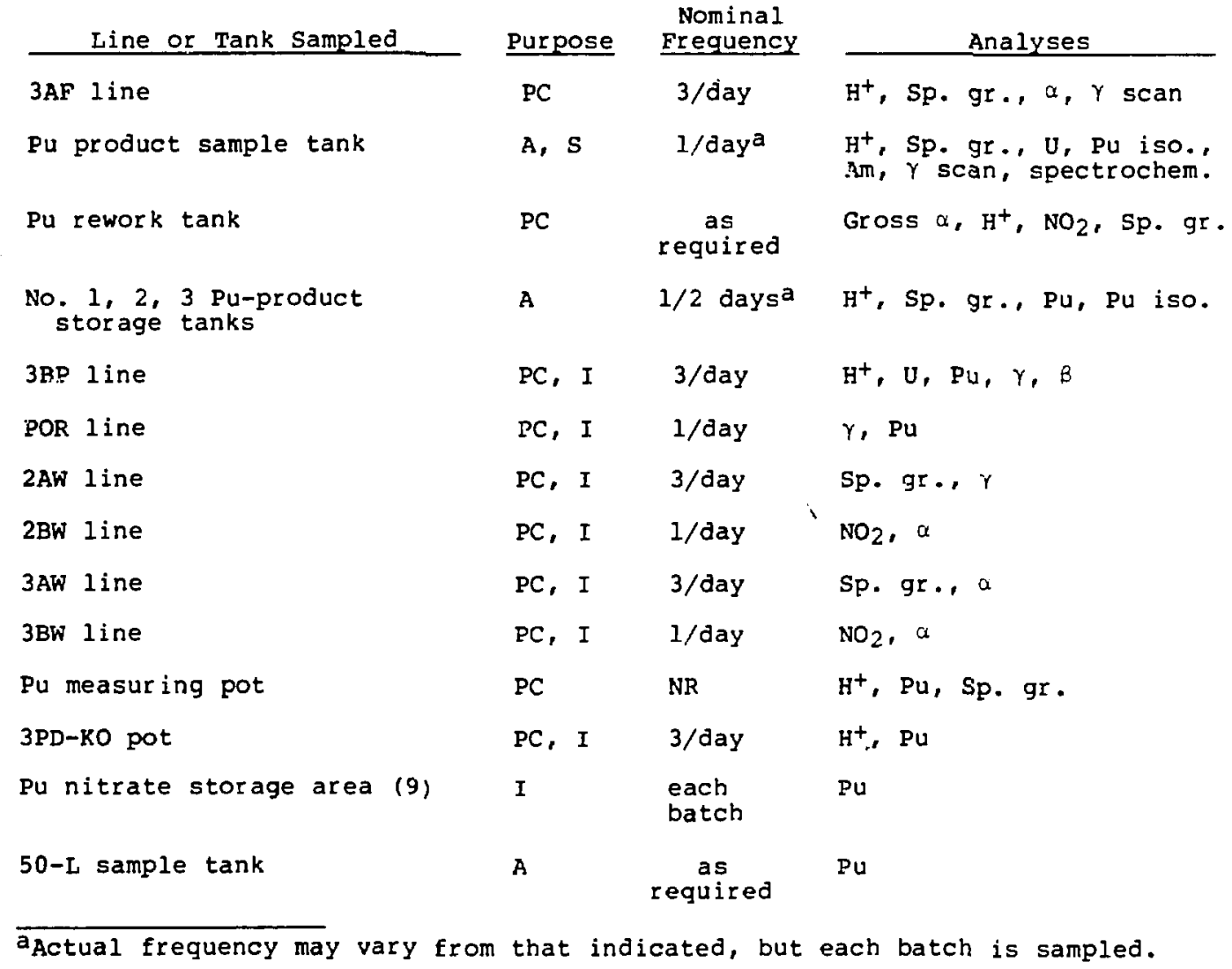

TABLE XII

LOCAL SAMPLERS TO HCLA

\begin{tabular}{|c|c|c|c|}
\hline Line or Tank Sampled & Purpose & $\begin{array}{c}\text { Nominal } \\
\text { Erequency }\end{array}$ & Analyses \\
\hline Iaboratory sample tank & $\underset{A}{P C}, I$ & $1 /$ day & $\mathrm{H}^{+}, \mathrm{Sp}, \mathrm{gr}, \mathrm{U}, \mathrm{P}$ \\
\hline $\begin{array}{l}\text { Service concentrator feed } \\
\text { tank }\end{array}$ & $\mathbf{I}$ & $1 /$ wk & $\mathrm{Pu}, \mathrm{U}, \mathrm{U}$ iso. \\
\hline $\begin{array}{l}\text { Service concentrator check } \\
\text { tank }\end{array}$ & $I$ & $1 /$ batch & Pu, U, U iso. \\
\hline
\end{tabular}


TABLE XII

ANALYTICAL METHODS USED IA FEFERENCE PLAHTS

\begin{tabular}{|c|c|c|}
\hline Meacurement Point. & Method & $\begin{array}{r}\text { Parameter } \\
\text { Determined } \\
\end{array}$ \\
\hline $\begin{array}{l}\text { Feed surge tank } \\
\text { Discolver flish accumulator } \\
\text { Accountability tank } \\
\text { lsf tank. } \\
\text { No. I feed adjustment tank } \\
\text { No. } 2 \text { feed adjustment tank } \\
\text { Solvent-burner feed tank } \\
\text { GPH check tank } \\
\text { Hrs cample tank. }\end{array}$ & $\begin{array}{l}\text { Isotope dilution } \\
\text { Mass spectrometry }\end{array}$ & $\begin{array}{l}\text { U, } 235 \text { u, pu } \\
\text { Pu } 1 \text { sotopics }\end{array}$ \\
\hline $\begin{array}{l}\text { Pl-product stor ne tanks (3) } \\
\text { lap surgo tank } \\
\text { Pl-rowor tank } \\
\text { Pu-peoduct sample tank } \\
\text { Pu-storage slab tanks }\end{array}$ & $\begin{array}{c}\text { Ampecometry or } \\
\text { coulometry }\end{array}$ & Pu \\
\hline $\begin{array}{l}\text { No. l solvent feed tank } \\
\text { No. } 2 \text { solvent fee-? tank } \\
\text { Carbonate diversion tank } \\
\text { Solvent-batch stripping tank } \\
\text { Solvent-burner Eeed tank: } \\
\text { LAWE check tank } \\
\text { Recovered-acid storage tank } \\
\text { Sump collection tank. }\end{array}$ & Alpha counting & Pu \\
\hline $\begin{array}{l}\text { Off-spec U-product tank } \\
U \text {-prnduct sampio tank. }\end{array}$ & $\begin{array}{l}\text { Gravimetry, } \\
\text { potentiometry, } \\
\text { or coulometry }\end{array}$ & $\mathrm{U}$ \\
\hline $\begin{array}{l}\text { No, } 1 \text { solvent system feed tank } \\
\text { No, } 2 \text { solvent system feed tank } \\
\text { Solvent-batch stripping tank } \\
\text { Solvent-burner feer tank } \\
\text { LAWB check tank } \\
\text { Pecovered-acid storago } \\
\text { Service concentrator feed tank } \\
\text { Service concentrator check tank } \\
\text { Sump collection tank }\end{array}$ & $\begin{array}{l}\text { Fluorimetry or } \\
\text { spectrophotomatry }\end{array}$ & $\mathrm{U}$ \\
\hline $\begin{array}{l}\text { Accountability tank } \\
\text { u-product sample tank } \\
\text { Interim Pu-product storage } \\
\text { tank (3) }\end{array}$ & Density measurement & Density \\
\hline
\end{tabular}

are listed in Table VII. The tarks are equipped with air-spargers and sampling devices for measu rement of NM content. The flushing process reduces the residual NM in tank heels, pipes, and so forth as much as is practicable.

A materials balance is taken after each physical inventory by adding all measured receipts (KMPs 2, 7, 9, and 10) to thi initial inventory (KMPs $B$ and $C$, initial) and subtracting all measured removals (KMPs 4, 5, 6, and 8) and the final inventory (KMPs $B$ and $C$, final).

c. MBA 3--Uranyl Nitrate Product. MBA 3 is an S/R MBA. The shipper's value is accepted under KMP 6 and is obtained from chemical analysis of a sample and volume measurement of the uranium product sample tank. The receiver's value is accepted under KMP 11 and is derived from chemical analysis of a sample and volume measurement of 
TABLE XIV

QUANTITIES OF PIUTONIUM IN DAILY SAMPLES

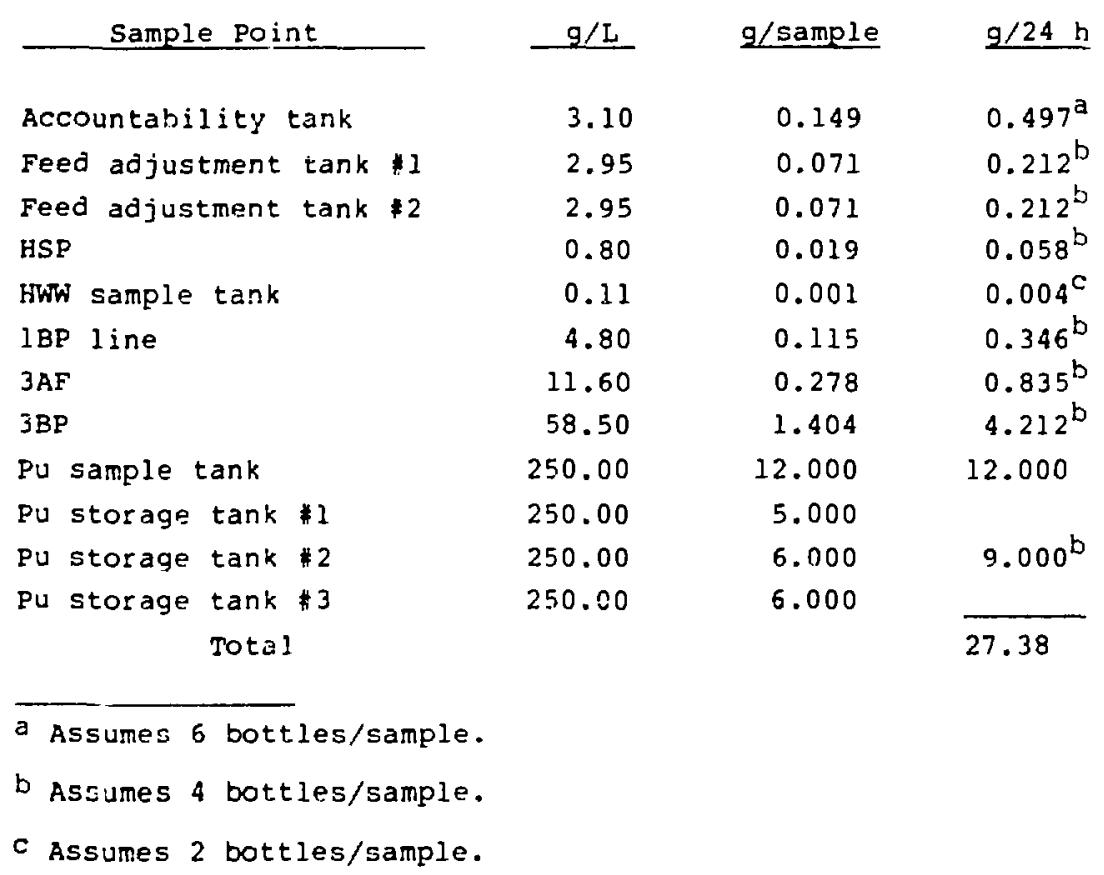

the uranyl nitrate accountability tank at the headend of the UF $_{6}$ facility. MBA 3 has no inventory because solution is transferred directly from the uranium product tank in the chemical separations area (MBA 2) to the collocated UF ${ }_{6}$ facility.

d. MBA 4--Plutonium Nitrate Product Storage. MBA 4 contains slab tanks capable of storing $33000 \mathrm{~L}$ of plutonium nitrate at a concentration of $250 \mathrm{~g} \mathrm{Pu} / \mathrm{L}$. This $\mathrm{MBA}$ is an $S / R$ MBA. The amount of plutonium nitrate solution transferred from the plutoniumproduct measuring tank to the plutonium-nitrate storage-facility slab tanks through KMP 8 constitutes the shipper's value. The nitrate product transferred to the receipt tanks in the collocated oxide-conversion plant constitutes the output of MBA 4 through KMP 12. The receiver's value is determined by volume measurements and samples taken for chemical analysis in the receipt tanks. Alternatively, plutonium nitrate product that does not meet specifications can be recycled through KMP 9 from the slab tanks back through the separations process area (MBA 2) on a campaign basis. In this case the 
receiver's value is determined in the plutonium rework tank in MBA 2 by volume measurements and chemical analysis.

A physical inventory in MBA 4 (KMP E) requires volume measurements, sampling, and analysis of all solutions in the storage area or confirmation that tamper-safe seals are intact and prior measurements are still valid.

e. MBA 5--Conversion Process. MBA 5 includes the entire conversion process area from the receipt tanks to the product loadout area. Plutonium nitrate solution from the plutonium nitrate storage facility is fed to a receipt tank (KMP 12). The receipt tank is air-sparged and mechanically agitated, and an accountability sample is taken before batches are metered to the process. The oxide product is transferred to a container for sampling and storage (KMP 14). Recycle solutions and laboratory samples can be sent to MBA 2 from the conversion MBA through KMP 10. Intermediate-level liquid waste is accumulated in the waste-run tank where volume measurements are made and samples are taken for chemical analysis before transfer out of MBA 5 through KMP 13.

During a physical inventory (KMP F), all tanks are drained, the precipitators are flushed, and the flush solutions are collected in precipitator flush tanks. The furnaces and dump-and-assay stations are swept and the powder is collected for measurement. The recycling process vessels are drained and solutions are measured in the anion-resin waste and product tanks.

f. MBA 6--Plutonium Oxide Storage. MBA 6 is the storage vault and is an S/R MBA. Therefore, the shipper's value for the plutonium oxide in sealed canisters is accepted at KMP 14 and the receiver's value (at the fabrication plant) is accepted at KMP 15. A physical inventory (KMP G) requires confirmation that tamper-safe seals are intact and that prior measurements are still valid.

2. Dynamic Materials Accounting. Conventional accounting with a stringent measurement control program may satisfy current IAEA suggested minimum international standards (see Table III). They also should satisfy the more stringent safeguards-effectiveness criteria that have beeri proposed for uranium: $75 \mathrm{~kg}$ of contained ${ }^{235} \mathrm{~L}$ during 1 yr with 5\% false alarm and $95 \%$ detection probabilities (Sec. v). However, conventional accounting measures will not satisfy any reasonable criteria for plutonium (Sec. V); therefore, materials accounting for plutonium in the process MBAs must be upgraded. 
Materials accounting and control can be improved substantially if conventional materials balance accounting measures are augmented by dynamic materials accounting methods (App. E). The dynamic materials accounting system is designed for near-real-time control of NM.

Under dynamic materials accounting, a process MBA is partitioned functionally into discrete accounting envelopes, or UPAAs. A UPAA can include the entire MBA or portions of the MBA. The distinguishing feature of a UPAA is that materials balances are closed in near-real-time by measuring all significant materials flows and in-process inventories. By comparicon, conventional materials balances are closed once each physical inventory.

The two process MBAs in the reference facility are the chemical separations MBA (MBA 2) and the conversion MBA (MBA 5). Dynamic materials accounting strategies for plutonium in these two areas are discussed below.

a. Chemical Separations Process Area. The chemical separations process area (Fig. 4) can be treated either as a single UPAA (UPAA 12), or as two UPAAs: a codecontamination-partitioning process UPAA (UPAA 1) and a plutonium-purification

\section{UPAA 12 \\ CHEMICAL SEPARATIONS}

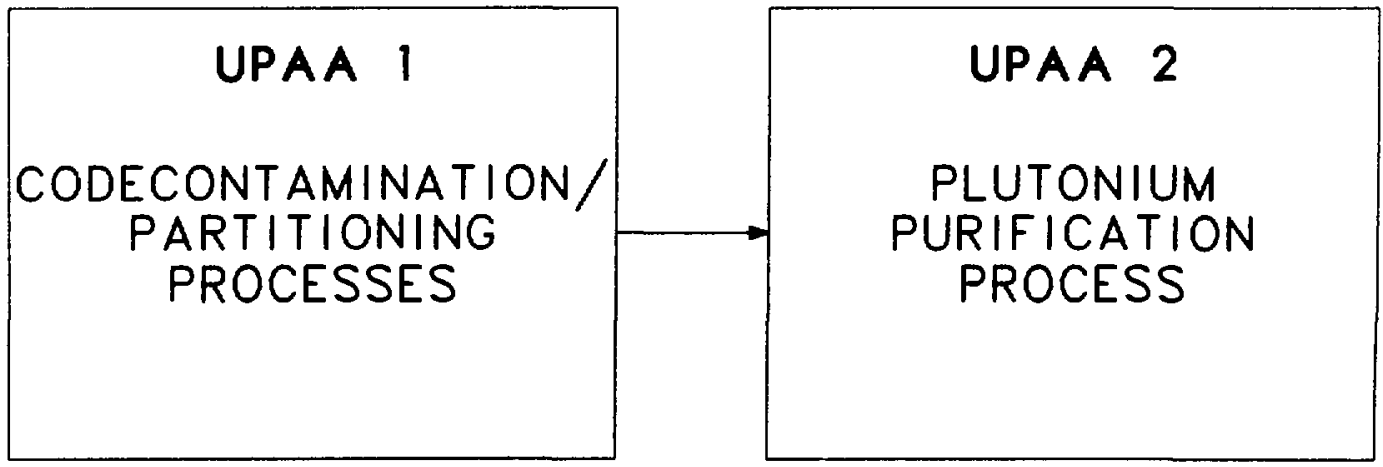

Fig. 4. UPAAs in the chemical separations process area. 
process UPAA (UPAA 2). This UPAA structure is complementary because dynamic materials balances can be taken about the chemical separations area in two ways.

(1) UPAA 12 2--Chemical Separations Process. The chemical separations process MBA can be treated as a single UPAA if measurements of the in-process inventory are made on each of the major process vessels in the process area. The process vessels in UPAA 12 , starting with the feer-adjust tanks, are shown in Figs. 5 and 6 . The inventory measurements that must be added to the inventory KMPs (KMPs Bl and B2 in Table VII) are given in Table $X V$. Measurement methods that are added for near-real-time materials accounting are discussed in App. L. Methods for estimating in-process inventor ies in contactors are discussed in App. J.

In-process inventory measurements can be combined with flow $\mathrm{KMPs} 2,4,5,6,7,8$, 9, and 10 to form a dynamic materials balance approximately every 2 days. Because most of the material is transferred through the feed and product KMPs, the frequency of taking materials balances is governed by the feed and product batch frequencies. Under normal operating conditions, two and one-half accountability batches and one product batch are processed every day. Therefore, process logic dictates that a materials balance can be taken every 2 days to include an integral number of feed and product batches. Smaller batches, for example, waste batches to high-level waste, are included in the materials balances when the measurements become available.

Alternatively, a materials balance could be taken around UPAA 12 after each feed batch (approximately every $9.6 \mathrm{~h}$ ) if an on-line plutonium product measurement were added on the 3PCP stream (see Fig. 6). The product measurement would consist of flow and concentration measurements (see Table $X V$ ).

(2) UPAA 1--Codecontamination-Partitioning Processes. A separate UPAA can be formed around the codecontamination-partitioning processes (CPP) if flow and concentration measurements are added to the 1BP, ISP, and POR streams (see Fig. 5). These measurements are given in Table XV. A dynamic materials balance can be taken about UPAA 1 for each feed accountability batch (every $9.6 \mathrm{~h}$ ) by combining measurements of the concentration and volume of the feed batch, the concentration and flow in the 1BP, 1SP, and POR streams, the initial and final in-process inventories in the process vessels, and the concentration and volume of the high-activity waste (HAW) sample tank solution. 


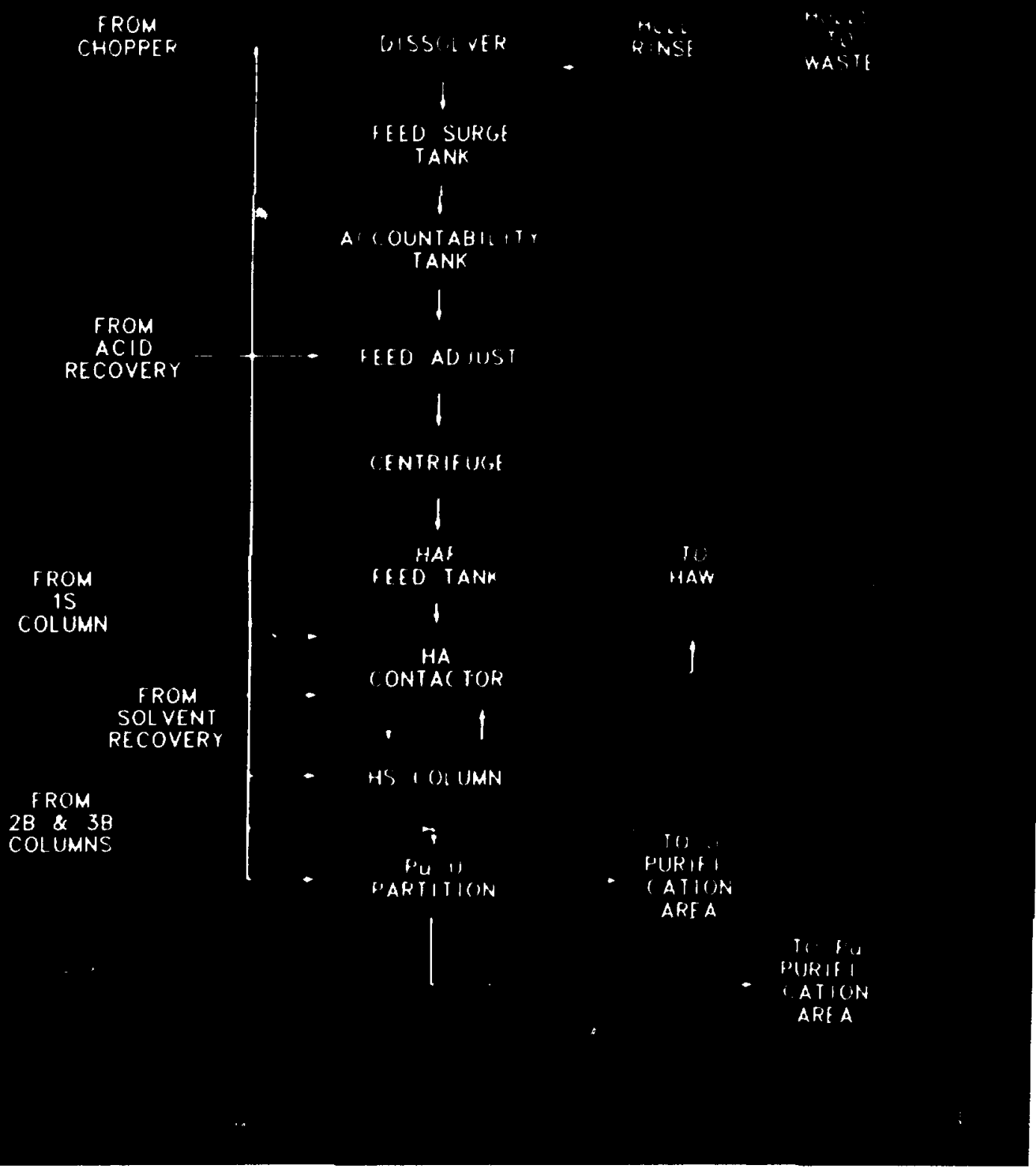

Fig. 5. Dissolution-coseparation process. 


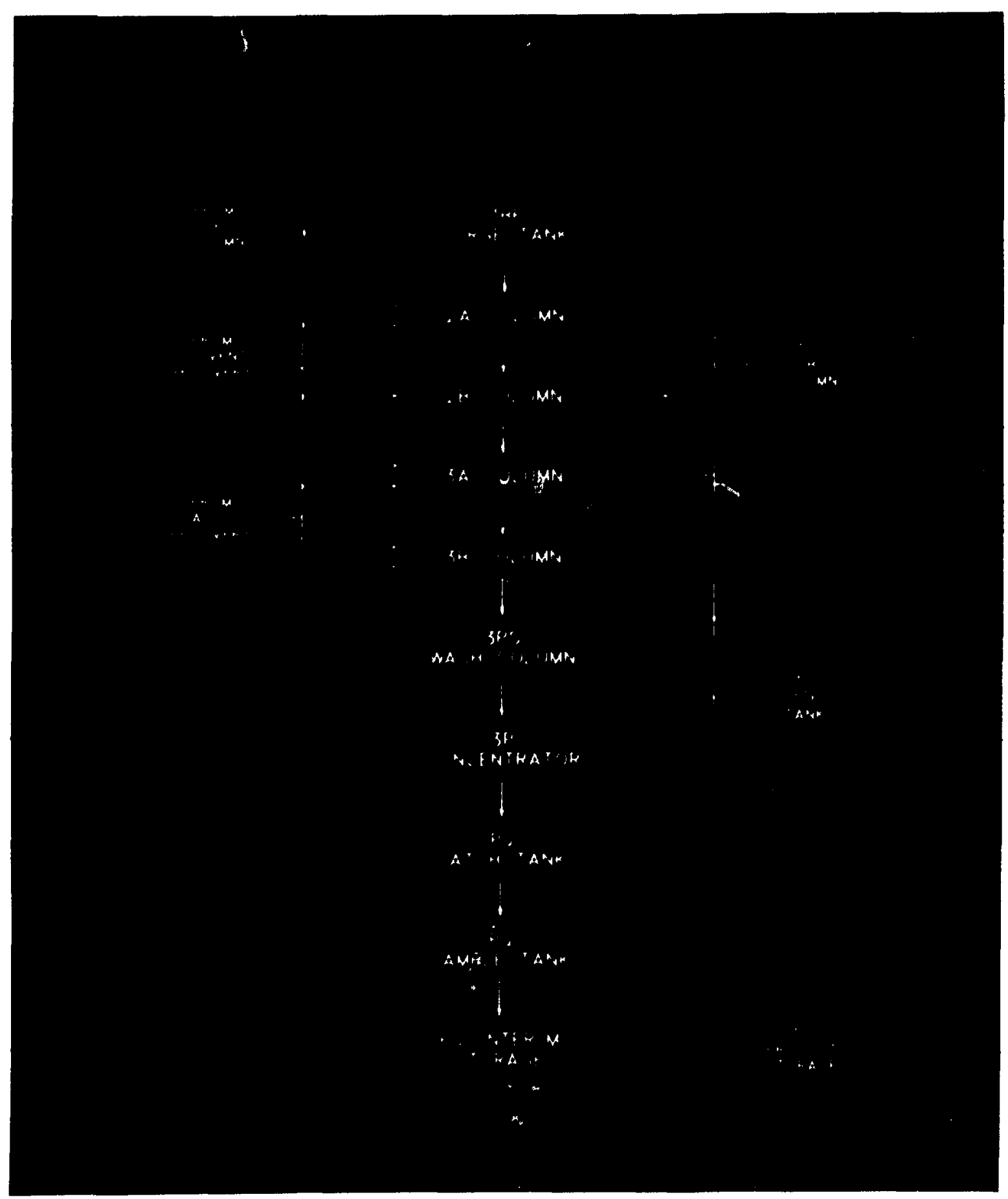

Fig. 6. Plutonium purification process. 
MEASUREMENTS ADDED FOR DYNAMIC ACCOUNTABILITY IN THE CHEMICAL SEPARATIONS PROCESS

Measurement point

HA feed tank

HS column

1.B column

lsp stream

POR stream

1BP stream

IBP surge tank

2A column

2AM stream

2B column

2BW stream

3A column

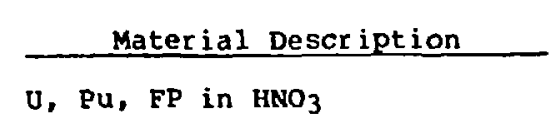

${ }_{2}, \mathrm{Pu}^{\mathrm{FP}}$ in $\mathrm{HNO}_{3}$

$\mathbf{U}, \mathrm{Pu}$, residual $\mathrm{FP}$ in organic and $\mathrm{HNO}_{3}, \mathrm{Pu}$ inventory

$U$, Pu in organic, $\mathrm{Pu}$ inventory

$U$, pu in organic

$<0.1 \mathrm{~g} \mathrm{Pu} / \mathrm{L}$

$U$, pu in organic

$0.01 .9 \mathrm{Pu} / \mathrm{L}$

$\mathrm{U}, \mathrm{Pu}$, residual $\mathrm{FP}$ in $\mathrm{HNO}_{3}$

$400 \mathrm{~L} / \mathrm{h}$

$5 \mathrm{~g} \mathrm{Pu} / \mathrm{L}$

U, Pu, residual $\mathrm{FP}$ in $\mathrm{HNO}_{3}$

$5 \mathrm{~g} \mathrm{Bu} / \mathrm{L}$

U, Pu, residual FP in aqueous, organic phases; Pu inventory

U, $\mathrm{Pu}$, residual FP in $\mathrm{HNO}_{3}$

$500 \mathrm{~L} / \mathrm{h}$

$<0.1 \mathrm{~g} \mathrm{Pu} / \mathrm{L}$

U, Pu, trace FP in aqueous, organic phases. $\mathrm{Pu}$ inventory

$U$, trace Pu in solvent

$150 \mathrm{~L} / \mathrm{h}$

Trace $\mathrm{Pu}$

U, Pu, trace FP in aqueous, organic phases, Pu inventory
Instrument

Precision

Measurement Type

Volume

Concentration

See App. J

See App. J

Flow rate

NDA, $\alpha$

Flow rate

NDA, $a$

(\$ 10)

Calibration

Error

3

$-$

20

20

5
10

5

Flow meter

Absorption-edge densitometry

Volume

Density

See App. J

Flow meter

NDA, $\alpha$

$\frac{1}{2}$

See App. J

5-20

Flow meter

NDA, $a$

5
10

1

See App. J

5-20 
TABLE XV (cont)

Measurement Point

3AW stream

3B column

3BW stream

3PS diluent-wash

P concentrator

3PD stream

3PCP stream
Tnstrument Precision Measurement Type

Material Description

$\mathrm{U}, \mathrm{Pu}$, trace $\mathrm{FP}$ in $\mathrm{HNO}_{3}$ $215 \mathrm{~L} / \mathrm{h}$ $<0.1 \mathrm{~g} \mathrm{Pu} / \mathrm{L}$

$U$, Pu in aqueous, organic phases; Pu inventory

$U$, trace $\mathrm{Pu}$ in solvent $105 \mathrm{~L} / \mathrm{h}$ Trace Pu

Pu in aqueous phase, trace

$\mathrm{Pu}$ in organic phase; $\mathrm{Pu}$ inventory

Concentrated plutonium nitrate $250 \mathrm{~g} \mathrm{Pu} / \mathrm{L}$

Residual $\mathrm{Pu}$ in $\mathrm{HNO}_{3}$

$32 \mathrm{~L} / \mathrm{h}$

$<0.1 \mathrm{~g} \mathrm{Pu} / \mathrm{L}$

\section{Flow meter}

NDA,

See App. J

Flow meter

NDA, $\alpha$

See App. J

Volume (constant)

See text

Flow meter

NDA, $\alpha$

Plutonium-nitrate product

$8 \mathrm{~L} / \mathrm{h}$

$250 \mathrm{~g} \mathrm{Pu} / \mathrm{L}$
Flow meter

Absorption-edge densitometry
10

5-20

5

1
Calibration

Excor

$\begin{array}{ll}5 & 1 \\ 10 & 2 \\ 5-20 & -\end{array}$

$\frac{1}{2}$

1.5

$\frac{1}{2}$

0.5 
(3) UPAA 2--Plutonium Purification Process. Dynamic materials balances can be taken about the plutonium purification process (PPP) if flow and concentration measurements are added to the aqueous and organic recycle streams (2AW, 2BW, 3AW, 3BW, and 3PD). These measurements are also given in Table $X V$. The balances can be taken by using one of two product measurements: the daily batch in the plutonium sample tank or the on-line flow and concentration measurements on the concentrator product (3PCP) stream.

b. Conversion Process. The conversion process is amenable to several near-real-time accounting strategies because it comprises parallel process lines and because the material being processed is relatively pure (a block diagram of a single process line is given in Fig. 7). Parallel process lines can be treated easily as separate UPAAs. Processing relatively pure material facilitates the use of near-real-time measurements, thus presenting more possibilities in partitioning each process line. As shown in Fig. 8, the accounting strategies can be developed hierarchically:

1) Treat the entire conversion process area as a single UPAA, UPAA 345 ;

2) Divide the conversion process into three parallel UPAAs, one of each process line, UPAA 3, UPAA 4, and UPAA 5;

3) Divide each process line into two UPAAs in series, feed adjust/precipitation (UPAA 3A, 4A, and 5A) and calcination/product loadout (UPAA 3B, 4B, and 5B). In each accounting strategy, dynamic materials balances are formed from periodic measurements of transfers and in-process inventories. For each materials balance, (1) receipt tank in-process inventory, (2) precipitator in-process inventory, (3) precipitator product (wet cake in filter boats), (4) filtrate and wash solutions, and (5) product cans are measured. Approximately once a day, (1) precipitator flush solution, (2) boat flush solution, and (3) loose powders recovered from the dumping station are measured. The loose powders recovered from the furnace are measured approximately once a week. The measurements that must be added to the flow and inventory KMPs (KMPs 12, 13, and 14 in Table VI; and KMPs F1, F2, F3, and F4 in Table VII) are given in Table XVI.

(1) UPAA 34 5--Conversion Process Area. The entire conversion process area is treated as a single UPAA. The UPAA boundaries are the receipt tanks and the product dump-and-assay stations. The UPAA in-process inventory includes the contents of each precipitator and the contents of wet boats in each of the furnaces. 


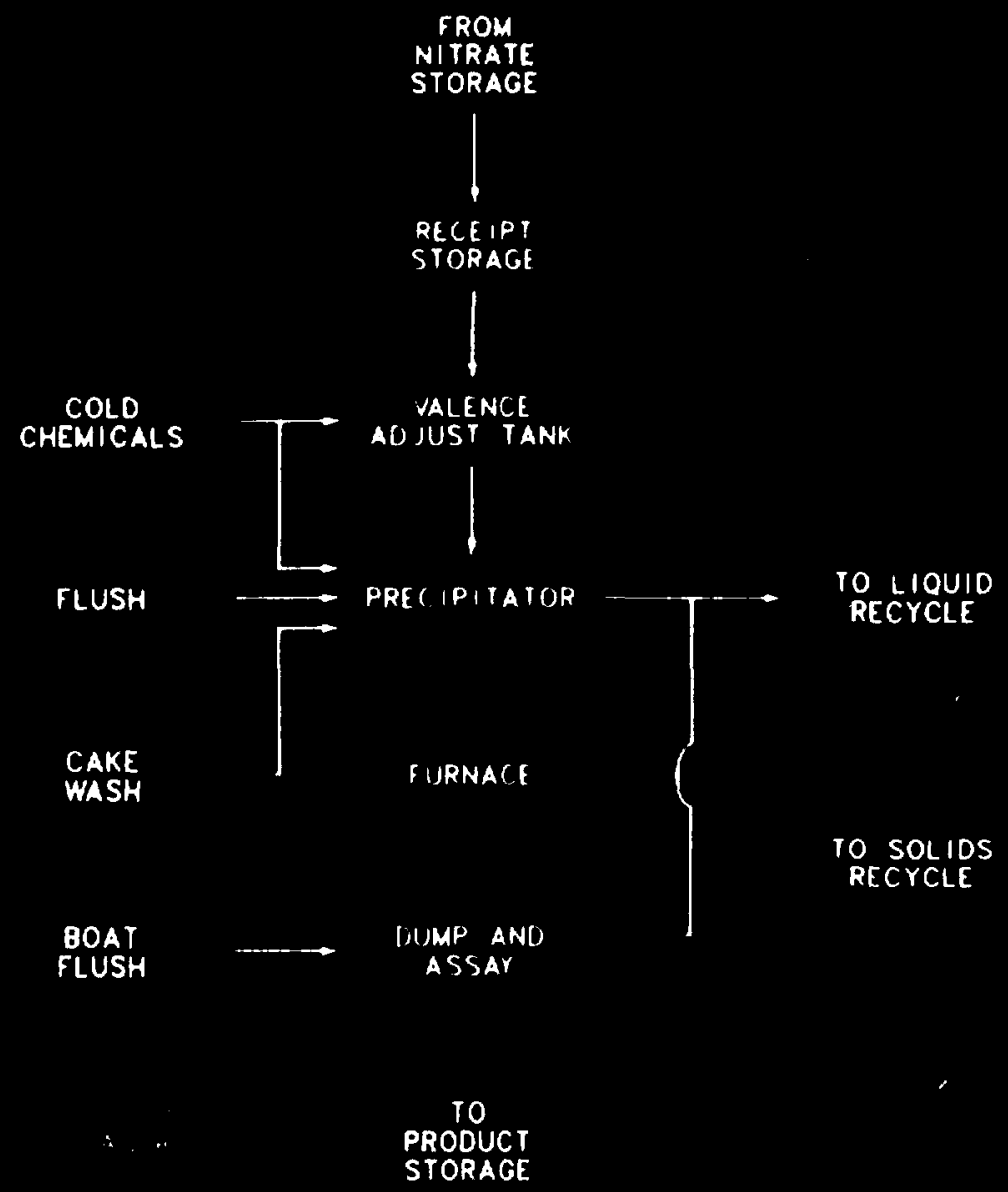

Fig. 7. Conversion process block diagram. 


\section{UPAA $3 \quad 4 \quad 5$ CONVERSION PROCESS}
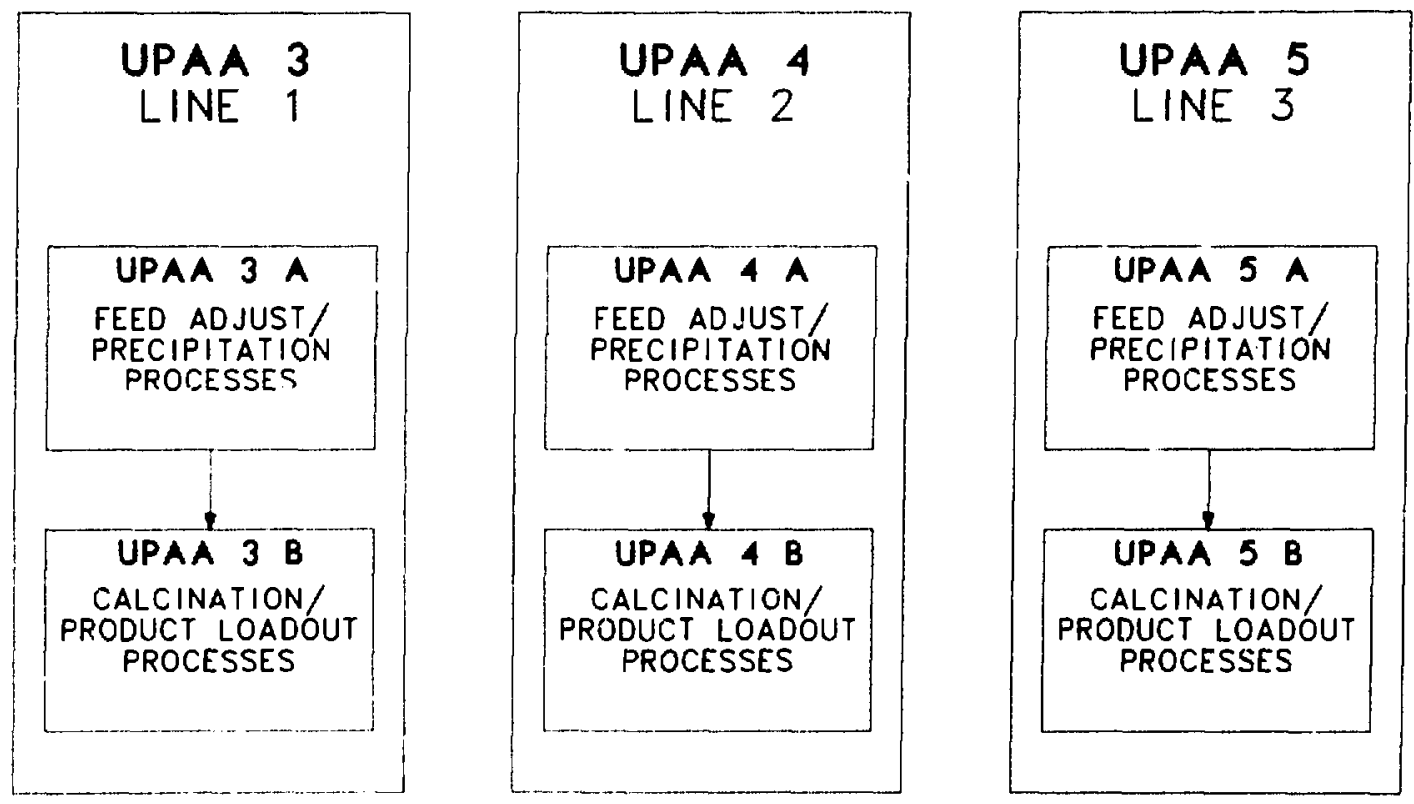

Fig. 8. UPAAs in the conversion process.

(2) UPAA 3, UPAA 4, UPAA 5--Conversion Process Lines. In this accounting strategy, each process line is a separate UPAA. The UPAA boundaries are the receipt tanks and a single product dumping station. The in-process inventory includes the precipitator contents and the contents of wet boats in the furnace of that process line. The use of parallel process lines having reduced throughput and inventory for the same total plant throughput can often markedly improve materials accounting sensitivity (App. E).

(3) UPAA 3A, UPAA 4A, UPAA 5A--Feed-Adjust/Precipitation Processes. This UPAA includes the feed-adjust and precipitation processes. The UPAA boundaries are the receipt tanks and the filter-boat loading station. 
TABLE XVI

MEASUREMENTS ADDED FOR DYNAMTC ACCOUNTABILITY IN THE CONVERSION PROCESS

\begin{tabular}{|c|c|c|c|c|}
\hline Measurement Point & $\begin{array}{c}\text { Matorial } \\
\text { Description }\end{array}$ & Measurement Type & $\begin{array}{l}\text { Tnstrument } \\
\text { Precision } \\
(810) \\
\end{array}$ & $\begin{array}{c}\text { CaIjbration } \\
\text { Error } \\
(810) \\
\end{array}$ \\
\hline Receipt tank. & $\mathrm{Pu}_{1,30 \mathrm{~g} / \mathrm{L}}$ & $\begin{array}{l}\text { Volume } \\
\text { Concentration (by } \\
\text { L-edge densitometry) }\end{array}$ & $\begin{array}{l}0.2 \\
0.5\end{array}$ & $\begin{array}{l}0.1 \\
0.3\end{array}$ \\
\hline $\begin{array}{l}\text { Wet boat } \\
\text { (precipitator output) }\end{array}$ & Plutonium oxalate & $\begin{array}{c}\text { Mass (by neutron } \\
\text { well counter) }\end{array}$ & 4 & 5 \\
\hline Precipitator holdup & Plutonium slurry & $\begin{array}{l}\text { Mass (by He-3 } \\
\text { neutron counter) }\end{array}$ & 2 & -- \\
\hline Filtrate & $\begin{array}{l}\mathrm{Pu} \text { in } \mathrm{HNO}_{3} \text {, } \\
=30 \mathrm{mg} / \mathrm{L}\end{array}$ & $\begin{array}{l}\text { Volume } \\
\text { Concentration (by } \\
\text { alpha monitor) }\end{array}$ & 10.2 & $\begin{array}{l}0.1 \\
0.5\end{array}$ \\
\hline Precipitator flush & 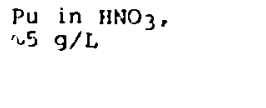 & $\begin{array}{l}\text { Volume } \\
\text { Concentration (by } \\
\text { l-edge densitometry } \\
\text { or } x-\text { ray spectrometry) }\end{array}$ & $\begin{array}{l}0.2 \\
1\end{array}$ & $\begin{array}{l}0.1 \\
0.3\end{array}$ \\
\hline Boat fiush & $\begin{array}{l}\mathrm{Pu} \text { in } \mathrm{HNO}_{3} \text {, } \\
\mathrm{ll.5} \mathrm{g} / \mathrm{I}\end{array}$ & $\begin{array}{l}\text { Volume } \\
\text { Concentration (by } \\
x-\text { ray fluorescence }\end{array}$ & $\begin{array}{l}0.2 \\
1\end{array}$ & $\begin{array}{l}0.1 \\
0.3\end{array}$ \\
\hline Furnace sweep & Plutonium oxide & $\begin{array}{l}\text { Mass (by neutron well } \\
\text { counter) }\end{array}$ & 2 & 0.5 \\
\hline Dump station sweep & Plutonium oxide & $\begin{array}{l}\text { Mass (by neutron well } \\
\text { counter) }\end{array}$ & 2 & 0.5 \\
\hline Product cans & Plutoni um oxide & $\begin{array}{l}\text { Mass (by neutron well } \\
\text { counter, calor imeter, } \\
\text { or gamma spectrometer) }\end{array}$ & 1 & 0.5 \\
\hline
\end{tabular}

(4) UPAA 3B, UPAA 4B, UPAA 5B--Calcination/Product Loadout Processes. This UPA.A includes the calcination and product dump-and-assay processes. The UPAA boundaries are the filter-boat loading station, the product of UPAA 3, and the product dumping station. Batch integrity is maintained in this UPAA; therefore, materials balances are taken for each batch as it is processed.

\section{Small Reprocessing Plant}

Because many present-day commercial reprocessing plants have capacities of less than $300 \mathrm{MTHM} / \mathrm{year}$, an MMAS typical of these smaller reprocessing plants is described below. The Tokai reprocessing plant is used as the reference facility ${ }^{37-40}$ (Sec. Il; App. B). The reference facility includes only a chemical separations facility; conversion process designs are under consideration, and plutonium nitrate product will be stored until a suitable conversion process is built.

The Tokai plant is used as a reference design because plant descriptions are available and because the applicability of improved safeguards techniques to Tokai is being studied. $^{52}$ The Tokai Advanced Safeguards Technology Exercise, TASTEX, includes 
tasks to develop and demonstrate various instruments, to evaluate surveillance techniques, and to study the application of near-real-time accounting techniques to small reprocessing plants.

The results of the study of the application of advanced accounting techniques to a small reprocessing plant ${ }^{37}$ are summarized below. The operator's MMAS is developed next using the same system structure, and measurement methods and errors as in the large chemical separation plant.

1. The Japan Atomic Energy Research Institute (JAERI) Study. A study on the applicability of advanced accounting techniques to a small reprocessing plant has been completed by the JAERI. ${ }^{37}$ The feasibiity of weekly plutonium materials balances was irivestigater on the basis of measurement capabilities available in the reference facility. The study concludes that semidynamic materials accounting based on weekly materials balances "can be recognized as a feasible and effective system for the model reprocessing plant" (Ref. 37, p. 11).

The weekly materials balance is formed by combining input dissolver batch, product batch, and waste batch measurements with weekly measurements of the contents of buffer and feed tanks. The balance is taken immediately after the evaporator is discharged and before the evaporator feed is restarted.

Measurements used in the JAERI study are given in Table XVII. The codecontamination-partitioning and plutonium purification processes block diagram are given in Figs. 9 and 10, respectively. Note that volume measurements and chemical analysis of samples are made for each major tank in the process line. In-process inventories in the mixer-settlers are not measured or estimated. Simulations of model mixer-settlers show that during normal operation the fluctuation in the unmeasured in-process inventory may be small. However, the fluctuation in the unmeasured in-process inventories is the limiting factor in the short-term detection sensitivity, and techniques are needed for estimating contactor inventories particularly for large plants.

Several flow and measurement simulations for different fuel types and burnups were considered in the study. Some sample results are given below for the case in which PWR fuel with a burnup of $20000 \mathrm{MMD} / \mathrm{MT}$ is reprocessed. During the 22-wk analysis period, $760 \mathrm{~kg}$ of plutonium were reprocessed. Conventional materials balance standard deviations ranged from 5.9 to $8.7 \mathrm{~kg}$ of plutonium for the cases of weekly recalibrations to no recalibration within the accounting period. These materials balance uncertainties do not satisfy any reasonable proposed detection goals, and therefore dynamic materials accounting is superimposed on the plutonium process areas: the codecontamination, 
TABLE XVII

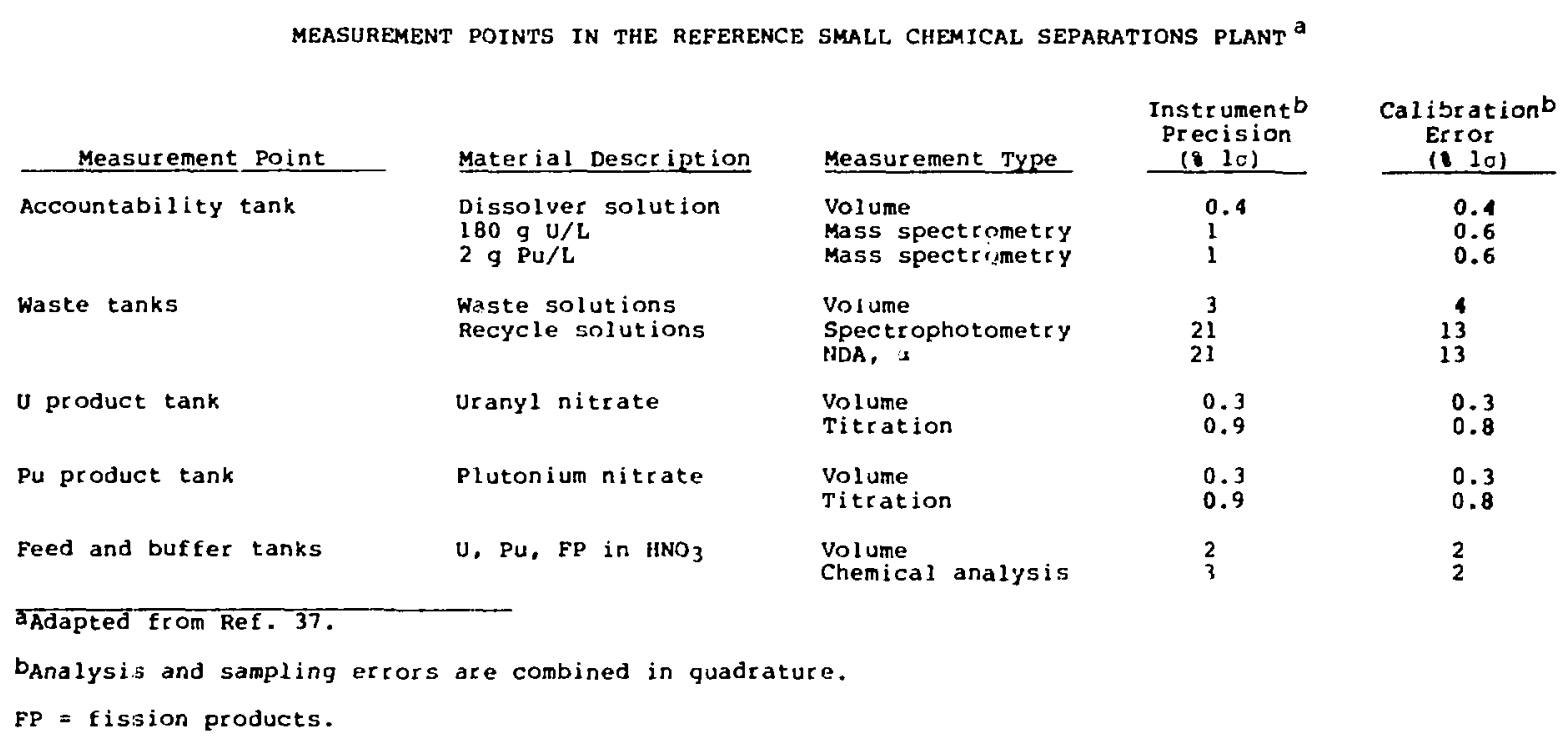

extraction, and plutonium purification processes. The dynamic materials accounting simulation studies show a loss-detection sensitivity of $\sim{ }_{10}$ MUF for a 1 -wk materials balance. For the cases considered, Io MUF varies in the range 224-506 $\mathrm{g}$ of plutonium. For the sample case the conventional materials balance $1 \sigma_{\text {MUF }}$ is $417 \mathrm{~g}$ of plutonium.

2. Conventional Materials Accounting. The physical inventory accounting system structure in a small plant is identical to that of the large plant described in Sec. IV.B.I. However, in this case only MBAs 1 through 4 and KMPs 1 through 9 (see Fig. 3) are applicable because only the chemical separations process is considered here. MBA I includes fuel receiving, storage, chop, and leach; it is an S/R MBA. MBA 2 comprises the chemical separations process area from the accountability tank to the uranium and plutonium nitrate product tanks and is treated as an MBA. MBAs 3 and 4, respectively, are the uranium and plutonium nitrate storage areas; they are S/R MEAs.

The flow and inventory KMPs are given in Table XVIII. The measurement types and instrument errors are identical to those of the large chemical separations facility. Possible measurements for spent fuel and leached hulls, and isboratory sampling procedures are discussed in Sec. IV.B.l. Estimation of mixer-settler in-process inventory is discussed in App. J. During physical inventory, solutions are measured and sampled from various tanks within the process line. 


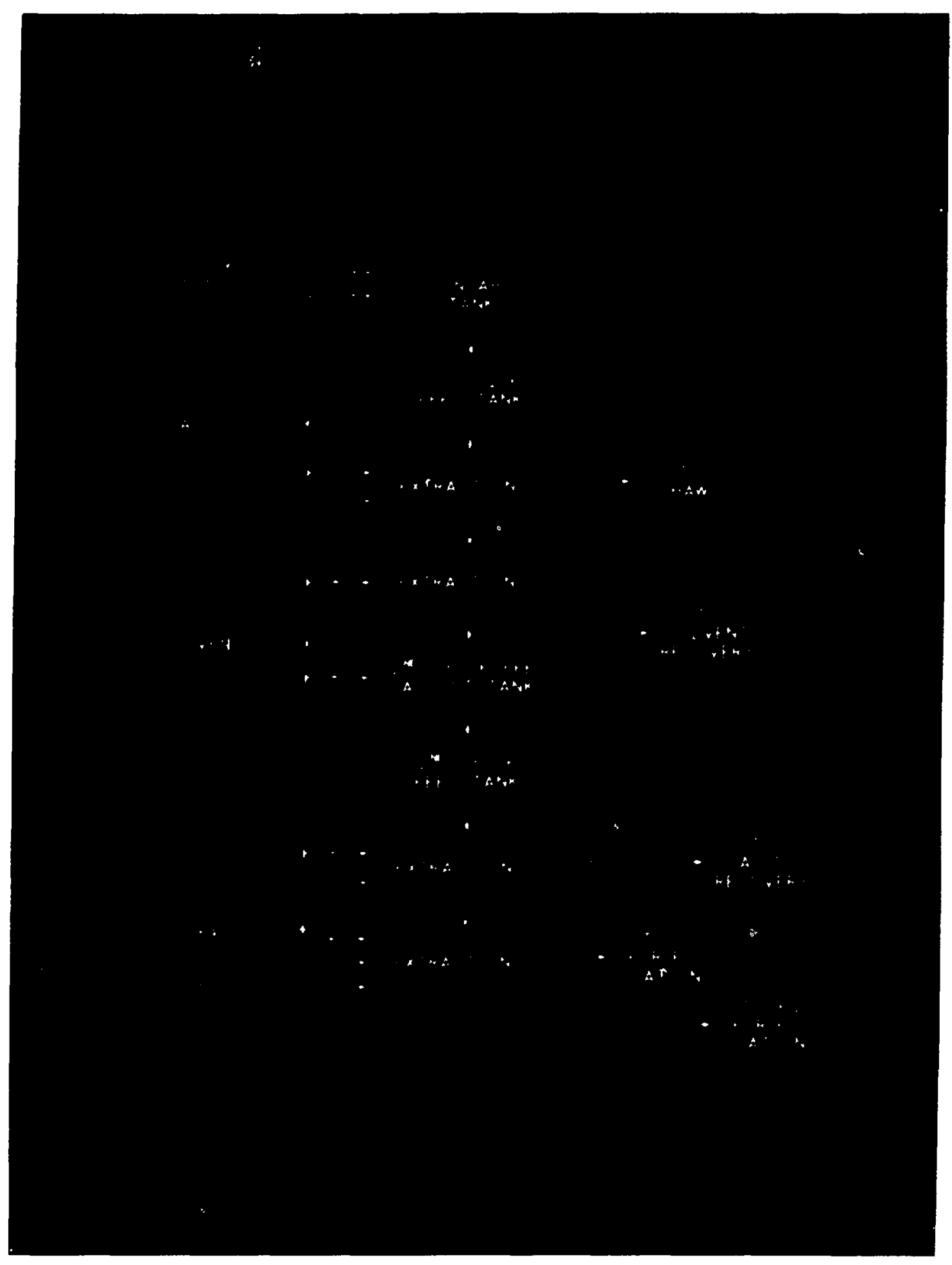

Fig. 9. Tokai codecontamination-partitioning process. 


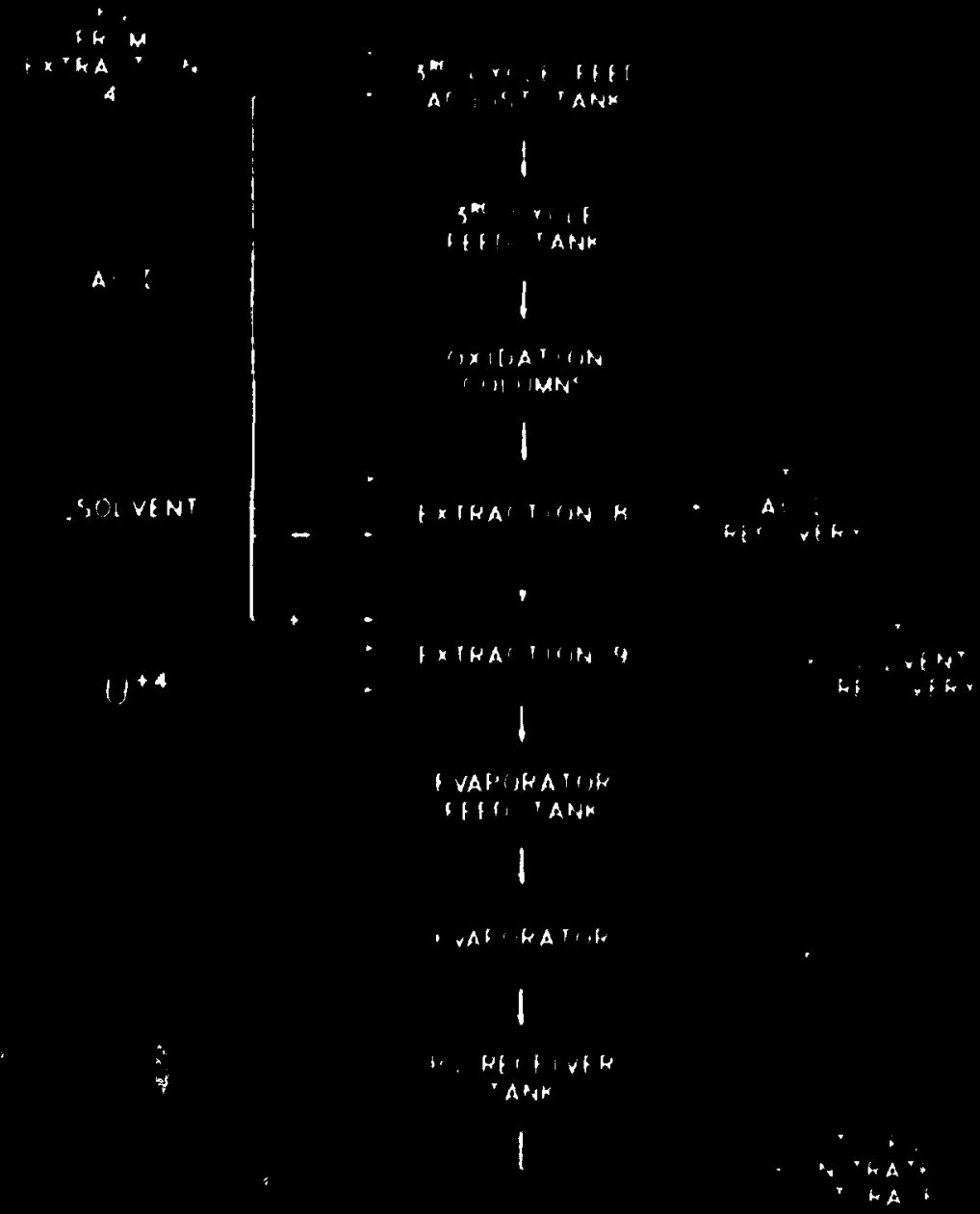

Fig. 10. Tokai plutonium purification process. 
TABLE XVIII

FLOW AND INVENTORY KEY MEASUREMENT POINTS

FOR CONVENTIONAL MATERIALS ACCOUNTING AT TOKAI-MURA

\begin{tabular}{|c|c|c|c|c|c|}
\hline$\underline{\text { KMP }}$ & Measurement Point & Material Description & Measurement Type & $\begin{array}{l}\text { Instrument } \\
\text { Precision } \\
(8 \quad 10) \\
\end{array}$ & $\begin{array}{c}\text { Celibration } \\
\text { Error } \\
\begin{array}{r}(810) \\
\end{array}\end{array}$ \\
\hline 1 & Cask-unloading pool & Irradiated Fuel & See Sec. IV.B & -- & \\
\hline $2 a$ & Accountability tank & $\begin{array}{l}\text { Dissolver solution } \\
180 \mathrm{~g} \mathrm{~L} / \mathrm{L} \\
29 \mathrm{Pu} / \mathrm{L}\end{array}$ & $\begin{array}{l}\text { Volume } \\
\text { Mass spectrometry } \\
\text { Mass spectrometry }\end{array}$ & $\begin{array}{l}0.3 \\
1 \\
1\end{array}$ & $\begin{array}{l}0.1 \\
0.2 \\
0.3\end{array}$ \\
\hline $2 b$ & MBA I laboratory samples & u, Pu, FP in $\mathrm{HNO}_{3}$ & Chemical analysis & -- & \\
\hline 3 & Leached-hull basket & $\begin{array}{l}S .5 ., 2 r \\
\text { Trace of } U, \text { Pu, FP }\end{array}$ & NDA & -- & \\
\hline 4 & Rework tank & Recycle acid & $\begin{array}{l}\text { Volume } \\
\text { Concentration }\end{array}$ & $\begin{array}{r}2 \\
10\end{array}$ & $\begin{array}{l}3 \\
5\end{array}$ \\
\hline 5 & Waste tanks & $\begin{array}{l}\text { Waste solutions } \\
\text { Recycle solutions }\end{array}$ & $\begin{array}{l}\text { Volume } \\
\text { Mass spectrometry }\end{array}$ & $\begin{array}{l}5 \\
1\end{array}$ & $\begin{array}{l}3 \\
0.5\end{array}$ \\
\hline 6 & U product tank & Uranyl nitrate & $\begin{array}{l}\text { Volume } \\
\text { Gravimetry }\end{array}$ & $\begin{array}{l}0.3 \\
0.25\end{array}$ & $\begin{array}{l}0.1 \\
0.1\end{array}$ \\
\hline $7 \notin 8$ & Rework tank & Rework solutions & & & \\
\hline 9 & Pu product tank & Plutonium nitrate & $\begin{array}{l}\text { Volume } \\
\text { Amperometry or } \\
\text { coulometry }\end{array}$ & $\begin{array}{l}0.3 \\
0.2\end{array}$ & $\begin{array}{l}0.1 \\
0.1\end{array}$ \\
\hline A & Spent fuel pool & Irradiated Fuel & See Sec. IV.B & -- & \\
\hline B & Chemical separations area & Various solutions & $\begin{array}{l}\text { Volume } \\
\text { Chemical analysis }\end{array}$ & $\begin{array}{l}2 \\
3\end{array}$ & $\begin{array}{l}2 \\
2\end{array}$ \\
\hline$c$ & Laboratory & Assorted samples & Chemical analysis & -- & \\
\hline
\end{tabular}

3. Dynamic Materials Accounting. Near-real-time accounting of plutonium can be applied to the chemical separations area, as a single UPAA, without additional measurement points by periodically sampling for chemical analysis and measuring the volume of each of the process vessels, and estimating the in-process inventory in each mixer-settler. These measurements are necessary for determining the in-process inventory. The UPAA boundaries are the accountability tank, the plutonium receiver tank, and the waste and recycle acid tanks (see Figs. 9 and 10). A dynamic materials balance can be drawn after any integral combination of feed and product batches; i.e., as often as once a day immediately after the evaporator is discharged and before the evaporator feed is restarted (two feed batches and one product batch).

A near-real-time accounting system for plutonium in the Tokai-mura reprocessing plant uses conventional chemical analysis and a weekly materials balance is described in Sec. IV.C.l. This procedure is easily extended to daily materials balances. However, daily balances may increase the chemical analysis burden beyond acceptable limits, 
requiring the addition of at-line NDA capability, x-ray fluorescence, and absorption-edge densitometry for analysis of in-process inventory samples. These types of measurements are being considered in the TASTEX program.

As shown in Fig. 11 the near-real-time accounting system could be extended to include three UPAAs and combinations thereof within the chemical separations area.

The UPAAs within the chemical separations area would be codecontaminationpartitioning, UPAA 1; codecontamination, UPAA 1A; partitioning, UPAA IP; and plutonium purification, UPAA 3. The codecontamination-partitioning can be divided into two UPAAs because of the buffer tanks that are between the first and second extraction cycles. This option is lacking in the large chemical separations plant where such a division is not possible. Additional measurements required for this system are given in Table XIX and include flow and concentration measurements of the streams between the UPAAs as well as on-line or at-line concentration measurements for determining in-process inventories. The feed and product batch measurements rely on the traditional volume measurements and chemical analysis that are in place (Table XVIII). In-process inventory volume measurements are also in place. Methods for determining in-process inventories in contactors are discussed in App. J.

TABLE XIX

MEASUREMENTS ADDED FOR DYNAMIC ACCOUNTABILITY AT TOKAI-MURA

\begin{tabular}{|c|c|c|c|c|}
\hline Measurement Point & Material Description & Measurement Type & $\begin{array}{l}\text { Instrument } \\
\text { Precision } \\
(810) \\
\end{array}$ & $\begin{array}{c}\text { Calibration } \\
\text { Error } \\
\left(\begin{array}{ll}8 & 10\end{array}\right) \\
\end{array}$ \\
\hline Extractors & $\begin{array}{l}\mathrm{U}, \mathrm{Pu}, \mathrm{FP} \text { in organic } \\
\text { and } \mathrm{HNO}_{3} \text {, Pu inventory }\end{array}$ & See App. J & 20 & -- \\
\hline 2nd cycle feed tank & $\begin{array}{l}U . \mathrm{Pu}, \text { trace } \mathrm{FP} \text { in } \mathrm{HNO}_{3} \\
0.6 \mathrm{~g} \mathrm{Pu} / \mathrm{L}\end{array}$ & $\begin{array}{l}\text { Volume } \\
x-r \text { ay } f l \text { uorescence }\end{array}$ & $\begin{array}{l}3 \\
3\end{array}$ & $=$ \\
\hline 3rd cycle feed tank & $\begin{array}{l}\text { Pu in } \mathrm{HNO}_{3} \\
2 \mathrm{~g} \mathrm{Pu} / \mathrm{L}\end{array}$ & $\begin{array}{l}\text { Volume } \\
\text { L-edge densitometry }\end{array}$ & $\begin{array}{l}3 \\
1\end{array}$ & -- \\
\hline Oxidation columns & $\begin{array}{l}\text { Pu in } \mathrm{HNO}_{3} \\
\text { Pu inventory }\end{array}$ & NDA text & 20 & -- \\
\hline 2nd cycle feed & $\begin{array}{l}\mathrm{U}, \mathrm{Pu}, \text { trace FP in } \mathrm{HNO}_{3} \\
0.6 \mathrm{~g} \mathrm{Pu} / \mathrm{L}\end{array}$ & $\begin{array}{l}\text { Flow } \\
x-r \text { ay fluorescence }\end{array}$ & $\frac{1}{3}$ & $\begin{array}{l}0.5 \\
0.5\end{array}$ \\
\hline 3rd cycle feed & $\begin{array}{l}\mathrm{Pu} \text { in } \mathrm{HNO}_{3} \\
2 \mathrm{~g} \mathrm{Pu} / \mathrm{L}\end{array}$ & $\begin{array}{l}\text { Flow } \\
x-r \text { ay fluorescence }\end{array}$ & $\frac{1}{1}$ & $\begin{array}{l}0.5 \\
0.5\end{array}$ \\
\hline
\end{tabular}

$\overline{\text { FP }}$ = fission products. 


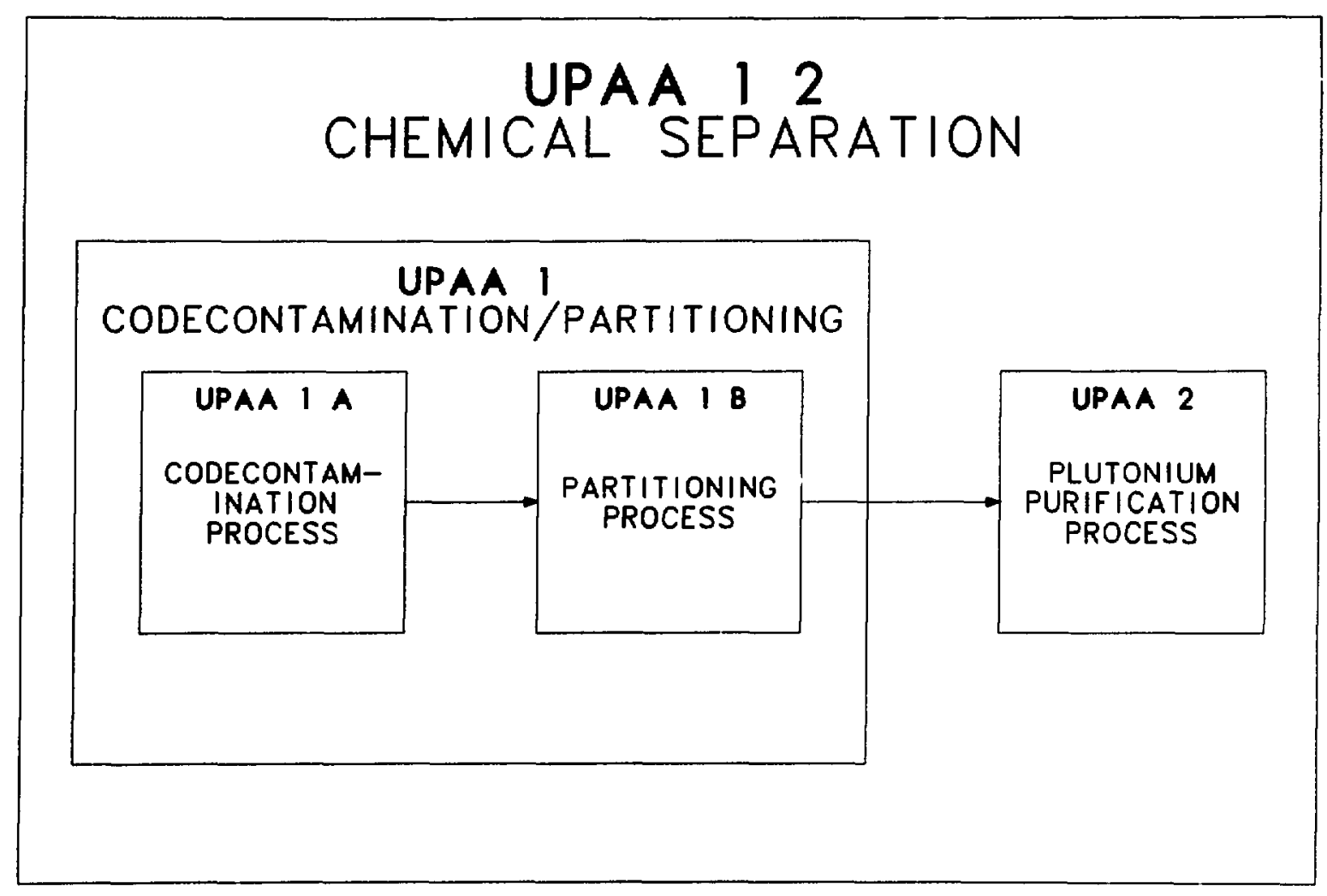

Fig. 11. SPAs in the reference small chemical separations facility.

51 


\section{OPERATOR'S SAFEGUARDS SYSTEM: EFFECTIVENESS OF THE MATERIALS MEASUREMENT AND ACCOUNTING SYSTEM}

\section{A. Introduction}

The effectiveness of the operator's MMAS in detecting diversion is evaluated in this section. First, the effectiveness of the MMAS for the large reference facility is evaluated. Second, the effectiveness of the MMAS for the small reprocessing plant is evaluated by postulating a measurement system consistent with that for the large plant. The reference facility is described in Sec. II and App. B. The operator's safeguards system structure is described in Sec. III. The operator's MMAS, including accounting strategies and measurement requirements, is given in Sec. IV. Measurement methods are described in Apps. $\mathrm{K}, \mathrm{L}$, and $\mathrm{M}$. The modeling, simulation, and analyses techniques used to design and evaluate these MMASs are described below and in App. F.

In the evaluation of conventional accounting, the buildup of measurement correlations caused by long-term errors was simulated. Correlations caused by small relative biases between input and output measurements are the major contributors to materials balance uncertainties over long accounting periods. Better control of these relative biases will result in significant improvements in the sensitivity of conventional materials accounting to protracted diversion.

Small long-term biases have a much smaller effect on near-real-time materials balances taken over short accounting periods. For these short accounting periods, short-term errors (errors that persist over a given calibration period) become the dominant factor in the materials balance uncertainty. In the evaluation of near-real-time accounting, control of short-term errors was simulated for the feed and product streams. The potential improvement in detection sensitivity obtained by controlling the short-term errors is illustrated in the examples given later in this section. Control of short-term errors involves careful design of a measurement control program for each measurement technique, and, in particular, for those techniques applied at the flow KMPs.

\section{B. Modeling, Simulation, and Analysis Techniques}

1. Modeling and Simulation Approach. The design and evaluation of MMASs are based on computer simulations of the reference facilities because the facilities either have not been built or have not operated in a full production mode. Furthermore, advanced MMASs do not exist. Modeling and simulation techniques permit the dynamic behavior of materials flows to be predicted over a wide range of operating parameters and 
allow the rapid accumulation of data equivalent to relatively long operating periods. Alternative operating, measurement, and accounting strategies can be readily compared. Therefore, even if nuclear fuel-cycle facilities with advanced MMASs were operating, their use in the design and evaluation of alternative operating, measurement, and accounting strategies probably would be too time consuming, expensive, and impractical.

The modeling and simulation approach has been used extensively in safeguards concept studies. $^{1-3,8}$ This approach requires ${ }^{64}$ (1) a detailed dynamic model of the process based on actual design data and operator experience; (2) simulation of the model process on a digital computer; (3) a dynamic model of each measurement system based on best estimates of instrument performance and behavior; (4) simulation of accountahility measurements applied to NM flow and in-process inventory data generated by the model process simulation; and (5) evaluation of simulated materials balance data from various materials accounting strategies. Brief descriptions of the process and measurement models are given below. More detailed descriptions are given in App. B.

a. Process Model. A computer code based on standard Monte Carlo techniques $^{65,66}$ is written to simulate the operation of the process. The GASP IV 67 simulation package is used to schedule events. When an event is scheduled in a particular process step, the values of all concentrations, materials transfers, and in-process inventory associated with that step are computed and stored in a data matrix.

b. Measurement Models. Model measurements are applied to the simulated process-flow and in-process inventory data by using the Monte Carlo computer code MEASIM (Measurement Simulation) developed for that purpose. MEASIM simulates instrument operation by using either an additive or a multiplicative measurement-error model (see App. F), then stores the measured values, or appropriate combinations thereof, with their uncertainties, in a measurement data base for eventual retrieval and analysis by the safeguards data-analysis code DECANAL (Decision Analysis). Each UPAA and each accounting strategy requires a specialized version of MEASIM.

c. Materials Balances. The measured values computed in MEASIM are combined to form dynamic materials balances. A materials balance is a linear combination of measured transfers (inputs positive, outputs negative) and measured inventories (initial inventory positive, final inventory negative). Usually, the dynamic materials balance frequency is dictated by process logic, for example, by the feed and product batch frequency. 
2. Data Analysis Techniques. Analysis of materials accounting data for detection of possible NM diversion is one of the major functions of the MMAS. Diversion may occur in the range between two basic patterns: abrupt diversion (the single theft of a relatively large amount of NM) and protracted diversion (repeated thefts of NM on a scale too small to be detected in a single materials balance because of measurement uncertainties).

The use of unit process accounting and dynamic materials balances (see Sec. IV.B.3) enhances the ability to detect such diversions, but it also means that the operator of the safeguards system will be inundated with materials accounting data. Furthermore, although these data contain much potentially useful information concerning both safeguards and process control, the significance of any isolated (set of) measurements is seldom readily apparent and may change from day to day, depending on the plant operating conditions. Thus, the safeguards system operator could be presented with an overwhelmingly complex body of information from :mich he must repeatedly determine the safeguards status of the plant. Clearly, he must be assisted by a coherent, logical framework of tools that address these problems.

Decision analysis (see Refs. 68-72), which combines techniques from estimation theory, decision theory, and systems analysis, affords such a framework and is well suited for statistical treatment of the dynamic materials accounting data that become available sequentially. Its primary goals are (1) detection of the event(s) in which NM has been diverted, (2) estimation of the amount(s) diverted, and (3) determination of the significance of the estimates.

The application of decision analysis to NM accounting is reported in several papers, ${ }^{68-70}$ and only a brief overview is given here. The detection and estimation functions of decision analysis are based on classical hypothesis testing and modern state-variable estimation techniques. The systems analysis portion attempts to set rational thresholds for the hypothesis tests, for example, by using utility theory to determine desirable false-alarm and detection probabilities.

The detection function is based on acceptance of the hypothesis that some (initially unknown) amount of $N M$ is missing vs the hypothesis that all NM is present. One useful kind of decision test compares a likelihood ratio to a threshold, the likelihood ratio being defined roughly as the ratio of the probability that NM is missing to the probability that it is not, with the threshold determined by the desired false-alarm and detection probabilities. This structure can accommodate both parametric tests, which require detailed knowledge of measurement error statistics, and nonparametric tests, which do not. Furthermore, the set of tests enables a search for diversion that may have occurred 
in any pattern, and in each test all possible sequences of the available materials balance data are examined.

The decision analysis algorithms include the Shewhart chart, cumulative summation (Cusum), uniform diversion test (UDT), sequential variance test (SVT), smoothed materials balance test (SMBT), and Wilcoxon rank sum test. The algorithms for the Shewhart chart, Cusum, UDT, SVT, and SMBT are structured to account for correlated data so that correct variances are computed for the associated decision tests. The actual false-alarm and detection probabilities for the Wilcoxon test depend on the degree of data correlation. If correlations are large, the Wilcoxon test performance will suffer unless corrective measures are taken.

a. Shewhart Chart. The Shewhart chart is the oldest graphical-display tool to be widely used by industry for process control. 73,74 In the chart's standard form, measured data are plotted sequentially on a chart where $2 \sigma$ and $3 \sigma$ levels are indicated. In safeguards applications, the Shewhart chart is a sequential plot of the materials balance data with $1 \sigma$ error bars.

b. Cusums. A Cusum is computed after each materials balance period. It is the sum of all materials balances for the unit process since the beginning of the accounting interval. The Cusum variance is a complex combination of the variances of individual materials balances, because these balances usually are not independent. Correlation between materials balances has two principal sources. The first is the correlation, discussed previously, between measurement results obtained by using a common instrument calibration. The magnitudes of the associated covariance terms depend on the magnitude of the calibration error and the frequency of each instrument recalibration; omission of these terms can cause gross underestimation of the Cusum variance. The second solirce of correlation between materials balances is the occurrence, with opposite signs, of each measured value of in-process inventory in two adjacent materials balances. As a result, only the first and last measurements of in-process inventory appear in the Cusum, and only the corresponding variances appear in the Cusum variance.

c. Uniform Diversion Test. The Kalman filter is applied widely to communications and control systems for signal processing in stochastic environments. It is a powerful tool for extracting weak signals embedded in noise. It has been applied recently to safeguards, $68-70,75-78$ because dynamic accountability systems rapidly generate 
large quantities of data that may contain weak signals caused by repeated, small diversions embedded in the noise produced by measurement errors. The Kalman filter is the basis of the UDT, the SVT, and the SMBT.

The UDT is designed to detect a small, constant diversion during each materials balance period. Minimum-variance, unbiased estimates of the diversion and the inventory at each time are given by the Kalman filter described in Ref. 68 , which also gives a method for correctly treating correlated measurement errors. Similar, but less general, formulations are reported in Refs. 75-78.

The Cusum and the UDT are complementary in several respects. The Cusum estimates the total amount of missing NM at the current time, and its standard deviation is taken at the 10 error in the estimate of the total. The UDT, on the other hand, estimates the average amount of NM missing from each materials balance, and its standard deviation estimate is taken as the 10 error in the estimate of the average. Thus, both the Cusum and the UDT search for a persistent, positive shift of the materials balance data--the Cusum by estimating the total, the UDT by estimating the average. Both Cusum and UDT tests are performed sequentially, which facilitates their implementation on a small computer.

d. Sequential Variance Test. One characteristic to be expected when diversion is present is a larger materials balance error variance than when there has been no diversion. The SVT uses two Kalman filters (each similar to that for the UDT) to calculate the materials balance error variances for the two cases (diversion and no diversion). The result is roughly equivalent to a sequential formulation of the well-known $F$ test for variances. The corresponding assumption in the diversion scenario is that the diversion during each materials balance period is a Gaussian random variable having constant mean and variance, which are a priori unknown. Maximum-likelihood estimates of the mean and variance are computed sequentially for the likelihood ratio as the data are received.

The diversion pattern assumed for the SVT is much less restrictive than that for the UDT hecause almost any set of diversions could have been drawn from a white, Gaussian, random process, even if the diversion were constant or intermittent. The only real restrictions are that the mean and variance be constant over the test interval. However, the test procedure covers all possible intervals, so that this assumption is less restrictive than it might seem. 
A similar estimation algorithm is described in Refs. $75-78$, but no procedures for obtairing the diversion mean and variance are given. In addition, it is not clear what decision test was to be used.

As with the UDT, the SVT provides estimates of both the missing material and the inventory at each time. However, the total amount of missing material over the test interval is also computed by subtracting the last inventory estimate from the first inventory measurement and adding the intervening net transfers. This estimate of the total diversion is more indicative of the materials accounting situation. Note that the alarm-sequence chart (see Sec. V.3.a) refers not to the missing-material estimates, but to a possible shift in materials balance error variance.

e. Smoothed Materials Balance Test. Stewart ${ }^{79}$ noted earlier that better (smaller.variance) materials balances could be drawn if past data were used to calculate the beginning inventory of the current materials balance. He proposed use of the equivalent of a Kalman filter, assuming no diversion before the current time. The technique can be extended if one is willing to consider deferred decisions. That is, if we have data from $\mathrm{N}$ materials balance periods and wish to compute the materials balance at time $k$, where $k$ lies between 1 and $N$, then we can (1) run a "forward" Kalman filter from time 1 to $k$ to estimate the kth beginning inventory, (2) run a "backward" Kalman filter from time $N$ to $k+1$ to estimate the $k$ th ending inventory, and (3) subtract the result of (2) from that of ( 1 ) and add the intervening transfer measurement to find the smoothed materials balance at time $k$ based on the number of intervening materials balance periods. The ter., nnique includes Stewart's method as a special case.

Significant improvements in single materials balance uncertainties can be obtained with the SMBT at the price of a delayed decision. Care must also be taken when applying the test to intervals in which several diversions may have occurred; that situation violates the assumption (no diversion) on which the filters are based and can cause incorrect materials balance estimates.

f. Wilcoxon Rank Sum Test. Application of the nonparametric Wilcoxon test and the associated rank-sum chart to safeguards data is described in Ref. 1. The test has been used in other fields to analyze data for which the underlying distribution of the measurement uncertainty is unknown. Like the Cusum, the Wilcoxon test is very easy to implement; it calculates a weighted sum of the number of positive values in sets of materials balance data. 
3. Data Analysis Graphic Aids

a. Alarm Charts. The decision tests must examine all possible sequences of the available materials balance data because, in practice, the time at which a sequence of diversions begins is never known beforehand. Furthermore, to ensure uniform application and interpretation, each test should be performed at several levels of significance. Thus, it is essential to have a graphic display that indicates those alarm-causing sequences, specifying each by its length, time of occurrence, and significance. One such tool is the alarm-sequence chart, ${ }^{3}$ which has proven useful in summarizing the results of the various tests and in identifying trends.

To generate the alarm-sequence chart, each sequence that causes an alarm is assigned a descriptor that classifies the alarm according to its significance (false-alarm probability or FAP), and a pair of integers $\left(r_{1}, r_{2}\right)$ that are, respectively, the indexes of the initial and final materials balances in the sequence. The alarm-sequence chart is a point plot of $r_{1}$ vs $r_{2}$ for each sequence that caused an alarm, with the significance range of each point indicated by the plotting symbol. The correspondence of plotting symbol to significance is given in Table $X X$. The symbol $T$ denotes sequences of such low significance that it would be fruitless to examine extensions of those sequences; the position of the symbol $T$ on the chart indicates the termination point.

TABLE XX

ALARM CLASSIFICATION FOR THE ALARM-SEQUENCE CHART

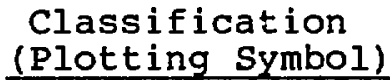

A

B

C

D

$\mathbf{E}$

$\mathbf{F}$

T
False-Alarm Probability

$$
\begin{aligned}
10^{-2} \text { to } 5 \times 10^{-3} \\
5 \times 10^{-3} \text { to } 10^{-3} \\
10^{-3} \text { to } 5 \times 10^{-4} \\
5 \times 10^{-4} \text { to } 10^{-4} \\
10^{-4} \text { to } 10^{-5} \\
<10^{-5} \\
\geq 0.5
\end{aligned}
$$


For example, consider a sequence of materials balance data beginning at balance number 12, and suppose that one of the tests gives an alarm with an FAP of $2 \times 10^{-4}$ at balance number 19. Then on the alarm-sequence chart for that test, the letter $D$ would appear at the point (19,12). This procedure continues for all possible sequences of the available materials balances. It is always true that $r_{1} \leq r_{2}$, so that all symbols lie to the right of the line $r_{1}=r_{2}$ through the origin. Persistent data trends (repeated diversions) cause long alarm sequences $\left(r_{1} \ll r_{2}\right)$, and the associated symbols on the alarm chart extend far to the right of the line $r_{1}=r_{2}$.

b. Examples. Sample diversion detection simulation results for a typical week of conversion process operation are given in Figs. 12-14. Each figure shows results obtained with one of the decision analysis tests described above. The three tests included in the example are the Shewhart chart, Cusum, and UDT. Each figure shows piots of the test statistic and the corresponding alarm chart for the case of no diversion (upper) and for the case of diversion (lower). In each case a uniform diversion of $53 \mathrm{~g}$ per balance is simulated in the 51-125 materials balances. The diversion ocrurs during the third, fourth, and fifth days of the week for a total diversion of $4 \mathrm{~kg}$. Note that significant alarms are given during the fourth day (the second day in the diversion scenario) and that the total diversion at that time is $\sim 2 \mathrm{~kg}$.

For each materials balance (Shewhart) chart, dynamic materials balances are plotted sequentially with $1 \sigma$ error bars. The associated alarm charts can indicate only single materials balance alarms. If the materials balance charts were not labeled, it would be impossible in most cases to know whether there had been diversion. Remember that the Safeguards Officer does not have the luxury of comparing charts with and without diversion for the same time period, and, of course, he would not know beforehand whether diversion had occurred. The materials balance charts have a limited capability to detect diversion except in case of a large abrupt diversion. That is the main reason why decision-analysis algorithms and alarm-sequence charts have been developed.

For each Cusum chart, cumulative summations of dynamic materials balances are plotted sequentially with lo error bars. Letter symbols on the associated alarm-sequence charts indicate the length and significance of sequences of dynamic materials balances that generate alarms (Table $X X$ ).

Kalman-filter estimates of the average amounts of missing material per balance period are plotted sequentially with $l \sigma$ error bars, along with their associated alarm charts. Note that the UDT is more sensitive generally than the Cusum test, that is, the UDT gives more alarms having higher significance in the diversion cases. 


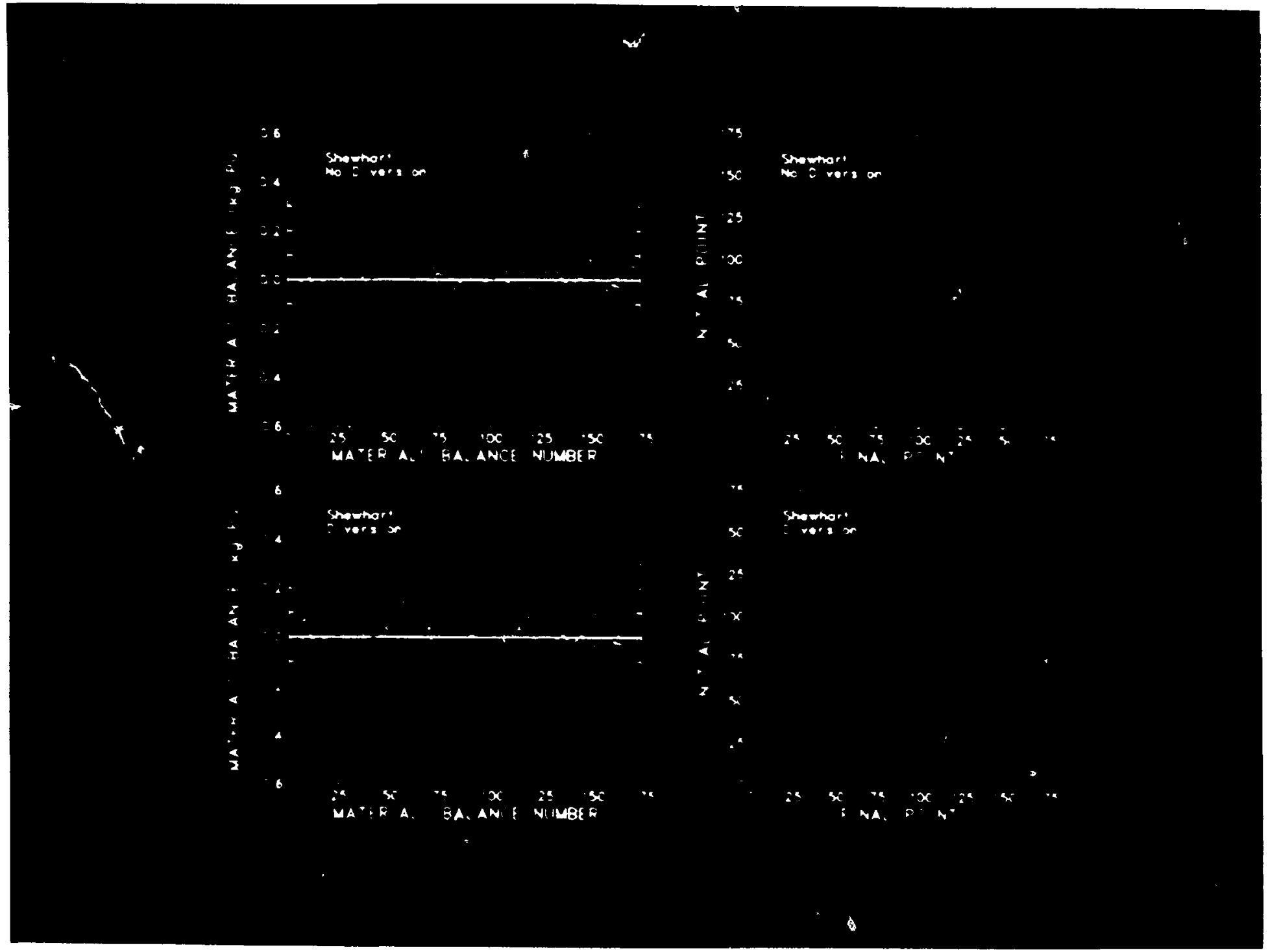

Fig. 12. Shewhart and alarm charts. 


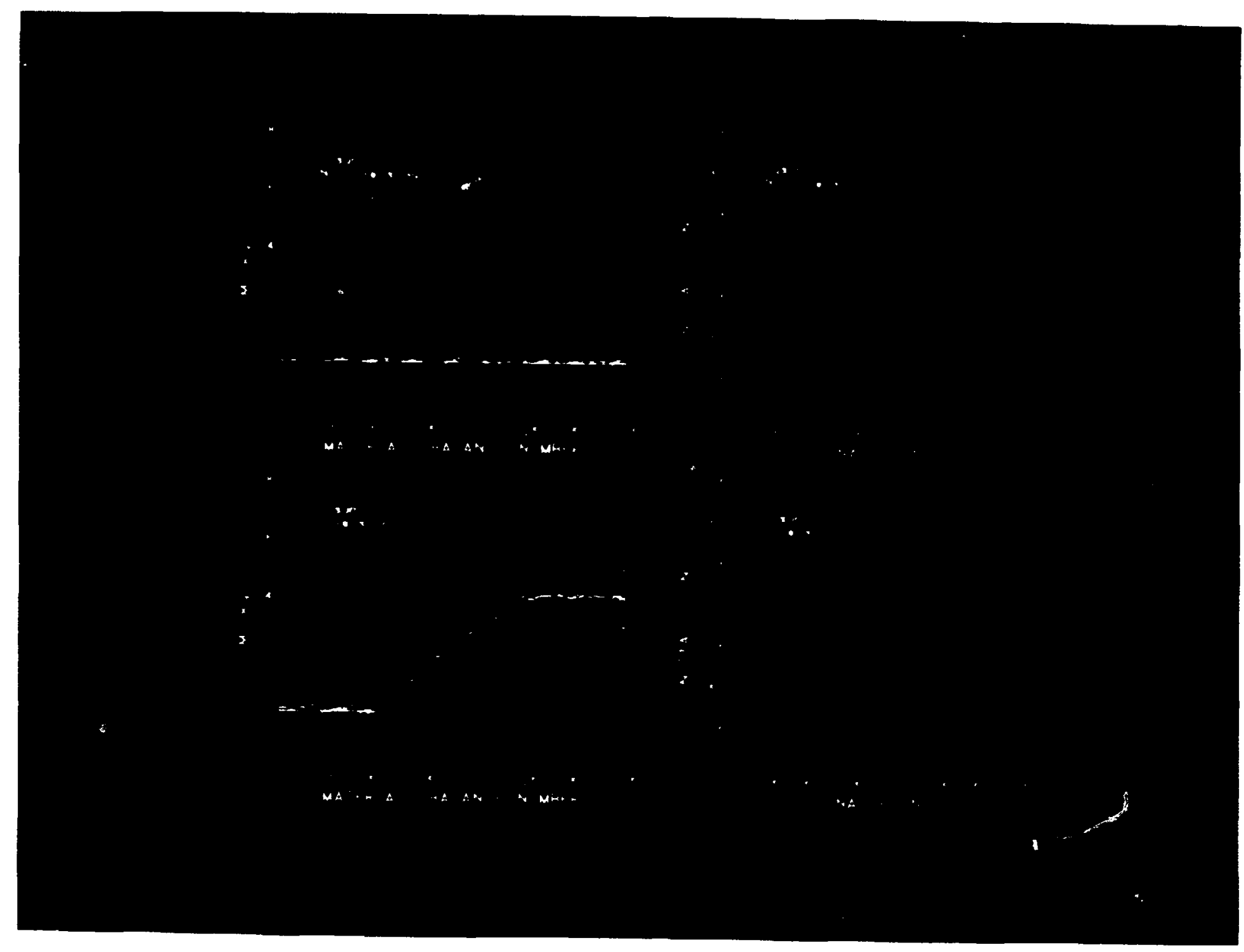




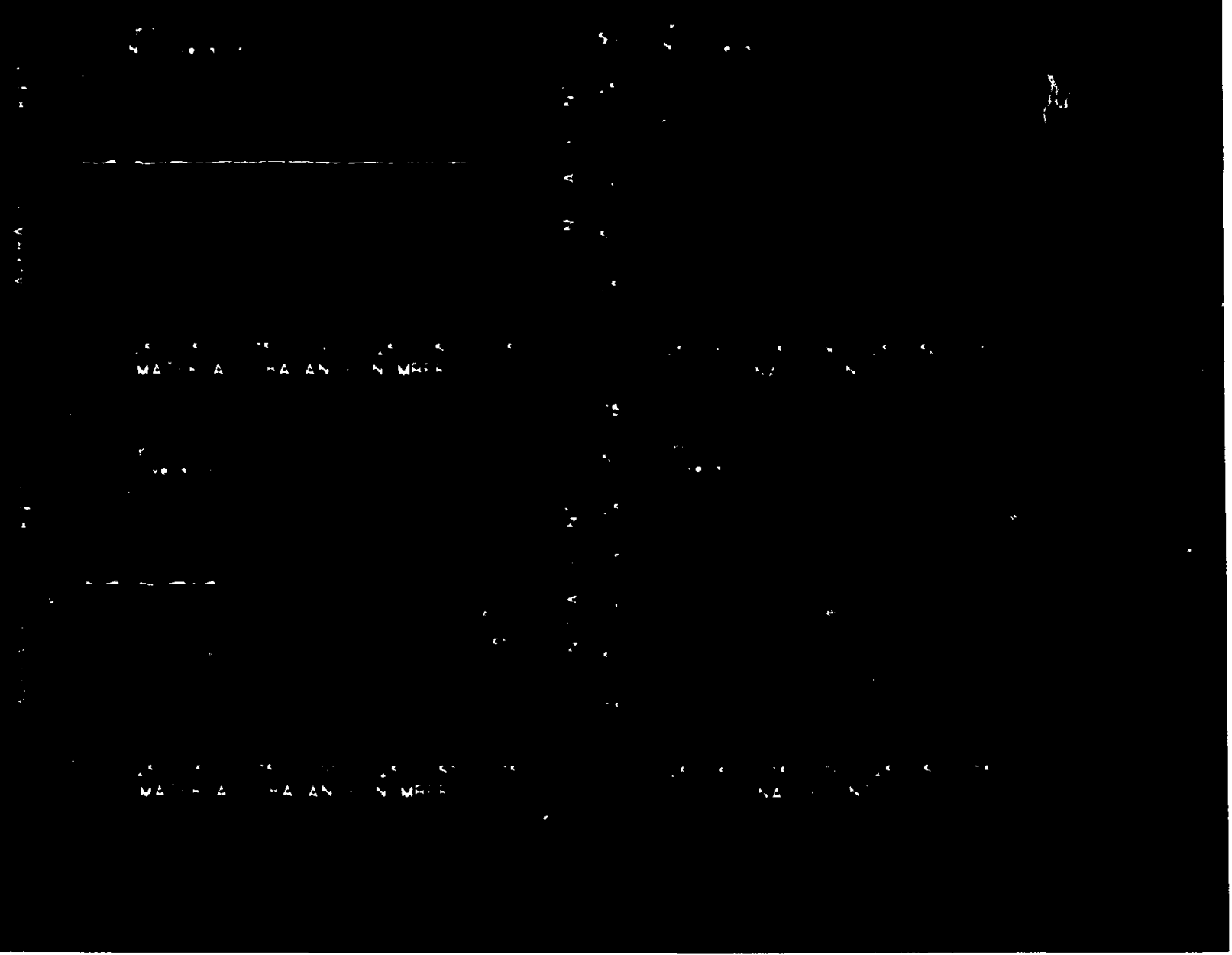

Fig. 14. UDT and alarm charts. 
4. Systems Performance Analysis. Essential to the design of NM accounting systems is an analysis of their expected performance in detecting losses of $N M^{80}$ Systems performance analysis, in turn, implies the definition of suitable performance measures that can be easily related to externally established criteria. Thus, there are two aspects of the analysis problem: first, defining performance measures, and second, relating those measures to established, quantitative performance criteria.

Performance measures for any NM accounting system embody the concepts of loss-detection sensitivity and loss-detection time. Because of the statistical nature of materials accounting, loss-detection sensitivity can be described in terms of the probability of detecting some amount of loss while accepting some probability of a false alarm. Loss-detection time is the time required by the accounting system to reach some specified level of loss-detection sensitivity. Note that the loss scenario is not specified; that is, whether the loss is abrupt or protracted, the total loss is the measure of performance. Note also that loss-detection time refers only to the internal response time of the accounting system.

a. Performance Surfaces. Intuitively, the performance of any accounting system is describable by some function

$$
P[L, N, \alpha]
$$

where $P$ is the accounting system's probability of loss detection, $L$ is the total loss over a period of $\mathrm{N}$ balances, and $\alpha$ is the FAP. Thus, a convenient way of displaying system performance would be a three-dimensional graph of the surface $P$ vs $L$ and $N$ for some specified value of $\alpha$. We call such graphic displays performance surfaces. They are plotted in the three-dimensional space (N, L, P) illustrated in Fig. 15. They portray (correctly) the expected performance of an accounting system as a function of the three performance measures, loss, time, and detection probability, rather than as a single point.

b. Cusum Performance Surfaces. Because systems performance may depend on the details of a particular diversion strategy as we!l as on details of the accounting system, the overall performance is difficult to quantify. Fortunately, however, the Cusum test does not depend on how the material was lost, but responds only to the total loss $L$ during any time interval $N$. Moreover, the Cusum test detects any loss relatively well, even though it is seldom the best test for any particular scenario. $68,70,81$ 


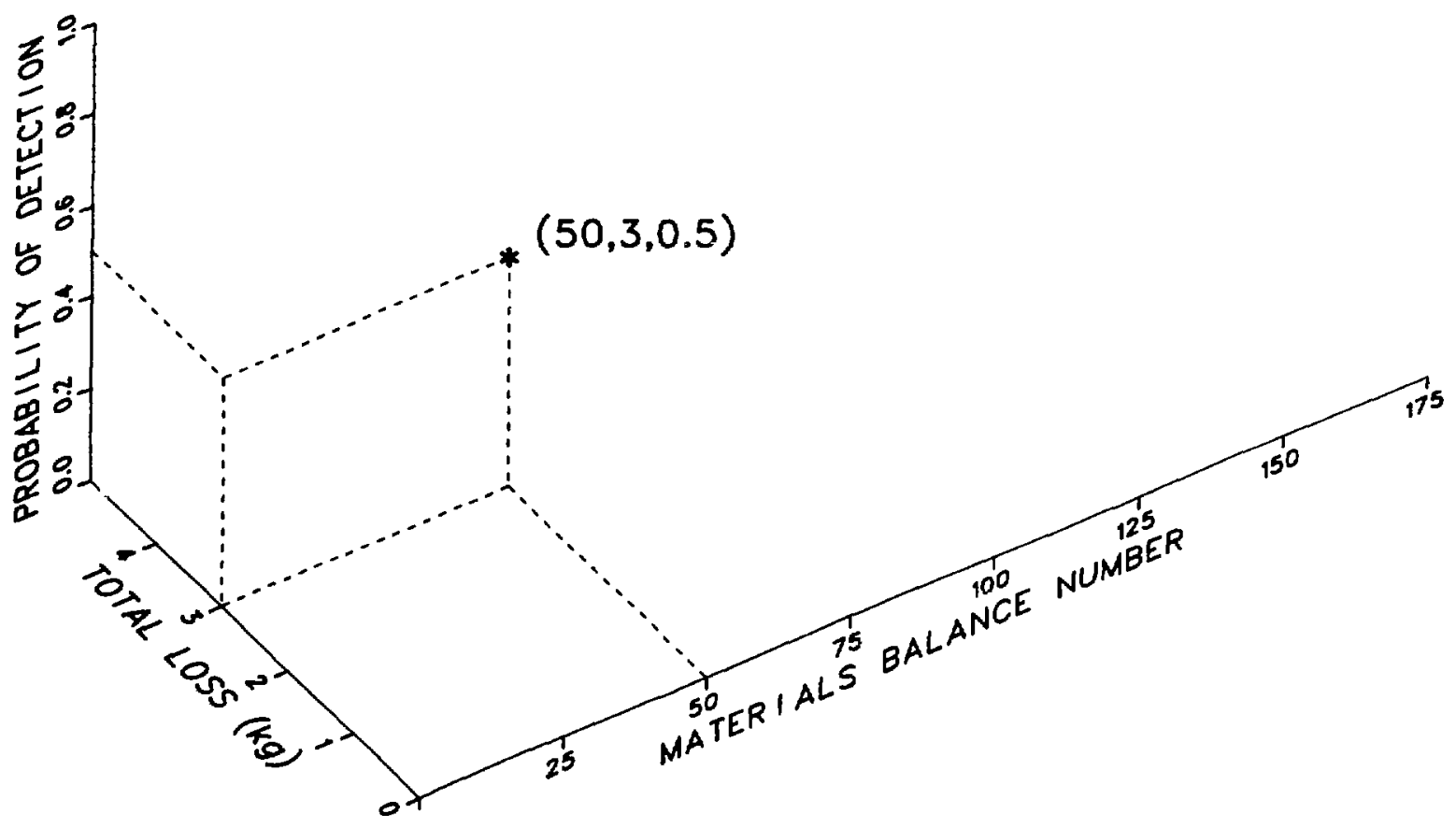

Fig. 15. Three-dimensional space of performance surfaces.

If the Cusum test is always among the tests applied to the accourting data, the performance of the accounting system will always be at least as good as the loss-detection power of the Cusum test. Thus, the Cusum test provides a conservative, scenario-independent measure of systems performance.

Performance surfaces generated using the Cusum test (only) are referred to as Cusum performance surfaces because they are approximations to the expected performance of the system. The performance of more powerful tests for specific loss scenarios should always be compared with the Cusum test performance to ensure that the Cusum approximation is not unduly pessimistic.

c. Examples. Figure 16 shows two examples of Cusum performance surfaces produced using a commercially available computer graphics program (DISSPLA) that plots isometric contours of total loss $L$ and materials balance number $N$. Note that contours of fixed loss-detection probability are also plotted on the Cusum performance surfaces in probability increments of 0.1 . 


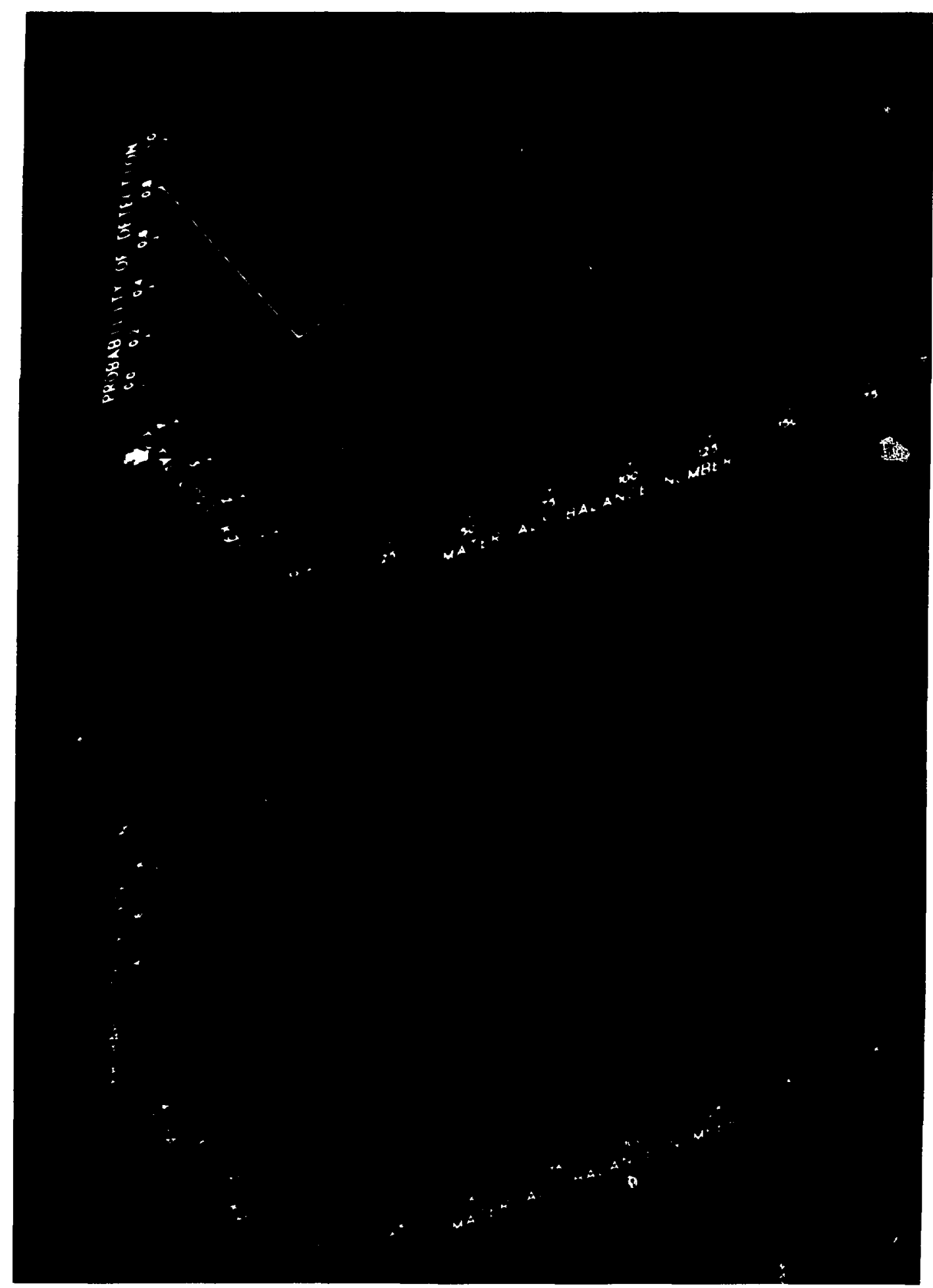

Fig. 16. Cusum performance surfaces for two accounting cases; worst (upper), best (lower). 
Figure 16 illustrates the use of Cusum performance surfaces in accounting systems design and analysis. The expected performance of worst-case and the best-case systems are shown. The improvement in sensitivity obtained by periodically recalibrating feed and product measuring devices is obvious by comparing the figures (see Sec. V.C for further examples).

Cusum performance surfaces are used in Sec. V.C to illustrate the expected performance of the advanced accounting systems.

C. Large Reference Facility

1. Conventional Materials Accounting. The sensitivity of conventional materials accounting for the large reference facility is discussed below. Materials balance standard deviations are given for periodic shutdown and cleanout physical inventories in the chemical separations MBA (MBA 2) and in the conversion process MBA (MBA 5). Two cases were considered. In the first case, the feed and product concentration measuring instruments were calibrated once every 2 days. In the second case, instruments were not recalibrated during the accounting period.

a. MBA 2--Chemical Separations Process. Materials balance standard deviations in MBA 2 for accounting periods of 3,6 , and 12 months for both ${ }^{235} U$ and plutonium are given in Table $\times X 1$. The materials balance errors are throughput-dominated; i.e., the feed and product batch measurements dominate the materials balance standard deviations. Errors in measuring waste batches and in measuring the residual holdup after process cleanup make a small contribution to the overall materials balance standard deviations.

TABLE XXI

MBA 2--CHEMICAL SEPARATIONS

CONVENTIONAL MATERIALS ACCOUNTING

Accounting Period (months)

3

6

12
Materials Balance Standard Deviations ( kg)

$\mathrm{U}-235$
$6.3-10.4$
$6.5-13.4$
$11.6-20.3$
$11.9-26.2$
$22 \cdot 3-40.1$
$27.5-52.1$ 
The materials balance standard deviation for ${ }^{235} U$ in a $1-y r$ accounting period without recalibration is $40.1 \mathrm{~kg}$. Ideally, the materials accounting sensitivity could be improved perhaps by as much as a factor of 2 if small relative errors were controlled. On the other hand, materials accounting sensitivity would be degraded if the measurement quality (Table VI) were not achieved. Our analysis indicates that the proposed IAEA criteria for ${ }^{235} \mathrm{U}$ (discussed in Sec. III) can be approached by conventional materials accounting.

Proposed IAEA detection sensitivity lir its for plutonium cannot be met in the large chemical separations MBA by conventional materials accounting. The materials balance standard deviation for plutonium for a 3-month accounting period is $6.5-13.4 \mathrm{~kg}$. It is unreasonable to assume a flushout/cleanout physical inventory more often than every 3 months; therefore, the conventional accounting system must be augmented by a dynamic materials accounting system.

b. MBA 5--Conversion Process. Materials balance standard deviations for the conversion process, for accounting periods of 1,2 , and 3 months, are given in Table $\times \times 1$. The materials balance uncertainties are dominated almost totally by the throughput because so little waste is generated in the conversion process, and after the process is flushed out, little residual holdup is left. Examination of the materials balance standard deviations shows that the proposed IAEA criteria cannot be met by conventional materials accounting; therefore, the conventional accounting system for the conversion process must be augmented by a dynamic materials accounting overlay.

2. Dynamic Materials Accounting. Here the performance of several dynamic materials accounting strategies (Sec. IV) are evaluated for the large reference facility.

\section{TABLE XXII}

MBA 5--CONVERSION PROCESS

CONVENTIONAL MATERIALS ACCOUNTING

Accounting Period (months)

1

2
Materials Balance Standard Deviations (kg Pu)

$$
\begin{aligned}
& 2.0-2.4 \\
& 4.0-4.9 \\
& 5.9-7.2
\end{aligned}
$$


a. Chemical Separations Area. The chemical separations area can be treated as a single UPAA, called UPAA 1 2, or as two UPAAs: the codecontamination-partitioning UPAA, called UPAA 1 , and the plutonium purification UPAA, called UPAA 2.

(1) UPAA 1 2--Chemical Separations. In this accounting strategy the entire chemical separations area, from the input accountability tank to the concentrated plutonium product, is treated as a single unit process accounting area. Materials balances are taken every 2 days by combining input accountability ( 5 batches) and product accountability (2 batches) measurements and with measurements of the in-process inventories of the various vessels and columns of the chemical separations area. Materials balance can also be taken every $9.6 \mathrm{~h}$ (for every input accountability batch) by adding flow and concentration measurements of the concentrator product stream and the 3PCP stream.

Dynamic materials accounting detection sensitivities using 9.6-h materials balances for periods from $9.6 \mathrm{~h}$ ( 1 balance) to 1 month (70 balances) are given in Table XXIII. Two

TABLE XXIII

UPAA 1 2--CHEMICAL SEPARATIONS

DYNAMIC MATERIALS ACCOUNTING ${ }^{a}$

\begin{tabular}{|c|c|c|c|}
\hline \multirow{2}{*}{$\begin{array}{l}\text { Accounting } \\
\text { Period } \\
\end{array}$} & \multirow{2}{*}{$\begin{array}{l}\text { Number of } \\
\text { Materials } \\
\text { Balances }\end{array}$} & \multicolumn{2}{|c|}{ Total at Detection $(\mathrm{kg} \mathrm{Pu})$} \\
\hline & & Case $1^{b}$ & Case ${ }^{\mathrm{C}}$ \\
\hline $9.6 \mathrm{~h}$ & 1 & 6.8 & 5.9 \\
\hline 2 days & 5 & 7.1 & 6.3 \\
\hline $1 \mathrm{wk}$ & 18 & 10.1 & 7.4 \\
\hline 2 wk & 35 & 15.8 & 8.9 \\
\hline 1 month & 70 & 28.5 & 11.6 \\
\hline
\end{tabular}

a Detection sensitivity at the 3- $\sigma$ limit.

$b_{\text {No }}$ recalibration within the accounting period, 20\% estimates of CPP column inventories, and $10 \%$ estimates Of PPP column inventories.

CTwo-day recalibrations of input/output concentration and flow measuring instruments, 208 estimates of CPP column inventories, and 58 estimates of PPP column inventories. 
cases are considered. In Case 1 , no instruments are recalibrated within the accounting period, and $10 \%$ estimates are made of the PPP column inventories. In Case 2, input/output concentration and flow-measuring instruments are recalibrated every 2 days, and 5\% estimates are made of the PPP column inventories. These accounting sensitivities can be improved by taking 2-day materials balances at the cost of timeliness (see Table XXXII, Sec. VIII).

The detection sensitivities in Table XXIII, and all other tables for the dynamic accounting system, are given at the 3- $\sigma$ limit. In most cases the sensitivities are based on the Cusum test because it gives a conservative estimate that is independent of diversion scenario (see Sec.-V.B.2).

Cusum performance surfaces (see Sec. V.B.4) for the two cases of UPAA 12 are shown in Fig. 17. The Cusum test threshold for this, and all other performance surfaces, is set at the 3- $\sigma$ limit, corresponding to a FAP of 0.001. In Case 2, the scalloping effect along the constani loss contours results from recalibration. It is obvious that recalibration of input and output measurements can improve materials accounting sensitivity. As a matter of fast, IAEA criteria for sensitivity may not be met unless these recalibrations are undertaken. Note that in Table XXIII, for an accounting period of 1 wk, the detection sensitivity for Case 2 is $7.4 \mathrm{~kg}$ vs 10.1 for Case l. The advantage shown for Case 2 is attainable if the dominating sources of error can be identified and if measurement control procedures can be established that are sensitive to, and can control, those errors. Therefore, the results given here should be regarded as illustrative of the improvements that can be achieved.

(2) UPAA 1--Codecontamination-Partitioning. The chemical separations UPAA, UPAA 1 2, can be divided into two UPAAs by adding a flow and concentration measurement on the IBP stream (see jec. IV.B.2.). In UPAA 1, a materials balance can be taken every $9.6 \mathrm{~h}$ by combining input accountability measurements with flow and concentration measurements of the IBP stream and with measurements of the in-process inventories of the vessels and columns of the codecontamination-partitioning process. Dynamic materials accounting detection sensitivities for UPAA 1 are given in Table XXIV, again, for two cases. In Case 1 , no instrument calibrations are performed during the accounting periods. In Case 2, the input concentration measuring instruments and the output flow and concentration measuring instruments on the IBP stream are recalibrated every 2 days. Materials balance sensitivities for periods of $\sim 1$ wk and less are dominated by the uncertainty in the in-process inventory. 


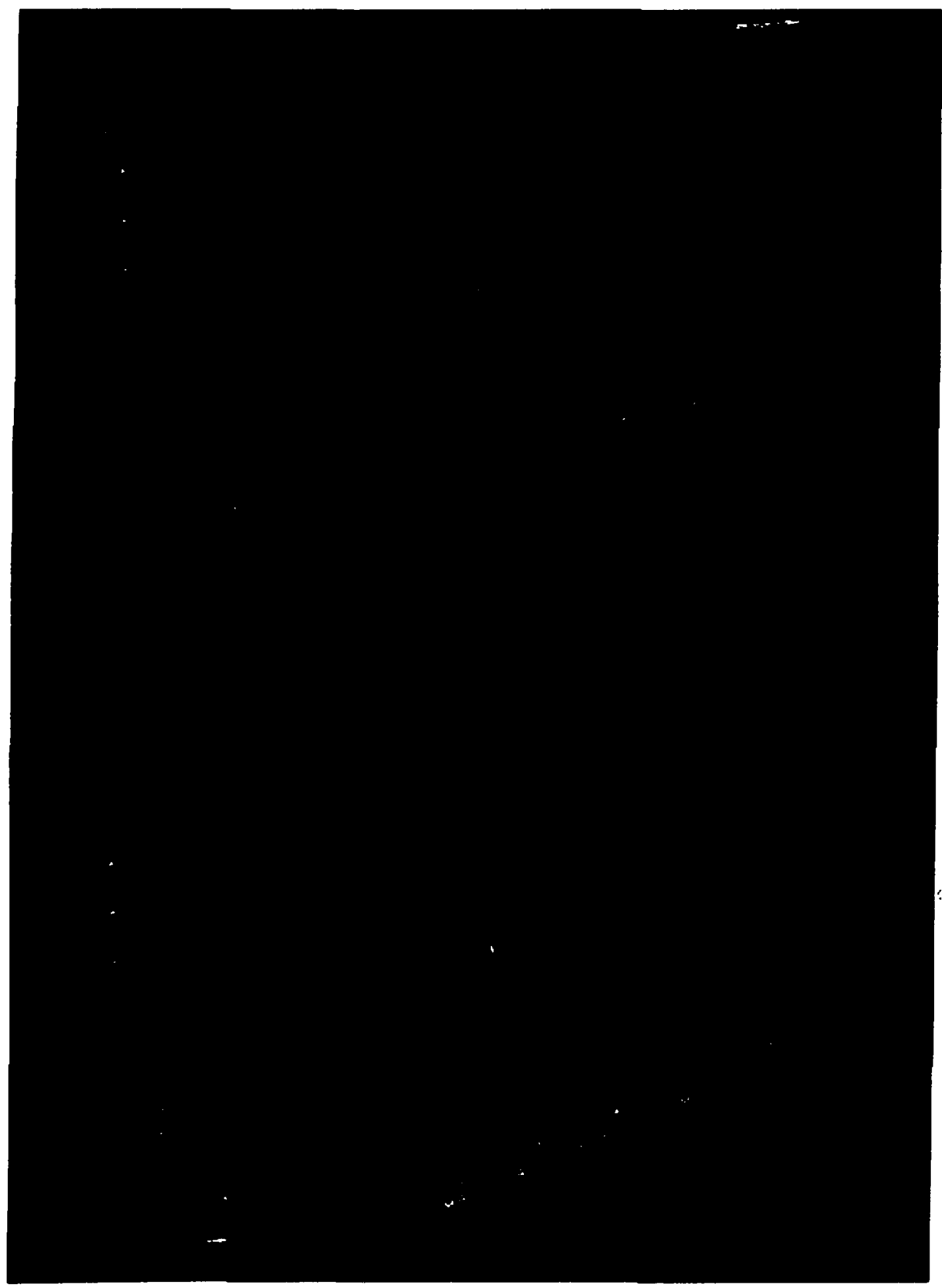

Fig. 17. UPAA 1 2--Cusum performance surfaces; Case 1 (upper), Case 2 (lower). 


\section{UPAA 1--CODECONTAMINATION-PARTITIONING} DYNAMIC MATERIALS ACCOUNTING

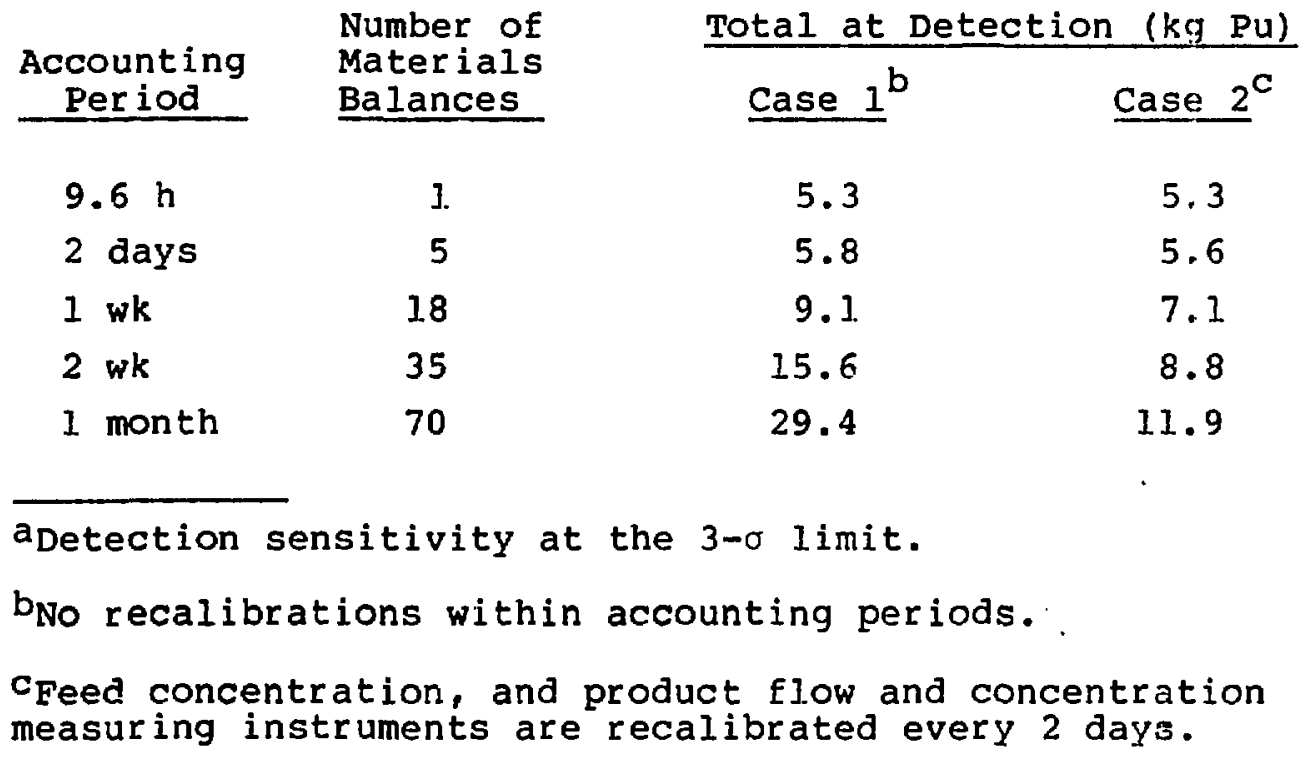

(3) UPAA 2--Plutonium Purification. Materials balances can be taken for UPAA 2 as often as every hour, because the input and output measurements are based on in-line flow and at-line concentration measurements. Detection sensitivities for 8 -h material balances for accounting periods irom $8 \mathrm{~h}$ ( 1 balance) to 1 month ( 84 balances) are given in Table XXV for two cases. Results obtained using the UDT are also given for comparison with the Cusum results. The UDT uses the Kalman filter to form estimates of the diversion and the inventory (Sec. V.B.2.c).

The materials balance uncertainties for periods of 1 wk and less are dominated by uncertainties in the in-process inventory because the in-process inventory in UPAA 2 is large $(\sim 40 \mathrm{~kg} \mathrm{Pu})$. Note that in this case of 8 -h material balances the UDT gives only a small improvement over the Cusum.

Detection sensitivities for 1 -h materials balances for UPAA 2 using the UDT are given in Table XXVI. A comparison of the $8-h$ balance and $1-h$ balance UDT detection sensitivities is instructive. An improvement of $260 \%$ in the 1-day UDT detection sensitivity is obtained by using $1-h$ instead of $8-h$ balances. That is because the Kalman filter technique, which is the basis of the UDT, makes steadily improving estimates of the 


\section{TABLE XXV}

UPAA 2--PLUTONIUM PURIFICATION

DYNAMIC MATERIALS ACCOUNTING, 8-h BALANCES ${ }^{a}$

\begin{tabular}{lc}
$\begin{array}{c}\text { Accounting } \\
\text { Period }\end{array}$ & $\begin{array}{c}\text { Number of } \\
\text { Materials } \\
\text { Balances }\end{array}$ \\
\cline { 1 - 2 } 8 h & 1 \\
1 day & 3 \\
1 wk & 21 \\
2 wk & 42 \\
1 month & 84
\end{tabular}

Total at Detection ( $\mathrm{kg} \mathrm{Pu})$

\footnotetext{
apetection sensitivity at the $3-\sigma$ limit.

$b_{N O}$ recalibrations within the accounting period and $10 \%$ estimates of column inventories.

CTwo-day recalibrition of input/output concentration and flow measuring instruments, and $5 \%$ estimates of column inventories.
}

in-process inventory, thus reducing the in-process inventory variance. The more materials balance data supplied to the Kalman filter, the better the in-process inventory estimate. Therefore, for 1-h balances, the UDT significantly improves detection sensitivities for accounting periods in which the in-process inventory error is dominant relative to the throughput error.

Cusum and UDT performance surfaces, for $1 \mathrm{wk}$ of $1 \mathrm{~h}$ balances for UPAA 2 are given in Fig. 18. Note that the UDT detection sensitivity is better than the Cusum sensitivity. To make this improvement more obvious, three-dimensional surfaces of the difference in performance between the Cusum and UDT are given in Fig. 19. The UDT shows a significant improvement in detection sensitivities, especially over short time periods and for small total losses. For larger total losses, the two perform equally well because the detection probability is near one. The detection sensitivities obtained by the UDT and the Cusum at the 3- $\sigma$ limit are compared in Fig. 20.

The sensitivity obtained using the Cusum test over a fixed time interval will not change if the frequency of materials balance taking is changed. That fact can be verified 


\title{
TABLE XXVI
}

\section{UPAA 2--PLUTONIUM PURIFICATION DYNAMIC MATERIALS ACCOUNTING, l-h BALANCES ${ }^{a}$}

\begin{tabular}{|c|c|c|c|}
\hline \multirow[b]{2}{*}{$\begin{array}{c}\text { Accounting } \\
\text { Period } \\
\end{array}$} & \multirow{2}{*}{$\begin{array}{l}\text { Number of } \\
\text { Mater ials } \\
\text { Balances }\end{array}$} & \multicolumn{2}{|c|}{ Total at Detection (kg Pu) } \\
\hline & & $\frac{\text { Case } 1^{b}}{\text { UDT }}$ & $\frac{\text { Case } 2^{\mathrm{C}}}{\text { UDT }}$ \\
\hline $1 \mathrm{~h}$ & 1 & 4.2 & 2.6 \\
\hline $8 \mathrm{~h}$ & 8 & 3.1 & 1.9 \\
\hline I day & 24 & 2.4 & 1.8 \\
\hline l wk & 168 & 8.7 & 4.5 \\
\hline
\end{tabular}

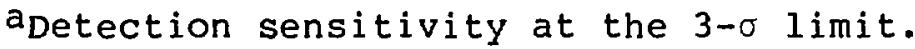

$b_{\text {No }}$ recalibrations within the accounting period and 108 estimates of column inventories.

CTwo-day recalibration of input/output concentration and flow-measuring instruments and 58 estimates of column inventories.
\end{abstract}

by comparing the Cusum performance surface for l-h balances in Fig. 18 (upper) with the detection sensitivities given in Table $X X V$. One might expect an improvement in the single-balance detection sensitivity for $1-h$ over 8 -h balances. An improvement does exist, but it is difficult to see because the uncertainty in the in-process inventory is the same in both cases and is the dominant contribution to the materials balance error.

b. Conversion Process Area. The performance of two accounting strategies in the conversion process area is evaluated below. In the first accounting strategy, the entire conversion process is treated as a single UPAA. In the second strategy, each process line within the conversion process area is treated as a separate UPAA; there are three parallel UPAAs. Strategies in which each process line is further subdivided into UPAAs are discussed in Ref. 2.

(1) UPAA 344 5--Conversinn Process Area. UPAA 3445 includes the entire conversion process from the receipt tanks to the product loadout area. Dynamic materials accouriting detection sensitivities for accounting periods from $0.96 \mathrm{~h}$ ( 1 balance) 


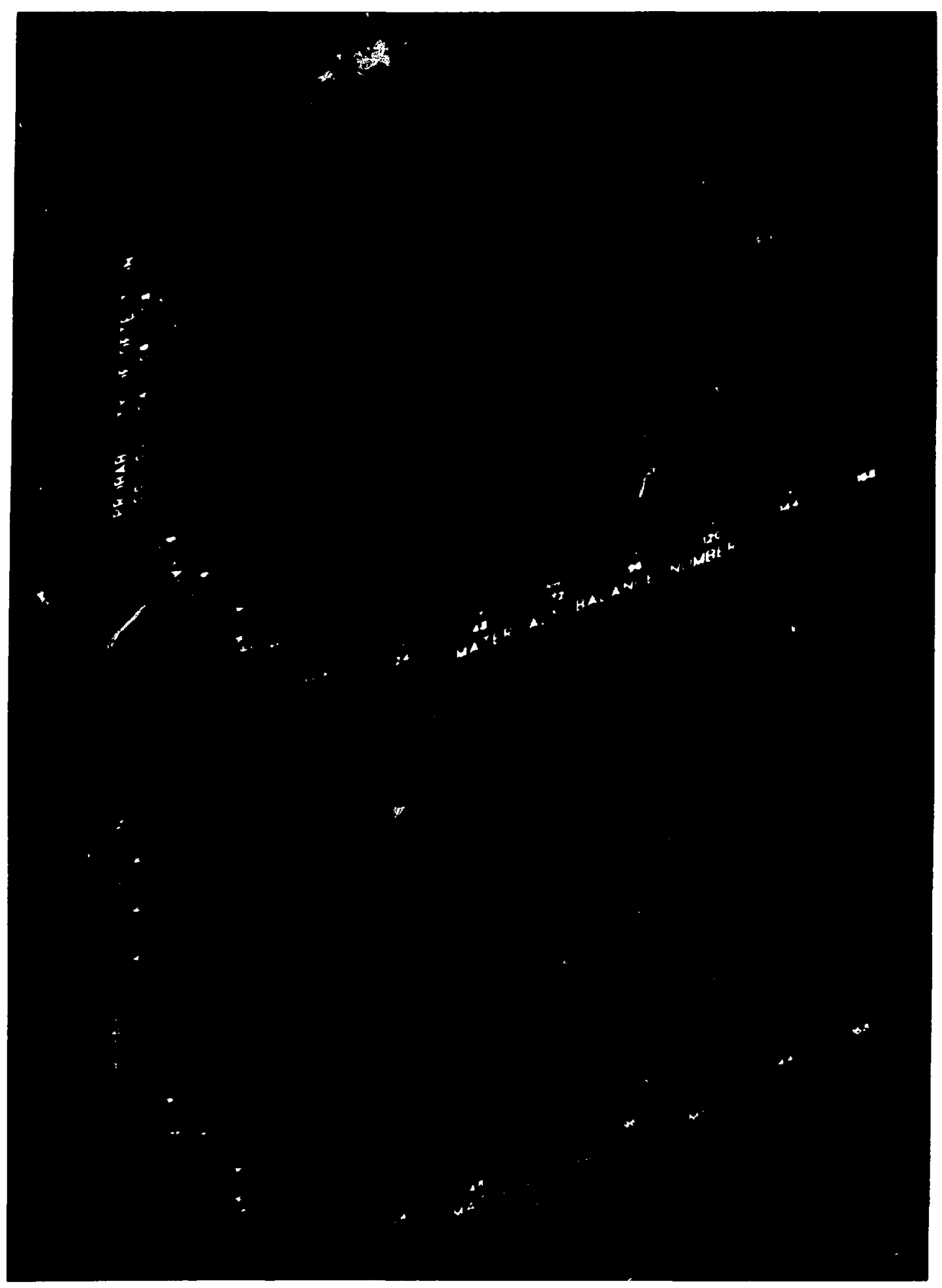

Fig. 18. UPAA 2--Performance surfaces; Cusum (upper), UDT (lower). 


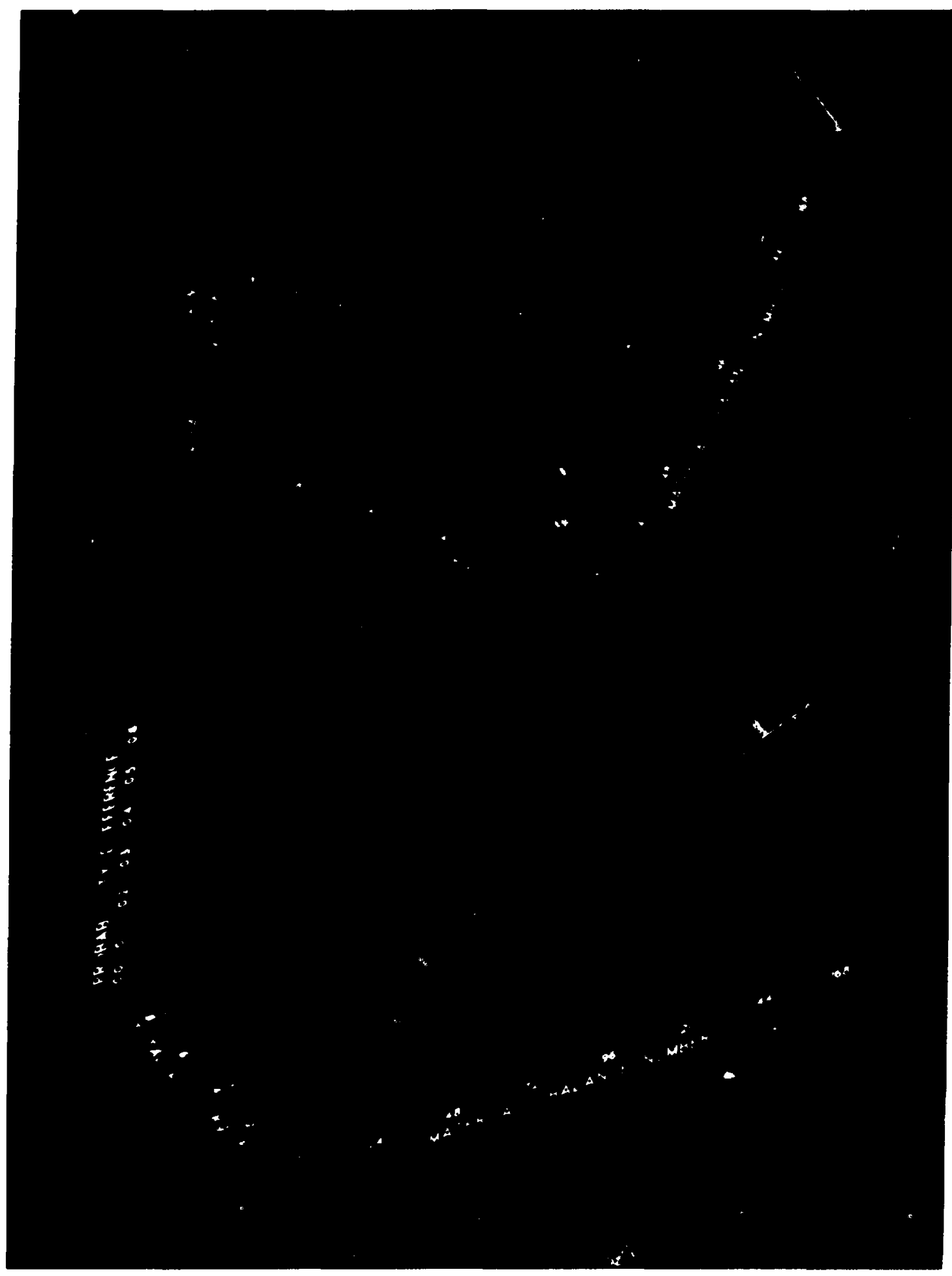

Fig. 19. UPAA 2--Performance surfaces detection probability difference. 


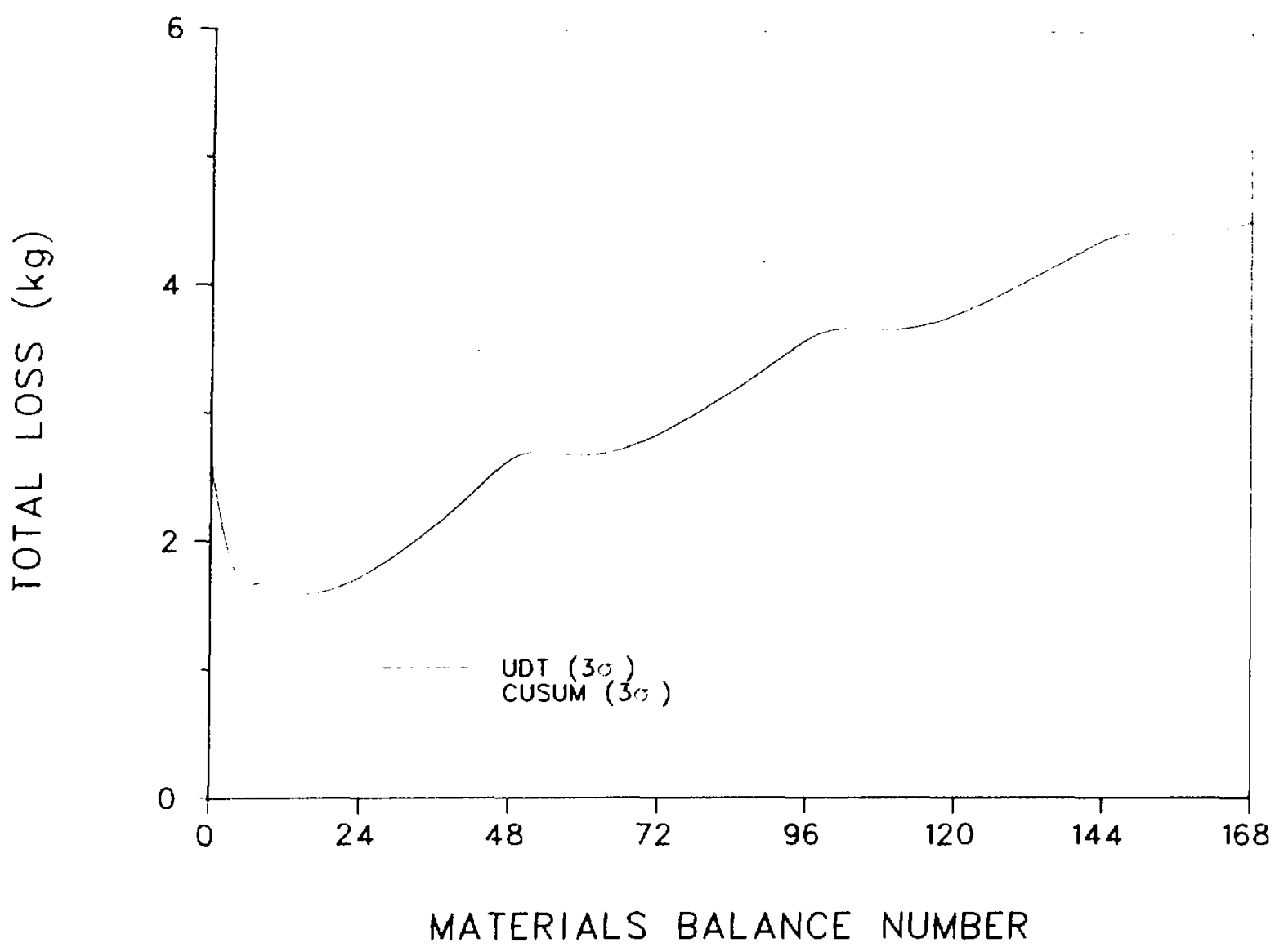

Fig. 20. UDT-Cusum detection sensitivities.

to 1 month (700 balances) are given in Table XXVII. In Case 1 , no instrument recaliorations are performed within the accounting period. In Case 2, the concentration measuring instruments at the receipt tanks and the product measuring instrument at the product loadout area are recalibrated every 2 days. When comparing these sensitivities to the conventional materials accounting sensitivities (Table XXI) remember that data from the on-line measuring instruments are not of the same quality as those from the chemical analyses used in conventional materials accounting. Normally, one would expect to update the on-line measurement data with the better quality chernical data when they become available. (The results of that accounting strategy are given in Table XXXII, Sec. VIII.) Also, note that the values in Table XXII are single materials balance standard deviations, whereas the values in Table XXVII are detection sensitivities given at the 3- $\sigma$ limit. 
TABLE XXVII

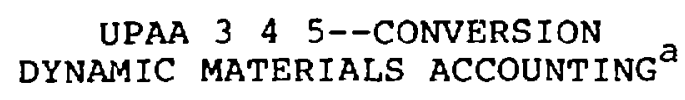

\begin{tabular}{|c|c|c|c|}
\hline \multirow[b]{2}{*}{$\begin{array}{l}\text { Acccunting } \\
\text { Period } \\
\end{array}$} & \multirow{2}{*}{$\begin{array}{l}\text { Number of } \\
\text { Materials } \\
\text { Balances }\end{array}$} & \multicolumn{2}{|c|}{ Total at Detection (kg Pu) } \\
\hline & & Case $1^{b}$ & Case $2^{c}$ \\
\hline $0.96 \mathrm{~h}$ & 1 & 1.2 & 1.2 \\
\hline 1 day & 25 & 1.5 & 1.5 \\
\hline 1 wk & 175 & 5.8 & 2.6 \\
\hline 2 wk & 350 & 11.4 & 3.5 \\
\hline 1 month & 700 & 22.6 & 5.4 \\
\hline
\end{tabular}

\footnotetext{
a Decection sensitivity at the $3-\sigma$ limit.

$b_{\text {NO }}$ recalibration within the accounting period.

CTwo-day recalibrations of input concentration and product measurements.
}

Cusum performance surfaces for the conversion process UPAA for the two cases are given in Fig. 21. The gain in detection sensitivity after recalibrations are performed is again obvious. For example, for a total loss of $10 \mathrm{~kg}$ in a 600-balance accounting period, the detection probability with no recalibration is $\sim 0.1$, whereas the detection probability with recalibration approaches 1 . This example illustrates the improvements that can be achieved if the dominating sources of error can be identified and controlled.

(2) UPAA 3, 4, and 5--Conversion Process Lines. In the second accounting strategy, each conversion process line is treated as a separate UPAA. The conversion process area therefore consists of three parallel UPAAs; UPAA 3, UPAA 4, and UPAA 5. A materials balance is drawn about each process line for each batch produced from that line--approximately every $2.9 \mathrm{~h}$. Detection sensitivities for a single process line UPAA for accounting periods from $2.9 \mathrm{~h}$ (1 balance) to 1 month ( 233 balances) are given in Table $X X V I I I$. The single materials balance detection sensitivity for a single process line is smaller than that of UPAA 345 because the in-process inventory is smaller. For a given time interval, the detection sensitivity for the single process line UPAA is also improved because the throughput is reduced. 


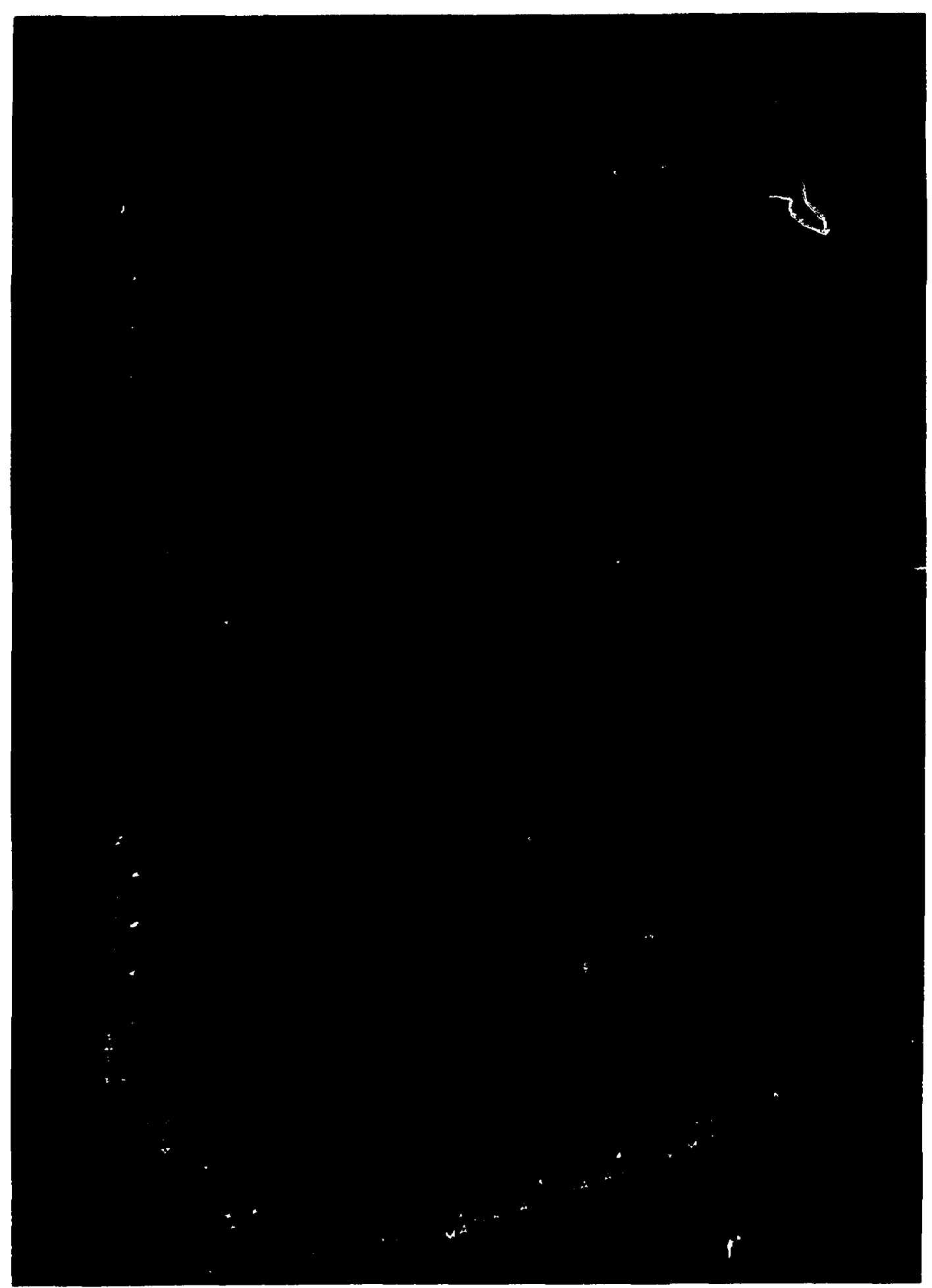

Fig. 21. Conversion process area Cusum performance surfaces; Case 1 (upper), Case 2 (lower). 
TABLE XXVIII

UPAA 3, UPAA 4, UPAA 5--CONVERSION PROCFSS LINES DYNAMIC MATERIALS ACCOUNTING ${ }^{\mathrm{a}}$

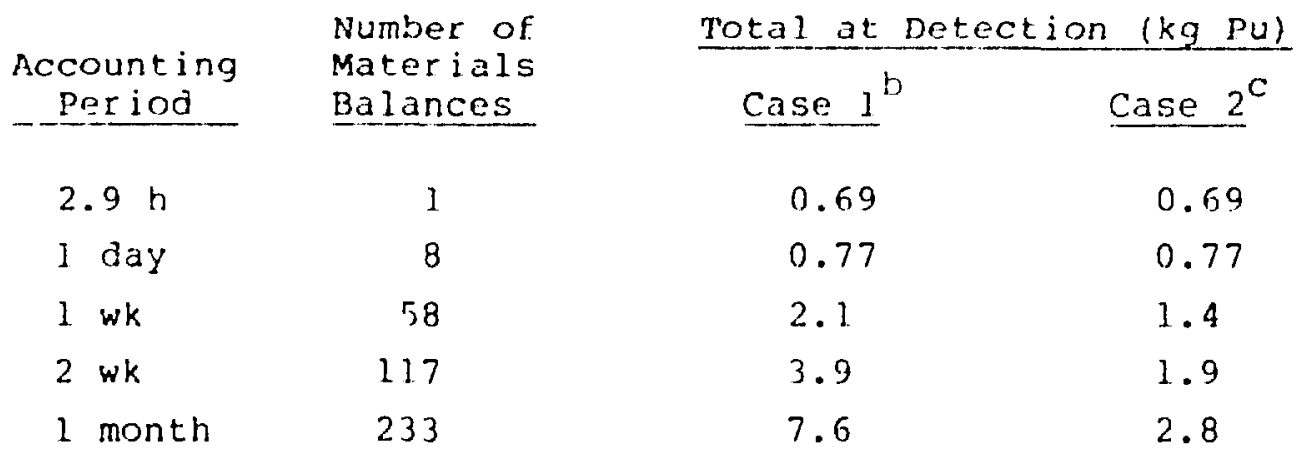

adetection sensitivity at the 3-1 limit.

bo recalibration within the accounting period.

CTwo-day recalibrations of input concentration and product measurements.

D. Materials Accounting in a Small Plant

1. Conventional Materials Accounting. Conventional materials accounting sensitivities for the model small separations process (MPA 2) are given in Table $X X I X$. Uranium-235 and plutonium materials balance standard deviations based on shutdown and cleanout physical inventories are given for several accounting periods. Two cases are considered. In Case 1, the feed and product concentration measuring instruments are calibrated once every 2 days. In Case 2, instruments are not recalibrated during the accounting period. When comparing these sensitivities to those of the JAERI study 37,82 (see Sec. IV.C.I), remember that the measurement errors invoked here are better than those in Ref. 37 (compare Tables $X V I I$ and $X V I I I$ ), and that the 6-month throughput is $1050 \mathrm{~kg} \mathrm{Pu}$ vs $760 \mathrm{~kg} \mathrm{Pu}$ in the JAERI analysis. When comparing the model small plant materials balance standard deviations (Table $X X I X$ ) with those of the large plant (Table $X X I)$, note that they differ by the throughput ratio, approximately a factor of 7 .

Conventional materials accounting should satisfy the proposed IAEA safeguardseffectiveness criteria for uranium (Table IV). However, it will not satisfy the criteria for 
TABLE XXIX.

SMAII. CHEMICAL SEPLRATIONS PLANT

CONVENTIOIAT, MATERTAJS ACCOUNTING

Mccounting prisior

(montho)

3

6

12
Materials Balance Standare Deviations

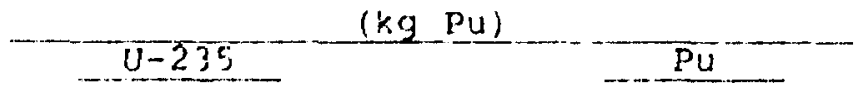
$0.8-1.3$
$0.94-1.9$
]. $5-2.6$
$1.7-3.7$
$2.8-5.1$
$3.2-7.3$

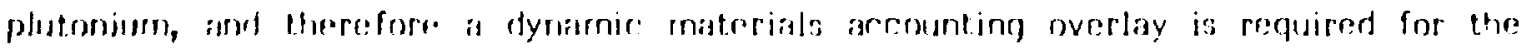
plutonium proressing portions of the sanall chernical separations plant.

2. Dyramic Malerials Accounting. The basic dynarnic materials accounting strategy for the reference small chemical separations process treats the CPP and the PPP as is single (JPAA. A maferials balance is taken nnce a day by combining measurement: of the contents of two feed batches and one product batch husing ronventional measurement inethods) with measurements of the in-process inventories in buffer tanks (using at-line NDA measurements) and with estimates of the in-process inventories in the mixer-settlers. Detection sensitivities for accounting perinds from 1 day (] balance) tn I month (28 balances) are given in Table $X \times X$ for two cases. In Case 1 , no instrument calibrations are performed during the accounting perind, and $20 \%$ estimates are made of the in-process inventory of each mixer-settler. In Case 2, 2-day recalibrations are performed on the input/output concentration measurements, and $10 \%$ estimates are made of the in-process inventory of each mixer-settler. Cusum performance surfaces for the two cases are shown in Fig. 22. These detection sensitivities should satisfy IAEA criteria. When comparing these sensitivities to the large plant detection sensitivities, remember that the large plant throughput is more than seven times that of the small plant, and that an on-line product measurement is made in the large plant, whereas conventional volume and chemical analysis product measurements are made in the small plant. 
TABLE XXX

SMALI CHEMICAL SEPARATIONS PIANT

DYNAMIC MATERIAIS ACCOUNTINGa

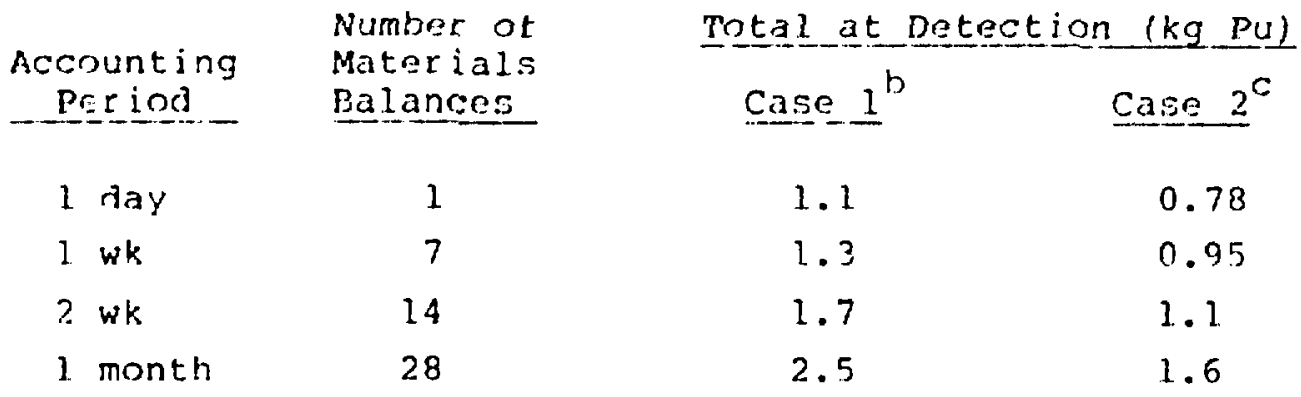

adetection sensitivity at the 3-o limit.

bNo recalibrations within the accounting period and 20 ostimates of mixer-settler inventories.

CTwo-day recalibration of input/output concentration measurements and 10 ostimates of mixer-settler inventories. 


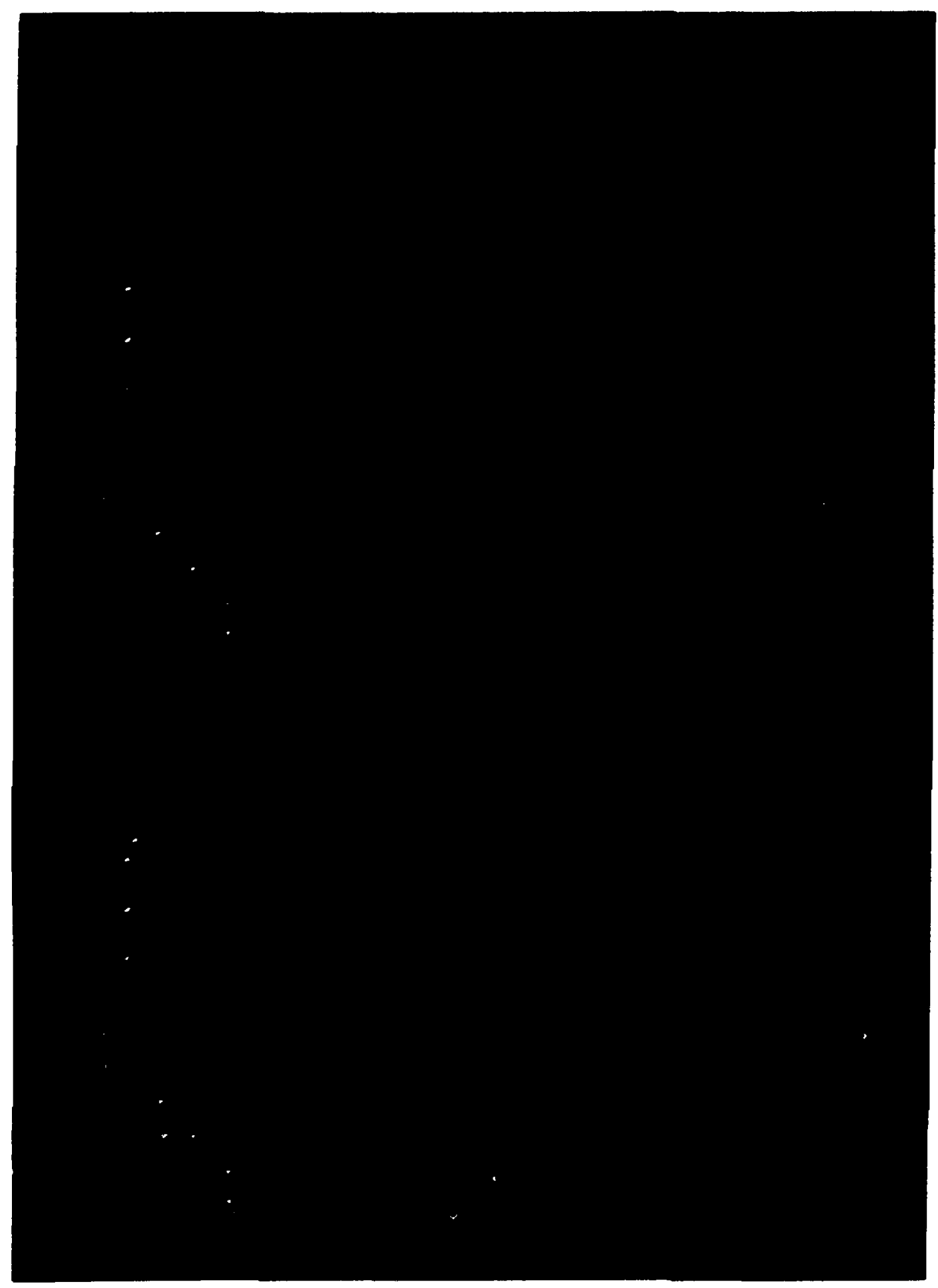

Fig. 22. Small plant performance surfaces; Case 1 (upper), Case 2 (lower). 
V1. J9.

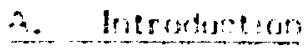

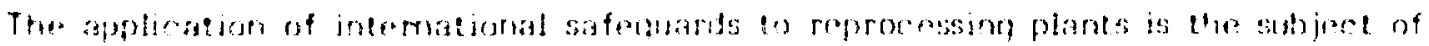

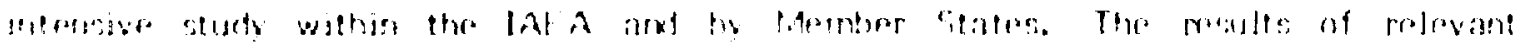

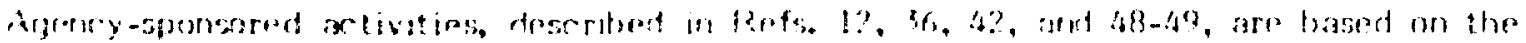

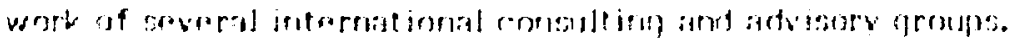

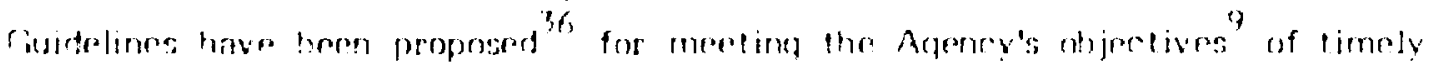

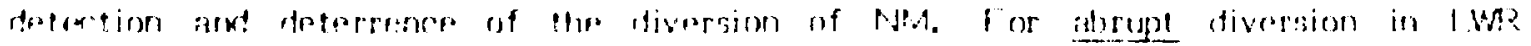

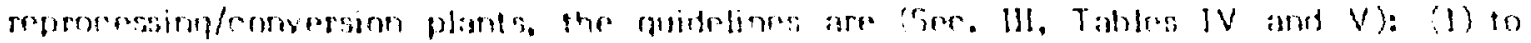

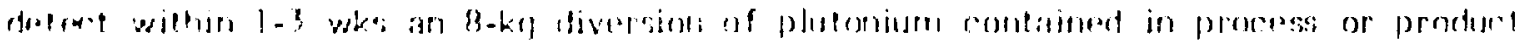

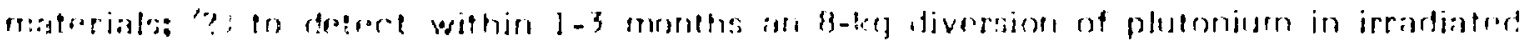

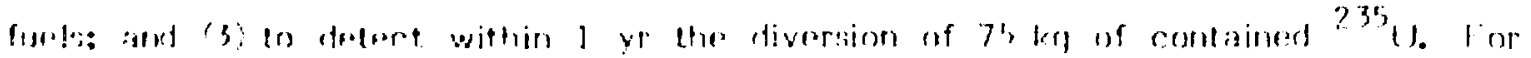

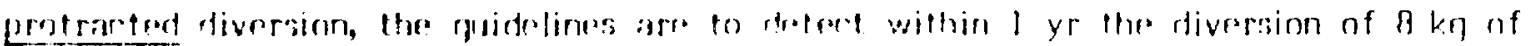

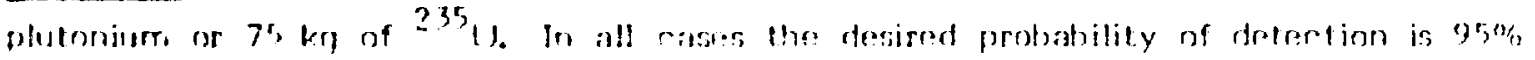
with a "s"s probahility af falso indications of tiversiom.

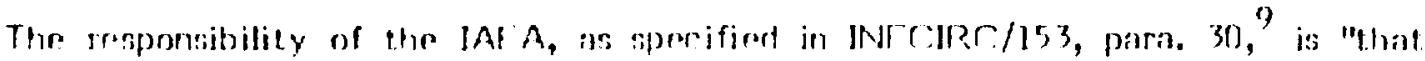
the trehnical romelusiom of tho Agreney's verification artivitios shall be a statemont, in

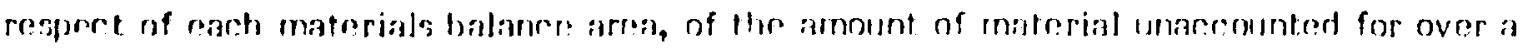
sperifir: periort, givim the limits of acrurary of thre imounts statre." That statement. hass threo important implirations. First, the oljocetive is a "tochnical conclusion." Clearly,

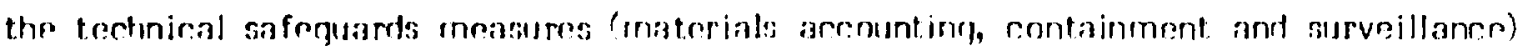
must. provide the basis for conclusinns having a minimum of ambiguity and subjectivity. Second, the conclusion is a stotement of MI JF and its associnted uncertainty for each MBA. This is not equivalent to a conclusion of possible diversion by the State. Conclusions conceming the possibility of diversion are derived from technical safeguards and other sources of information. Such conchusions may be initiated in the form of a statement by the Agency to the Board of Governors that it cannot meet its safeguards responsibilities in a particular State. Third, the conclusion is the result of the Agency's verification activities. Because international safeguards are a joint undertaking of the IAEA and its Member States, a two-step process must be implemented: the State's system of accounting and control must provide all information necessary for the Agency to meet its responsibilities, and the Agency must verify that information.

This two-step process is illustrated in Fig. 23, in which the Agency's function of independent verification is indicated as an overlay on the State's safeguards system and its nuclear facilities under safeguards. The IAEA plays a dual role. In partnership with 
STATE

WTERATIONA SATEGUAROS

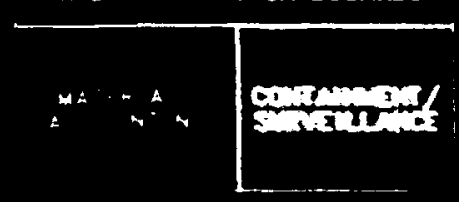

arisicy

${ }_{\text {AN }}$

$\therefore$

Fintzetion

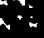

Fig. 23. Structure of the international safeguards system. 
Member States, the Agency promotes the development of effective and efficient State's safeçuarts systems. It must make full use of the State's system of arcounting and control. Conversely, the Ageney must determine whether the State's system is adequate? for the Arjency to discharge its saferjuards responsithilitins and must verify the information provided by the State. Because the State must he virued as a potential adversary; independent verifiration is imperative.

To meet its obligations, tive Agency considers that continuous inspectinn is necessary in reproecssing/conversion plants 'Ref. 12 and INFCIRr. 66, ${ }^{35}$ Annexes; 1 and II). This is consistent with the maximum permitted rnutinn inspection offort given in INFCIRC/153, para. 80, which corresponds to more than 1000 man-days of inspection per year for a $200-M T H A$ plant. ${ }^{33}$ Inspectors need not necessarily be in the plant at. all times, but may be available on call nearby for important verification activities.

Two sensitive issues are the protection of design information that the operator requarts as proprietary and insperetor access inside the plant. The Anency will require detailed plant and process design information to plan the safnquarts approarh. Details of the Purex process !ave been disseminated wirdelv, but detals for a particular installation, especially the design of sensitive proress equipment, may be ennsidered proprietary. Nevertheless, the Aneney will neer information about :he throughput, caparity, residual hold-up, and accossibility of process equipment, and the operator will need reasonable assurance that such information will be adequately proter ter.

To maintain effective surveillance, inspectors will require access to sensitive areas of the reprocessing plant, such as the control room, analytical labnratory, spent-fuel receiving and storage areas, and product storacye and shipping areas. 13oth human and instrumental surveillance will be maintainerl. To achieve short detection-time noals, the inspectors also must havre access to process and operating information, much of which contains important source data for arriving at timely safonuards conclusions. Furthermore, the operator will have to make provision in his production plans for critical inspector verification activities. Continuous inspection, with access to sensitive plant areas and process data, clearly is an extension of past practice that places an additional burden on the operator, but it will he necessary if the postulated safeguards goals are to be achiever.

Effective safeguards in reprocessirig/conversion plants cannot be based on conventional materials balance accounting alone. In particular, short detection-time goals cannot currently be met in small or large reprocessing plants. An overlay of advanced safeguards measures, including containment, surveillance, and near-real-time materials accounting, is designed specifically to address the abrupt diversion problem. In 
the feed and product storage and handling areas, the emphasis is on enhanced containment and surveillance supplemented by materials accounting. In the main process areas, the emphasis is on enhanced materials accounting supplemented by containment and surveillance. In the small plants currently under safeguards, a retrofit of advanced safeguards measures appears to be both feasible and adequate. ${ }^{37}$ Integration of safeguards criteria into future plant and process designs should ensure that advanced safeguards techniques can effectively counter abrupt diversion in large commercial plants (App. C).

Achieving a satisfactory sensitivity to protracted diversion may be the most difficult technical safeguards problem. The application of advanced containment and surveillance measures, including inspector surveillance, to the fuel receiving and storage areas, the headend process area, and the product storage and shipping areas, should be effective means to detect and deter protracted diversion from those areas. For materials accounting in the main process areas, the factor limiting the detection of protracted diversion may well be the uncertainty in residual, long-term relative biases between the input and output accountability measurements. Although considerable effort is currently expended on input and output accountability measurements (separately), insufficient attention has been given to controlling the long-term relative uncertainties between these measurements. It is expected that these relative uncertainties can be controlled within the range $0.1-1 \%(1 \sigma)$ of throughput. Thus, improved input-output flow control may yield a detection threshold $(3.3 \sigma)$ for protracted diversion of perhaps $0.5 \%$ of throughput. On an annual basis, that corresponds to a diversion rate of one significant quantity ( $8 \mathrm{~kg} \mathrm{Pu}$ ) per year from a 200-MTHM plant. The potential protracted diversion rate from large plants (1500 MTHM) will likely exceed one significant quantity per year.

Consequently, there is presently some disparity between the suggested IAEA criterion for sensitivity to protracted diversion and the near-term projected capability of even advanced safeguards systems. At the same time, safeguards technology is still evolving, continuing to narrow the gap between desired and realizable performance. In recognition of these facts, alternative forms and values of criteria ought to be investigated, from the standpoint of both technical and institutional/political ramifications.

The criteria-performance discrepancy is not nearly so large as it might seem because of severe practical limitations imposed on a potential divertor. If advanced safeguards techniques having adequate international verification can be implemented, then the would-be divertor is forced to consider the most bizarre diversion strategies, that is, abrogation and seizure of facilities and materials or covert strategies involving 
numerous small removals from many locations in the plant or, more generally, from many locations in the fuel cycle. The overt strategies must be addressed primarily by international political and institutional measures rather than by technical safeguards measures. If extreme strategies of multiple low-level diversions are the only covert paths left for a potential divertor, technical safeguards measures should be judged effective and complete. To implement such strategies would present the divertor with formidable problems of complex concealment involving many people over long periods, and surveillance should be an effective means of detection. Application of effective measures to deter this and all other diversion possibilities will be enhanced by extending the current institutional and political arrangements designed to control weapons proliferation. This subject is treated in Sec. VII.

\section{B. Diversion Possibilities}

The IAEA identifies two limiting types of diversion schemes referred to as abrupt and protracted (Ref. 1., Part A), and it recognizes several methods of concealing diversion of NM that are related to those two schemes. Complete description of a diversion strategy requires specification of (1) the location(s) in the process or fuel cycle where diversion is to occur, (2) the temporal structure (abrupt, protracted; uniform, random, etc.) of the diversion, (3) the mode of physical removal from the facility, and (4) related concealment activities. We discuss these specifications next, concentrating on aspects relevant primarily to materials accounting.

1. Possible Diversion Locations. Reference 12, Sec. 3, lists six areas for reprocessing plants where diversion might occur:

- Receipt and storage of irradiated fuel,

- Transfers to and treatment in the chop-leach section,

- Input accountability tank,

- Process area,

- Output accountability, and

- Product storage.

Reference 12 also gives more specifics on diversion activities, concealment possibilities, and countermeasures for each of these areas.

The diversion location affects materials accounting because measurement capability depends on the form and type of NM, that is, on the place from which NM is taken. It is generally advantageous to divert NM from an area encompassing several NM types having widely disparate measurement uncertainties. Then, diversion of NM that is more 
attractive to the divertor is easier to hide within the normal measurement errors associated with poorly measured NM.

2. Possible Diversion Patterns. In addition to the abrupt or protracted diversion scenarios already discussed, the divertor must decide on the total NM he needs, on the allocation of possibly multiple diversions among several materials balance periods, and on the best time for diversion within a balance period. Only the divertor can say how much NM he needs, but for planning purposes the IAEA takes $8 \mathrm{~kg}$ of plutonium as a significant quantity that would be useful to a potential national divertor.

For protracted diversion, the divertor may choose any of several allocations among the materials balance periods. Small uniform diversions would be among the hardest to detect, as would small random diversions designed to conceal the diversion pattern more effectively. The divertor must also allow for process operating procedures, personnel work schedules, etc., and be ready to take advantage of unforeseen opportunities, such as process upsets, as they occur. He is well qualified to do that, being the operator of the facility.

As a general rule, diversion immediately following the drawing of the previous materials balance maximizes the time before possible detection, which can be significant if balances are drawn only at 6-month intervals, for example. However, other factors dependent on the particular situation must be consideren.

3. Mode of Physical Removal. This specification generally is of less concern to materials accounting. However, if the divertor attempts to remove NM by concealment within a normal transfer out of the facility, and if that transfer is measured, or at least monitored, for materials accounting purposes, then the divertor's risk of detection increases.

4. Concealment Activities. Methods of diversion concealment, relevant mainly to materials accounting, can be categorized as follows:

- Diversion hidden by measurement uncertainties

- Falsification

-NM tampering

-Instrument tampering

-Data tampering

-Falsification of measurement error statistics.

Next we describe each of these methods briefly. 
a. Diversion Hidden by Measurement Uncertainties. Balances drawn by the materials accounting system are never closed exactly to zero because of measurement errors and statistical uncertainties. The usual practice is to estimate the standard deviation of the materials balance on the basis of historical information concerning the characteristics of the instruments. Each materials balance is considered to be abnormal only if it differs from zero by more than two standard deviations.

The diversion opportunity arises because of the size of the standard deviation of the materials balance. That is, if the alarm level is set at two standard deviations, diversion of an amount of NM equal to two standard deviations would have a 50\% chance of not being detected. Thus, in a reprocessing plant of the size of the base-line facility, a two-standard-deviation alarm level of $1 \%$ of throughput for a 6-month accounting period corresponds to $75 \mathrm{~kg}$ of plutonium, and a divertor is afforded up to 6 months of diversion opportunity.

b. Falsification. Materials tampering, having the operator's and inspector's instruments measure suitably constituted NM other than that declared, is potentially effective against materials accounting. However, the divertor must be careful to allow for all the consistency checks available to the inspector. Moreover, this method involves physical movements of $\mathrm{NM}$, which may be subject to the inspector's surveillance measures.

Instrument tampering can take several forms, including rendering the instrument inoperative, inducing instrument bias to mask diversion, or increasing the measurement errors, for example, by artificially increasing instrument noise. The first possibility is not practicable over an extended period without arousing the inspector's suspicions, particularly because the inspector can invoke the overlapping UPAA concept discussed in App. $H$, Sec. C. Inducing instrument bias is subject to detection by statistical analysis, comparison with the inspector's independent measurements, and requests for calibration checks using blind standards from the inspector. Artificially increasing the measurement noise provides no advantage; in fact, the technique will cause a higher false-alarm rate, which the divertor certainly does not want unless he is deliberately trying to discredit the inspector's system. However, the inspector will know the proper characteristics of the measurement systems if he participates in the measurement control program.

Data tampering can occur at the outputs of the instruments, after the operator's data are collected, or anywhere in between--the objective being to report suitable false values to the inspector. Again, this method is subject to statistical analysis, measurement comparisons, and consistency checks. The divertor must choose his falsified values carefully as discussed in App. $H$, Sec. D. 
Another kind of falsification using NM substitution and instrument and data tampering is the creation of clandestine feed and product streams, either by modification of the process or by partial reporting of the inputs and outputs. The former method is a violation of declared operation and possibly detectable by inspector surveillance. The latter method is more difficult to detect, especially if the unreported inputs and outputs within each materials balance period are about equal.

Falsificaton of measurement error statistics would allow the divertor to hide a higher level of diversion within the measurement uncertainties. However, the divertor's ability to pursue this method would be limited by the inspector's participation in the measurement control program.

\section{Verification Activities--General}

The IAEA's verification activities apply to the location, identity, quantity, and composition of all NM subject to safeguards. The verification process has three steps: 11,12 (1) examination of the information provided by the State in the Design Information Questionnaire (DIQ), in the initial accounting report, and in subsequent routine and special accounting reports; (2) collection of independent information by the IAEA in inspections; and (3) evaluation of the information provided by the State and collected in inspections for the purpose of determining the completeness, accuracy, and velidity of the information provided by the State.

A divertor may obtain NM from a single location or from several points in the process or, more generally, in the fuel cycle, by using complicated falsification strategies for concealment. In the establishment of effective countermeasures, a principal advantage of international safeguards is the requirement that the State declare all flows and quantities of NM within and among its nuclear facilities and state the procedures associated with operating those facilities. Armed with this a priori information, the Agency attempts to establish a network of correlations, based on a sufficient number of observations, to detect any credible diversion stategy and thus deter a potential divertor. Unexplained abnormalities in these correlations are the main diversion indicators to be derived from the Agency's technical conclusions. Generally speaking, correlations that are established to verify the declared flow and inventory quantities depend primarily or materials accounting measures supported by complementary containment and surveillance, whereas correlations to verify the declared design and operation of the process depend primarily on containment and surveillance measures supported by materials accounting. 
1. Inspections. The Agency distinguishes between three types of inspections: ad hoc, routine, and special inspections. Ad hoc inspections are carried out to: (1) verify information provided in the initial report; (2) identify and verify any changes subsequent to the initial report; and (3) verify international transfers. Routine inspections are carried out to: (1) verify that reports are consistent with records; (2) verify the location, identity, quantity, and composition of all NM subject to safeguards; and (3) verify information on the possible causes of MUF, S/R differences, and uncertainties in the book inventory.

Special inspections are made: (1) to verify the information contained in special reports; or (2) if the Agency considers that information made available by the State, including explanations from the State and information obtained from routine inspections, is not adequate for the Agency to fulfill its responsibilities. Special inspection procedures must be tailored specifically for each situation. For example, inadequate reporting would require a review of the records to determine whether the operator's accounting system follows the procedures set out in the DIQ; if the procedures are not followed or there is other evidence that the operator's accounting system is out of control, the possibility of taking an immediate physical inventory must be considered.

2. Measures. The measures to be used are materials accounting with complementary containment and surveillance. ${ }^{9}$ Quoting from Ref. 12, pp. 4-10:

"It is clear that the inspection activities... do not assume closing material balances at short intervals through frequent clean-out physical inventory takings. ....To achieve safeguards objectives with respect to the timeliness and the sensitivity of the detection of possible diversions, a combination of procedures is needed. The particular combination appropriate for any specific facility will depend, inter alia, upon the characteristics of the facility and its operating practices. The appropriateness of the particular procedures depends upon the timeliness of detection of diversion which the procedures afford, upon their limits of uncertainty of material measurement, and upon the degree to which the procedures provide independent verification in the particular circumstances." 
3. Containment and Surveillance. Containment and surveillance measures are used to detect activities associated with undeclared movement or access to NM. Any positive indication that undeclared actions have been taken could result in a call for a new inventory verification by the IAEA inspectors.

The containment and surveillance system has two main parts:

- The containment, which comprises the physical boundaries within which NM is expected to remain; and

- Surveillance, which is composed of human and/or instrumental sbservations that can detect movements of material through the containment barrier or can detect activities that may lead to violations of the containment.

Surveillance should be particularly effective in the pre-partition part of the process where the material is highly contaminated with fission products and the plutonium concentration is low; furthermore, the spent fuel in the storage pool resides in discrete fuel assemblies. Thus, diversion activities in this area would have to be concealed as normal activities because diversion would require massive shielding, bulky equipment, and undeclared process operations, all of which should be highly visible.

Surveillance also should be particularly effective in product storage and shipping areas. For liquid storage, valves can be continuously monitored and radiation detectors can be placed on lines leaving the storage area. For storage of dry powders (after nitrate conversion), seals on storage canisters and continuous surveillance of the storage vault are envisioned.

Surveillance of the process line differs in post-partition processing because a significant quantity of NM can be removed more easily in small increments through lines penetrating the containment. Detection efforts in this area must be concentrated on careful review of the design information for placement of the most sensitive instruments available.

Covert process changes are a problem for surveillance systems, particularly in the post-partition process areas. Such changes include the introduction of undeclared paths through the containment, deliberate misoperation of the process to create upset conditions, or undeclared operations while surveillance systems are inoperative.

Strategic points for the application of containment and surveillance measures at a reprocessing plant, (Ref. 12) include: (1) irradiated fuel receiving and storage area; (2) uranium and plutonium product storage and take-out points; and (3) vessels, valves, and transfer lines, as appropriate. At those strategic points, a listing of applicable instruments and devices includes: $^{12}$ (1) surveillance cameras at the spent-fuel bay and at the transfer point to chop-leach; (2) crane monitors for transfers of irradiated fuel 
assemblies; (3) seals or other devices to monitor valves and transfer lines at plutonium product take-out points; (4) seals on containers of plutonium and uranium products; (5) seals or other devices to monitor valves and transfer lines related to plutonium product storage vessels; (6) temporary attachment of seals for physical inventory verification purposes; (7) seals on inventory items that could be left sealed between two physical inventories to simplify the next physical inventory taking (PIT); and (8) seals on storage of the Agency's samples, standards, instruments and supplies.

The containmient and surveillance system has the important additional function of protecting the integrity of the materials accounting system. This function ranges from tamper-safing instruments (see App. H, Sec. C for some suggestions on technical approaches) to ensuring that no significant NM flows and inventories bypass the key measurement points.

Containment and surveillance methodology and evaluation of applicable surveillance instruments for a reprocessing/conversion facility are being studied by SLA. ${ }^{84}$ Appendix $O$ considers the integration of materials accounting techniques with containment and surveillance procedures.

4. Materials Accounting. Materials accounting for international safeguards depends on the inspector's ability to verify the operator's materials accounting results. Recause of the nature of the inspector's technical conclusion, ${ }^{9}$ he must verify a materials balance, whether based on the operator's measurements, his own independent measurements, or a mix of the two, which is the usual case.

As discussed in Sec. VI.B.4, the operator, as a potential divertor, can attempt to conceal diversion in several ways. Techniques available to the IAEA inspector to combat those activities can be categorized comparably as follows:

To address diversion hidden by measurement uncertainties, the inspector might

- Draw a materials balance using the operator's data, and

- Make additional measurements of his own to decrease measurement uncertainties.

To address falsification, the inspector might

- Analyze the operator's data for consistency,

- Make independent tamper-safed measurements,

- Tamper-safe the operator's instruments, and

- Participate in the measurement control program.

The subject of tamper-safing is treated briefly in App. $H$, Sec. $r$, and procedures for the inspector's analysis of all the data are derived in App. $H$, Sec. D. 
a. Data Analysis. To understand the ramifications of the inspector's analysis in terms of his required measurement capability, consider a simple example. As in App. $\mathrm{H}$, Sec. $D$, suppose that a single materials balance is drawn for one portion of the process (see Fig. H-3). The operator reports to the inspector possibly falsified measured values of the inventories and transfers (taken here to be single measurements so that there are four values total), and their measurement error variances as follows:

$$
\begin{aligned}
& \overline{\mathrm{I}}^{\mathrm{r}}(0), \operatorname{var}\left[\overline{\mathrm{I}}^{\mathrm{r}}(0)\right]=\bar{\sigma}_{\mathrm{I}}^{2}(0), \\
& \overline{\mathrm{I}}^{\mathrm{r}}(1), \operatorname{var}\left[\overline{\mathrm{I}}^{\mathrm{r}}(1)\right]=\bar{\sigma}_{\mathrm{I}}^{2}(1), \\
& \overline{\mathrm{T}}^{\mathrm{r}}(0), \operatorname{var}\left[\overline{\mathrm{T}}^{\mathrm{r}}(0)\right]=\bar{\sigma}_{T}^{2}(0), \\
& \overline{\mathrm{T}}^{\mathrm{r}}(1), \operatorname{var}\left[\overline{\mathrm{T}}^{\mathrm{r}}(1)\right]=\bar{\sigma}_{T}^{2}(1),
\end{aligned}
$$

The measurements are assumed to be mutually statistically independent. Likewise, the inspector obtains his own measurements and their measurement error variances:

$$
\begin{aligned}
& \tilde{I}(0), \operatorname{var}[\tilde{I}(0)]=\tilde{\sigma}_{I}^{2}(0), \\
& \tilde{I}(1), \operatorname{var}[\tilde{I}(1)]=\tilde{\sigma}_{I}^{2}(1), \\
& \tilde{T}(0), \operatorname{var}[\tilde{T}(0)]=\tilde{\sigma}_{T}^{2}(0), \\
& \tilde{T}(1), \operatorname{var}[\tilde{T}(1)]=\tilde{\sigma}_{T}^{2}(1),
\end{aligned}
$$

If the inspector does not make all these measurements, then that fact is accounted for in the analysis by setting the corresponding variance to infinity, which is equivalent to saying the inspector has no information from that measurement. If the inspector uses an 
operator's measurement for his own, then the corresponding error variances for the two measured values are equal to the error variance of the operator's measurement, as is the error covariance between the two measurements.

Next the inspector forms the sufficient statistic in Eq. (H-38), making use of Eq. $(\mathrm{H}-39)$ :

$$
\begin{aligned}
\text { ISS }= & \frac{1}{2} \frac{\left[\bar{I}^{r}(0)-\tilde{I}(0)\right]^{2}}{\bar{\sigma}_{I}^{2}(0)+\tilde{\sigma}_{I}^{2}(0)}+\frac{1}{2} \frac{\left[\bar{I}^{r}(1)-\tilde{I}(1)\right]^{2}}{\bar{\sigma}_{I}^{2}(1)+\tilde{\sigma}_{I}^{2}(1)} \\
& +\frac{1}{2} \frac{\left[\bar{T}^{r}(0)-\tilde{T}(0)\right]^{2}}{\sigma_{T}^{2}(0)+\tilde{\sigma}_{T}^{2}(0)}+\frac{1}{2} \frac{\left[\bar{T}^{r}(1)-\tilde{T}(1)\right]^{2}}{\bar{\sigma}_{T}^{2}(1)+\tilde{\sigma}_{T}^{2}(1)}+\frac{M_{p}^{2}}{2 \sigma_{p}^{2}},
\end{aligned}
$$

where the quantities in the last term are given by

$$
\begin{aligned}
M_{p}= & \frac{\tilde{\sigma}_{I}^{2}(0) \bar{I}^{r}(0)+\bar{\sigma}_{I}^{2}(0) \tilde{I}(0)}{\bar{\sigma}_{I}^{2}(0)+\tilde{\sigma}_{I}^{2}(0)}-\frac{\tilde{\sigma}_{I}^{2}(1) \bar{I}^{r}(1)+\bar{\sigma}_{I}^{2}(1) \tilde{I}(1)}{\bar{\sigma}_{I}^{2}(1)+\tilde{\sigma}_{I}^{2}(1)} \\
& +\frac{\tilde{\sigma}_{T}^{2}(0) \bar{T}^{r}(0)+\bar{\sigma}_{T}^{2}(0) \tilde{T}(0)}{\bar{\sigma}_{T}^{2}(0)+\tilde{\sigma}_{T}^{2}(0)}-\frac{\tilde{\sigma}_{T}^{2}(1) \bar{T}^{r}(1)+\bar{\sigma}_{T}^{2}(1) \tilde{T}_{T}(1)}{\bar{\sigma}_{T}^{2}(1)+\tilde{\sigma}_{T}^{2}(1)}, \\
\sigma_{p}^{2}= & \frac{\bar{\sigma}_{I}^{2}(0) \tilde{\sigma}_{I}^{2}(0)}{\bar{\sigma}_{T}^{2}(0)+\tilde{\sigma}_{I}^{2}(0)}+\frac{\bar{\sigma}_{I}^{2}(1) \tilde{\sigma}_{I}^{2}(1)}{\bar{\sigma}_{I}^{2}(1)+\tilde{\sigma}_{I}^{2}(1)} \\
& +\frac{\bar{\sigma}_{T}^{2}(0) \tilde{\sigma}_{T}^{2}(0)}{\bar{\sigma}_{T}^{2}(0)+\tilde{\sigma}_{T}^{2}(0)}+\frac{\bar{\sigma}_{T}^{2}(1) \tilde{\sigma}_{T}^{2}(1)}{\sigma_{T}^{2}(1)+\tilde{\sigma}_{T}^{2}(1)} .
\end{aligned}
$$

The first four terms in Eq. (1) deal with falsification by differencing the operator's and inspector's individual measurement values. If any operator's reported value has been falsified, then ISS will increase above the level normally expected on the basis of 
statistical fluctuations. The amount of increase depends inversely on the uncertainties in both the operator's and inspector's measurements.

An important conclusion can be drawn from Eq. (1): If the inspector fails to make one of the measurements, say $\tilde{I}(0)$, then effectively $\sigma_{I}^{2}(0)=\infty$, and the ISS provides no indication of whether or not $\overline{\mathrm{I}}^{\mathrm{T}}(0)$ was falsified. Furthermore, presuming the operator has falsified intelligently, using Eq. $(H-3 l)$ for example, the pooled materials balance, $M_{p}$, will be smaller because it includes the falsified measurement $\bar{I}^{r}(0)$. Under these circumstances, the inspector's only recourse is to tamper-safe the operator's instrument that provides $\overline{\mathrm{I}}(0)$ and use that value as if it were his own and unfalsified. Failing that, the inspector can make no statement concerning whether or not $\widetilde{\mathfrak{l}}^{\mathrm{r}}(0)$ was falsified, and tinerefore can draw no conclusion about the occurrence of diversion.

Thus, assuming the divertor is intelligent, the inspector can protect against falsification in just two ways: (I) by securing the operator's instrument beforehand and (2) by making an independent check, or measurement, of the operator's result after the fact. Each method has differing implications for cost, intrusiveness, and degree of protection.

The term $M_{p}$ in Eq. (2) is a pooled materials balance based on the aggregation of the operator's and inspector's values, and $\sigma_{p}^{2}$ in Eq. (3) is the error variance of $M_{\mathrm{p}}$. As before, if the inspector fails to make one of the measurements, for whatever reason, then the corresponding terms in $M_{P}$ and $\sigma_{p}^{2}$ reduce simply to the operator's values. This results in two conclusions: (I) $M_{p}$ is subject to the same degree of falsification that the individual measurement is, and (2) the sensitivity of the ISS to diversion hidden by measurement uncertainties is degraded because each term in $\sigma_{p}^{2}$ is no larger than the smallest of the operator's and inspector's corresponding variances.

To illustrate more clearly the advantage in calculating a pooled materials balance in this manner, consider a further simplified example. Suppose that the inspector were able to make measurements of the same quality as the operator; that is, $\tilde{\sigma}_{I}^{2}(0)=\bar{\sigma}_{I}^{2}(0)$, etc. Then,

$$
\begin{aligned}
M_{p}= & \frac{1}{2}\left[\bar{I}^{r}(0)+\tilde{I}(0)\right]-\frac{1}{2}\left[\bar{I}^{r}(1)+\tilde{I}(I)\right] \\
& +\frac{1}{2}\left[\bar{T}^{r}(0)+\tilde{T}(0)\right]-\frac{1}{2}\left[\bar{T}^{r}(1)+\tilde{T}(1)\right] \\
= & \frac{1}{2}(\bar{M}+\tilde{M}),
\end{aligned}
$$


or just the average of the operator's and inspector's materials balances. The variance of $M_{p}$, Eq. (3), for this special case is

$$
\sigma_{p}^{2}=\frac{1}{2}\left[\bar{\sigma}_{I}^{2}(0)+\bar{\sigma}_{I}^{2}(1)+\bar{\sigma}_{T}^{2}(0)+\bar{\sigma}_{T}^{2}(1)\right],
$$

or one-half the error variance of the operator's materials balance. For inspector measurements of worse quality, $\sigma_{p}^{2}$ is larger, but never larger than the operator's materials balance variance.

These simple examples show that the inspector makes independent measurements for two reasons: (1) to combat falsification and (2) to improve the sensitivity to diversion hidden by measurement uncertainties. Note that the second reason is also of benefit to the operator, if the inspector and operator share measurement data, in efforts to protect against subnational diversion. In addition, the sensitivity to falsification can also help the operator to control his systematic measurement errors because an inadvertent operator's bias is detectable by the inspector in the same manner as a falsification.

The conclusion that the inspector must independently verify all the operator's measurements is based on the assumption that an operator bent on diversion would know which measurements the inspector failed to make. In practice, this need not be as if the inspector can randomize his verification measurements from the operator's viewpoint. This technique can allow a significant reduction in inspector effort, but it must be applied with careful consideration of the statistics and the state of the operator's knowledge. Further reductions in inspector effort can be obtained if the inspector aggregates materials accounting data from several materials balance areas and periods and accounts for correlations among the data properly. That analysis has not yet been done.

b. Materials Balance Methods. We have presented some analysis techniques for the materials accounting data available to the inspector. Methods for acquiring those data depend on the ability to measure, or estimate, all significant flows and inventories of NM. All such methods are referred to generically as PITs in Ref. 12, and several specific ones are described there. The suitability of each method and the particular combination of methods selected by the operator for his plant will depend on a variety of process-specific factors. Brief descriptions of four such methods follow. ${ }^{12}$ 
(1) Cleanout. Physical Inventory Taking (CPIT). This is the best known and most accurate method of PIT. The process line is drained and flushed into holding tanks for measuremerit, and the residual holdup in the process equipment is measured directly or is estimated on the basis of historical data. Because the CPIT method requires an extended shutdown period, it is costly and can be applied only infrequently. However, it provides essential information on the residual plant holdup, which is the zero base for more timely PIT methods.

(2) Draindown Physical Inventory Taking (DPIT). The DPIT method is similar to CPIT, except that there is minimal flushout of the process line after draindown. The DPIT method may be an economically attractive alternative to CPIT if the plant is designed for effective application of this method (see App. C).

(3) Running Physical Inventory Taking (RPIT). The purpose of RPIT is to provide more timely materials balances than are possible with CPIT. The in-process inventory is measured when the process is operated near steady state. If certain process run conditions can be repeated periodically, the in-process inventory will be essentially reproducible at those times. If the in-process inventory is always measured under the same set of run conditions, hiases associated with the inventory measurements will tend to cancel from the materials balances, and the detection sensitivity will be improved. The process can be divided into accounting units smaller than the MBA, depending on the availability of flow and inventory measirements. The sensitivity is better than might be expected, even though the inventory measurement uncertainties are larger than for CPIT, because the flow measurements are generally the dominant sources of uncertainty for a rep rocessing plant.

(4) Running Book Inventory Taking (RBIT). The RBIT method is distinguished by the fact that not all in-process inventory components are measured. Measurements are made on those process vessels that contain significant fractions of the in-process inventory and that are instrumented for rapid inventory determination. The unmeasured components of the in-process inventory are estimated by difference, and those by-difference estimates are compared with independent estimates of normal plant holdup that are based on historical data. Thus, the RBIT method is applied only under normal operating conditions similar to conditions required for RPIT. Also, the process line can be divided into smaller accounting units, and by-difference estimates of the in-process (book) inventory in each 
unit can be obtained as often as input-output measurements become available. Depending on the variability of the unmeasured inventory and the quality of the input-oustput measurements, RBIT can provide good sensitivity to abrupt diversion.

A combination of conventional and near-real-time accounting methods will be necessary in reprocessing/conversion plants to meet the proposed IAEA criteria. Also, these methods must clearly be applied flexibly and must be based on sound principles of materials accounting (see App. E). For example, to achieve 2-4 conventional PITs per year, a combination of CPIT and DPIT methods is attractive. For timely detection of diversion between conventional PITs, near-real-time materials accounting systems incorporate and extend the attractive features of both the RPIT and RBIT methods.

\section{Verification Activities--Specific}

Based on our analysis and those described in Refs. 1J, 12, and 42, the following inspection activities are postulated to verify the operator's safeguards system for the model reprocessing/conversion plant. The safeguards technologies invoked are either available or under development. Their implementation, intrusiveness, and practicability will depend strongly upon the specific facility and the negotiated details of the facility attachment.

I. MBA 1--Fuel Receiving, Storage, Chop, and Leach. International verification at this point in the fuel cycle is essential. It presents the first opportunity to verify the plutonium produced in the power reactors and to check correlations with the fuel fabricator's and reactor operator's data. It is also the primary input accountability measurement point for the reprocessing plant.

a. Fuel Receiving and Storage. Receipts of all fuel assemblies must be verified. The inspector obtains a copy of the shipper's data, then checks and removes the IAEA seal, if any, from the shipping cask. Continuous surveillance is maintained during the unloading of each assembly to the storage pool. The identity of each assembly is checked, possibly using a tamper-indicating identification device applied at the time of fuel fabrication. $85-91$ After the cask is emptied and has been closed, the inspector may apply an Agency seal to the empty cask to verify that the cask is empty when it leaves the facility.

The inspector may conduct qualitative NDA measurements of the assemblies to con firm the burnup (App. N). Semiquantitative NDA measurements may also be available 
as an independent, direct check of the fissile content. These measurements may be made in the cask unloading pool. After rransfer of the assemblies to the storage pool, the inspector notes the identity and location of each assembly.

The data collected during fuel receiving are analyzed and compared with information from the fuel fabricator and the reactor operator and with any supporting data collected previously by the Agency. Correlations are checked on the basis of the initial enrichment, reactor power history, ${ }^{88}$ and burnup. Estimates of the fissile content of the spent fuel, derived from the correlations, are compared with any semiquantitative NDA measurements. On the basis of these analyses, provisional values for the ${ }^{235} \mathrm{U}$ and plutonium contents are established, pending more accurate chemical determination after dissolution.

Surveillance of the spent-fuel storage pool is continuous. ${ }^{86}$ Fuel movements are recorded by the operator, and the identity and location of the stored assemblies are checked by the inspector on a random-sampling basis. The checks may include an NDA attribute check, for example, using the recently developed Cerenkov technique. ${ }^{89-90}$

A verification strategy involving frequent checks of relatively small numbers of stored assemblies may have advantages in detecting unintentional errors in the data base and providing more timely verification. ${ }^{91}$ Continuous inspection would make this strategy possible.

b. Fuel Chop, Leach, and Input Accountability. All transfers of fuel assemblies to the mechanical shear are observed by an inspector. ${ }^{12}$ The identity and NM content of the assemblies that make up each dissolver batch are recorded.

The inspector observes the operator's procedure for sampling the dissolver solution and records the analytical results. Particular attention is given to the flushout of the dissolver between campaigns to ensure that the heel contains only a small amount of plutonium.

The inspector observes and records measurements of the leached hulls. Solid wastes from feed clarification are analyzed in the high-level waste concentrator feed tank. The inspector also obtains random samples of recycled acid to verify that the quantity of any NM recycled to the dissolver from MBA 2 is negligible.

The inspector obtains samples from all input accountability batches. The operator prepares his samples for isotope-dilution mass spectrometry (App. $K$ ) by separating the ission products in a hot cell. The inspector should receive duplicates of all prepared sirnples. He will require a designated area, perhaps adjacent to the chemistry laboratory, Pantling and storing those process samples and standards under Agency control. On a 10 
random basis, the inspector can request chemical analyses on process samples he has collected or on Agency standards. Inasmuch as possible, the identicy of the inspector's samples should be concealed from the operator so that the operator's analyses are performed as on blind control standards. If the operator maintains his own analytical equipment, such as an $x$-ray fluorescence spectrometer (App. L.) for rapid process analysis of highly radioactive samples, the inspector should monitor the calibration procedures and have standards under his control for random checks of the calibration.

Many of the inspector's process samples will be recycled back to the chemistry laboratory without a request for analysis. A fraction of the inspector's samples will be sent off-site for analysis and subsequent interlaboratory comparisons. Some of the samples for off-site analyses may be obtained by the resin-bead technique (App. K).

The inspector observes and records all volume measurements of the input accountability tank. Independent verification of tank volume can be obtained by acoustic, radio frequency, or isotopic techniques such as magnesium addition ( $A p p . K$ ). Observation by inspectors of the initial tank calibration procedures and the subsequent process measurements, although necessary, is not sufficient by itself and must be supported by more direct verification techniques.

Inspectors analyze the input accountability data for at least three purposes. First, isotopic correlations are checked to confirm the reactor plutonium production (App. $M$ ). The isotopic correlation methods depend on initial enrichment and burnup, but are independent of the input volume measurements. Heavy-isotope correlations (U/Pu ratio method) can be particularly useful. Second, plutonium and uranium mass balances should be checked across the headend operations, that is, from the storage pool to the input accountability tank. These balances can be checked between campaigns after the dissolver has been flushed (nominally once a week in the reference plant). Third, verified, high-quality measured values are established for the input to MBA 2.

2. MBA 2--Chemical Separations Process. The verification strategy proposed for the chemical separations process (MBA 2) consists of establishing and anaiyzing a network of materials balance correlations. The materials balances are obtained in near-real-time from verified input-output accountability measurements and from estimates of the major components of the in-process inventory that are derived from operator's process-control and on-line accountability measurements. Some of the in-process inventory estimates derived from operator's data can be confirmed independently by inspector surveillance and measurements. However, many of these inventory estimates can be confirmed only by analyzing the data for internal consistency. On-site analyses of the operator's and 
inspector's data are considered essential for timely detection. The inspector will need decision-analysis methods ${ }^{68,69}$ that are extensions of those discussed in App. $H$ and sufficient computational capability to analyze the data efficiently for trends and anomalies that require additional investigation.

a. UPAA 1--Codecontamination-Partitioning Process. The input to this area is the verified output of MBA 1 . The output measurement point is in the plutonium stream (IBP) after partitioning. The output measurement consists of process samples and either volume or integrated flow-rate measurements, depending on the process arrangement and the available buffer storage capacity after partitioning (Sec. IV).

To confirm the output measurement, the inspector can collect process samples, as described for the input accountability point. The operator may, however, use NDA equipment for rapid process analysis after partitioning (App. L). In that case, the NDA instrument should be designed for inspector verification. For example, the instrument could be equipped with standards for on-line calibration checks under computer control. Some of these standards could be controlled by the inspector and would not be identified to the operator. Some of the inspector's standards would be made up from process materials (see App. H). The inspectors can have their own NDA equipment, perhaps maintained in the chemistry laboratory, for analyzing low-activity process samples.

The inspectors would observe the operator's volume or integrated flow-rate measurements in the 1BP stream and the measurements of recycle streams from the PPP. Acid and solvent streams from recovery areas would be checked randomly for plutonium content. The small amounts of plutonium contained in the recycled acid wastes from the PPP should be checked more often. Organic waste streams from the PPP are recycled to the partitioning process for recovery of the residual uranium and plutonium. Any off-specification plutonium product is batched from the PPP, and the batches should be measured and verified in the plutonium rework tank before recycle.

Essentially all of the in-process inventory in UPAA 1 is contained in the feed-adjust tanks and the high-activity feed (HAF) tank. These tanks are instrumented for level and density, and the feed-adjust tanks are also equipped with sample lines.

The inspectors can check the feed-adjust-tank volume measurements by adding the amount of make-up acid from acid recovery to the input batch size from the accountability tank (so-called "flow follow-up" method ${ }^{12}$ ). Volume measurements in the HAF tank are complicated because at that point the process mode changes from batch to continuous and the tank receives and discharges continuously. However, the level 
recorder should provide volume estimates that are adequate for near-real-time materials balances.

The heavy-metal concentrations in these tanks can be derived from density measurements (App. K), and an estimate of the plutonium concentration can be obtained from the U/Pu ratio measured in the input accountability tank. On a random basis, the inspector can collect duplicate samples from the feed-adjust tanks, or concentration estimates can be obtained by using the flow follow-up method.

As proposed in Sec. IV, a materials balance could be drawn around the CPP after each input accountability batch (every $9.6 \mathrm{~h}$, on the average). At that time, one feed-adjust tank is full and the other is nearly empty. The inspectors would collect in-process inventory data on the feed-adjust and HAF tanks. The integrated plutonium output in the $1 B P$ stream also is required. If the $1 B P$ output is batched (as in the model small reprocessing plant), logical balances coult be drawn for integer numbers of input and output batches.

b. UPAA L--Plutonium Purification Process. The input to the PPP is the 1BP stream, and the output is at the primary output accountability point for the concentrated plutonium product solution.

Verification activities for product accountability are similar to those already described for input accountability, except that the much lower radiation fields facilitate accounting and verification measurements. The inspector should collect duplicate samples from all product batches and should obtain both on-site and off-site analyses, possibly by NDA methods (App. L) on random selections of these product samples.

On-line flow meters, as suggested for the concentrator-product (3PCP) stream, would provide integrated flow-rate measurements as an independent check on the tank volume measurements. Redundant liquid-level instruments as suggested for the accountability tank also could be used.

For near-real-time balances in the PPP (Sec. IV), useful time fiducials are one filling of the plutonium product catch tank (nominally every $B h$ ) and one filling of the plutonium product sample tank (nominally every $24 \mathrm{~h}$ ). The in-process inventory in the PPP is divided among the IBP surge tank, the pulsed crlumns, and the plutonium concentrator (see App. F).

The inspector could obtain estimates of the in-process plutonium inventory in the IBP tank using installed level, density, and sample lines. The plutonium concentration in the tank could be obtained by analyzing samples, by combining density and U/PU ratio measurements, or by flow follow-up. 
Techniques for estimating the inventories of the plutonium in the pulsed columns are particularly important for the PPP (App. J). Column inventory estimates can be obtained by using theoretical models and such process-control measurements as the flow controls on the feed streams and the alpha monitors (for plutonium concentration) on the waste streams (App. L).

For the plutonjum concentrator, most of the plutonium inventory is in a constant-volume overflow tank. The plutonium concentration in this tank can be estimated from the operator's temperature and density measurements and can be verified from in-line concentration measurements made in the plutonium product stream.

By collecting these process and accountability data, the inspector can draw plutanium mass balances in the PPP, from the 1BP stream to the plutonium catch tank, approximately every $8 \mathrm{~h}$. After the plutonium catch tank, the process operation changes from contimuous to batch in a series of tanks (plutonium sample and interim product storage tanks) that are instrumented for level and density measurements and that are equipped with sampler lines. Flow follow-up methods, along with random checks of sample density and plutonium concentration, can be used to confirm the batch transfers between these tanks.

c. UPAA 12 --Chemical Separations Frocess. By combining the same process and accountability data collected for UPAA 1 and UPAA 2, the inspector can examine near-real-time balances for the entire separations process. Basically, this involves removing the intermediate flow measurement in the $1 B P$ stream and combining the two data sets. The remaining data consist of the primary input and output accountability measurements and the in-process inventory estimates.

Over extended periods when the process is operated near steady state, that is, when the in-process inventory is approximately the same at the beginning and end of the period, correlations based on input-output measurements can be examined by the RBIT method. Complementary uranium mass balances can be obtained in near-real-time for the separations process by applying the same techniques used for plutonium. Thus, input-output correlations can be derived for plutonium, uranium, and U/Pu ratios and can be used to confirm the near-real-time materials balance information collected during the accounting period.

3. MBA 4--Plutonium-Nitrate Product Storage. The design of the plutonium product storage facility, hence the appropriate verification activities, depends to some extent on whether the conversion facility is collocated. If nitrate product is stored for 104 
shipment off-site to a separate conversion facility (now forbidden in the US and UK), more product storage capacity will be required at the reprocessing plant. If the conversion facility is collocated, a capacity sufficient only for maintaining isotopic uniformity in the conversion process feed solution will be required. Note that collocation of the conversion process may eliminate the necessity for concentrating the plutonium product from chemical separations. ${ }^{8}$ If the plutonium concentrator were eliminated, the inventory in the PPP would te reduced substantially (see App. F).

Plutonium-nitrate storage tanks should be designed for accurate level measurements and to maintain homogeneous solutions. The tanks should be kept under continuous surveillance. In the case of long-term storage, appropriate Agency seals should be applied to the tank valves to ensure that valves and associated piping are not opened or disassembled. Because of radiolysis, fresh acid is added periadically. Americium buildup may require plutonium repurification before use in the conversion facility. The inspector should observe all transfers and additions made in the storage area and should collect additional samples from the tanks for verification. Frequently, inspectors will check the seals and the liquid levels in static tanks. The possibility of having continuous, remote read-out of tank liquid levels from Agency-verified instruments should be considered. The inspectors would observe all product shipments, collect samples, and apply Agency seals to the shipping bottles.

If the conversion facility is collocated, one or more large mixing tanks may be present to buffer the chemical separations and conversion processes. Such tanks would require continuous surveillance and frequent verification of the contents by Agency inspectors. Flow follow-up methods should be useful for confirming transfers of NM from the output accountability point of the separations process to the input accountability point for conversion. Plutonium mass balances should be maintained for all such transfers.

4. MBA 5--Conversion Process. Verification strategies for the conversion process generally would follow those described for the chemical : parations process. A fundamental difference is that inspector surveillance and verification activities should be more straightforward because of the much lower radiation levels. More opportunities will be available for direct Agency surveillance of operational procedures and for independent verification measurements by inspectors using NDA equipment (App. L). The effectiveness of inspector-verified near-real-time accounting will be enhanced in the conversion process (Sec. IV). 
A second important difference is that the conversion product (plutonium-axide powder) is stored in canisters that are relatively easy to identify and to verify by using seals and NDA measurements. Substantial quantities of product probably will be stored in a vault, pending shipment to the fuel fabricators, and a significant amount of verification effort will be directed at the storage vault. Storage areas for the product of the conversion process (it may in fact be plutonium oxide or a MOX master blend), or even the entire conversion process itself, are candidates for facilities to be placed under some form of international control involving IAEA verification. ${ }^{2,8,34}$ This is an extension of the Bonded Crucial Facility (BCF), previously suggested as a nonproliferation aid (Refs. ?, 8; App. C) and discussed in more detail in Sec. VII. 


\section{INSTITUTIONAL ARRANGEMENTS}

A. Introduction

Effective international safeguards are essential to the peaceful development of nuclear energy and fundamental to a policy of international nuclear cooperation. The concept of safeguards, the magnitude, scope and complexity of the arena to which they are applied, and consequently, the ineasure of their effectiveness have evolved considerably over the past three decades. ${ }^{92,93}$ It is significant that while international safeguards have become institutionalized and legitimized over time, they represent an unusual departure from the normal pattern of State sovereignty. Their history reflects a reluctant and limited degree of State acceptance as well as significant accomplishments. For example, the Baruch Plan of 1946, which postulated the creation of an international atomic energy authority under United Nations auspices, incorporated the notion of comprehensive safeguards, including not only verification through inspection, but also physical control of potentially dangerous nuclear activities. ${ }^{94}$ Later definitions of international safeguards decoupled physical security and control from detection of the diversion of NM and focused only on the latter. Under the NPT the conceptual role of safeguards was even further circumscribed, but their scope of application was nevertheless extended to the entire peaceful program of participating states. For a review of the evaluation of safeguards see Refs. 95 and 96 . More recently, the sole adequacy of international safeguards to deter the risk of proliferation effectively has come into question. For a more authoritative statement on this topic, see Ref. 97. These factors bear heavily on institutional analysis of near-real-time accounting safeguards for LWR fuels reprocessing plants.

\section{B. Historical Evolution of International Safeguar ds}

The institutions and agreements that encompass international safeguards include at the general level, the IAEA and the NPT, and, at the level of implementation, two IAEA safeguards documents: INFCIRC/66/Rev. 2 and INFCIRC/153 which govern respectively non-NPT and NPT-based safeguards activities. The historical roots of the current international safeguards system are found in the Atoms-for-Peace plan initiated by the United States in 1954. Atoms-for-Peace was based on the idea that through controlled cooperation, the peaceful uses of atoric energy could be fostered while military nuclear proliferation might be deterred. Verification of adherence to political commitments not to misuse transferred NM and deterrence of such misuse was to be accomplished through the application of safeguards. 
Although safeguards initially were to be applied bilaterally, the US from the outset made clear its preference for international safequards as being more credible and acceptable. The establishment of the IAEA was intended to provide the institutional basis for these international safeguards. In fact, the role of safeguards was a particularly difficult issue during the negotiation of the Agency statute because of the reluctance of some non-nuclear weapon States to relinquish their sovereign rights and to permit international inspection of their territory. Efforts to link membership in the IAEA to acceptance of safeguards on national nuclear activities were rejected, and the idea of creating a safeguards system as one of the Agency's main functions was under constant criticism from the Soviet bloc and a group of third-world countries led by India.

The safeguards provisions finally inscribed in the IAEA Statute limited the application of Agency safeguards to situations where assistance was provided by, or through, the Agency; where nations that were party to bilateral or multilateral arrangements requested the application of Agency safeguards; or where a nation unilaterally submitted its nuclear activities to IAEA safeguards (see the Statute of the IAEA, Article 12).

Most US bilateral agreements included provisions for transferring safequards responsibilities eventually to the IAEA. Four years transpired, however, before the Agency was able to adopt guidelines for a safeguards system, and another two years before a system for small power reactors finally went into effect. After 1963 and a shift in the Soviet. attitude toward safeguards, the system was extended progressively to larger power reactors, reprocessing plants, and conversion and fuel-fabrication facilities.

\section{Basis for international Safeguards Arrangements}

The single most important qualitative change in international safeguards occurred when they were made an integral part of the NPT. The NPT contains an unprecedented concept in international relations: the general commitment of participating States to international inspection within national boundaries; the voluntary yielding of a part of national sovereignty to an international authority. Even here, however, the inscription of comprehensive safeguards was not automatic. On the one hand, advanced non-nuclear weapons States were concerned lest the application of international safeguards to the exclusion of comparable safeguards on competitive peaceful fuel cycles in weapons States disadvantage the non-nuclear weapons States in the development, commercialization and marketing of peaceful nuclear energy. On the other hand, the EURATOM countries, wt ' a already had a regional safeguards system based on the concept of adversary relationships, were concerned that substitution of IAEA for EURATOM safeguards might 
undermine the EURATOM community. These problems held up completion of a draft NPT. 98 They were finally resolved by (1) the US and the UK voluntary offers to place their peaceful facilities under IAEA safeguards, thereby neutralizing claims of discrimination between weapons and non-weapons States in peaceful use and development and (2) by a provision in the NPT for States to negotiate safeguards agreements with the IAEA either individually or together with other States, thereby preserving a place for the E.URATOM system.

Even more important from the proint of view of institutional analysis of reprocessing plant safequards strategies are some of the characteristics of the NPT safeguards system as articulated in INFCIRC/153. This document reflects a change in approach from the earlier Agency safeguards system. Whereas the purpose of INFCIRC/66/Rev. 2 was to ensure that assistance provided by or at the request of the Agency was not used to further any military purpose, INFCIRC/153 has a more specific objective (Ref. 9, para. 28): to ensure "the timely detection of diversion of significant quantities of NM from peaceful nuclear activities to the manufacture of nuclear weapons or of other nuclear explosive devices....and deterrence of such diversion by risk of early detection." The basis of the regime is a systems-analytic approach that focuses on NM and the total nuclear fuel cycle rather than only facilities, emphasizing statistical measurement techniques, "materials balance areas" and "strategic points" for measurement. While this approach served the purpose of providing greater precision in defining the objective of safeguards and of rationalizing their application in a full fuel-cycle situation, it also contributed significantly to the achievement of an important goal of advanced non-nuclear weapon States: minimizing the perceived economic, technical, and political intrusion on national sovereignty that safeguards represented.

A second characteristic of the INFCIRC/153 system is its requirement that countries in which NPT safeguards are to be applied establish national systems of accounting for and control of NM and that the Agency purpose be to verify the findings of the national systems. In light of the ever-increasing quantity of NM flowing through national fuel cycles, this provision offers an ohvious opportunity for effective materials accounting and control management without overburdening an international agency with limited resources. On the other hand, emphasis on verification of national accounting and control systems keyed to predetermined strategic measurement points establishes another boundary condition on international intrusion in national nuclear fuel-cycle activities. For an analysis of these points, see Ref. 99.

Essentially, the safeguards philosophy of INFCIRC/153 separates the control of NM from accounting for it. 100 This corresponds to the emphasis on materials accounting as 
the safeguards measure of fundamental importance, with containment and surveillance as complementary measures, and the coincident circumscription of physical inspection activities. For inventory-dominated facilities such as spent-fuel storage ponds or nuclear power reactors, this approach appears to provide effective international diversiondetection safeguards. A similar conclusion, however, cannot be reached regarding the efficacy of conventional materials accounting (with associated shutdown for physical inventory), in terms either of sensitivity to diversion or timeliness of detection, when applied in large throughput-dominated facilities such as commercial reprocessing plants. For this reason and in light of the Agency goal of seeking to achieve a 1-3-wk detection time for diversion of $8 \mathrm{~kg}$ of plutonium, a near-real-tirne mattials accounting methodology has been postulated as a means of achieving improved safeguards in such a situation. $^{101,202}$

\section{Institutional Issues Concerning Near-Real-Time Accounting}

The question at this point is, assuming that it would meet the requisite criteria, what institutional issues arise with respect to the adoption and deployment of a near-real-time materials accounting system for LWR fuels reprocessing facilities.

1. Operator Acceptance. There is first the question of securing adoption by plant operators of a near-real-time accounting system. While INFCIRC/153 provides that States shall establish and maintain accounting and control systems for NM, it is not in a position to mandate that plant operators must adopt any particular systern of materials control. Nor can it insist that States impose standards that only can be met by implementation of near-real-time accounting, although a State might independently reach such 7 conclusion. Some States may feel that the cost factor involved in adopting a very comprehensive materials control system is not justified by any potential benefits in operational efficiency or quality control, or access to timely information regarding the process status of the plant. Or, they may conclude that materials control can be met just as effectively by the application of advanced containment and surveillance measures. Others may be concerned that Agency verification of such a system might reveal proprietary information of potentially significant commercial importance. States could, of course, just as readily reach opposite conclusions.

IAEA access to facility design information for the purpose of application of safeguards and for specifying MBAs and KMPs (Ref. 9, para. 46a,b) as well as physical inventory procedures (Ref. 9, para. 46c) could lead a State subject to such a review to conclude that national prerogatives might better be protected through adoption of some 
form of near-real-time accounting. In designating procedures for establishing the frequency and intensity of routine inspections, INFCIRC/153, para. 81c provides that facility characteristics, especially the extent to which the design facilitates verification of the flow and inventory of NM, should serve as a criterion. Implementation of a system that requires less frequent physical cleanout and generaily less onerous inspection could prove sufficiently attractive for the State to consider its adoption, especially if it would be convincing to the IAEA and its membership that diversion was not occurring and that Agency goals were being attained. In principle, near-real-time accounting can be adapted to existing operating facilities as well as to riew facilities (Ref. 9, para. 47).

On the other hand, unlike INFCIRC/66/Rev. 2, para. 30, 31, which gives the IAEA explicit authority in some instances to satisy itself that a facility design will fermit the effective applications of safeguards before safeguarded material is introduced, INFCIRC/153, para. 8 only asserts that the Safeguards Agreement "should provide that to ensure the effective implementation of safeguards...the Agency shall be provided with information concerning...the features of facilities relevant to safeguarding...material" and "Information pertaining to facilities shall be the minimum necessary for safeguarding nuclear material subject to safeguards under the Agreement." Although this does not derogate the possibility for the Agency to make suggestions regarding the adoption of certain materials accounting and control features, it does risk limiting the scope of the opportunity to do so.

2. IAEA Verification. A more important question is whether and how the I.AEA can effectively carry out its independent verification responsibilities vis-a-vis a near-real-time accounting system in a large-scale nuclear fuels reprocessing plant. The point of departure for the assessment of this issue is the safeguards philosophy embedded in INFCIRC/153 mentioned earlier: separation of materials control and materials accounting. Accountability reports and on-site inspections are key elements of the international safeguards or non-NPT safeguards. However, emphasis on materials accounting in the NPT safeguards situation has led to a basic change regarding the scope of physical access available to the Agency inspector. This is particularly salient when considering verification capabilities applied to a throughput-dominated facility where materials accounting is so linked to the process that it is a captive operator system. Near-real-time materials accounting systems entail complex data-generating and data-recording instrumentation that is potentially vulnerable to tampering and falsification, especially where the operator and instrumentation interface closely. From the point of view of the IAEA inspector, the question is how to involve the IAEA 
sufficiently in this interface or to ensure the transparency of the system so that the inspector can verify the integrity of the information to satisfy himself and the international community. For example, through his involvement in the measurement control program, the inspector would have the prerogative to recalibrate the instrumentation by rerunning samples drawn either from the sample archives or from a source unknowri to the operator. Conceptually and practically, insofar as physical access is concerned, this need appears to require an inspector-operator interface that goes considerably beyond the current practices in INFCIRC/153-type of arrangements.* Some aspects of the international verification problem are discussed in more detail in Sec. VI and App. $H$.

Article XII.A.6 of the Statute of the IAEA states that inspectors are to have access at all times to all places and data necessary to account for NM and to ascertain compliance with safeguards responsibilities. These rights are essentially maintained under the implementing provisions of INFCIRC/66/Rev. 2 (see Ref. 142). INFCIRC/153 provides that the actual number, intensity, and duration of inspections sho be kept to the minimum consistent with fulfillment of the Agency'ș responsibilities (রt1. 9, para. 81). It also provides that for any routine inspections access is limited to predetermined and agreed strategic points (Ref. 9, para. 76c). Ad hoc or special inspections offering broader access are possible, but only with prior consultation and approval of the State in question (Ref. 9, para. 77). The general provisions for safeguards implementation in Ref. 9, para. 6 emphasize the employment of instruments and other techniques and the minimizing of human intrusion.

From a technical point of view, the maximum assurance of the integrity of the data contained in records and reports by facilities or States would be provided by a complete independent materials balance by the IAEA with little or no reliance on national systems and with a possibility for maximum inspections. This approach strikes not only at the access limitations inherent in INFCIRC/153, but also at the very concept of international auditing of national systems of accounting and control and cannot, therefore, be

*It has been suggested 103 that one way to meet the verification problem might be to substitute the IAEA for the facility operator for the application of materials accounting procedures. While this could go far toward resolving the verification problem, by providing direct and first-hand information and facilitating early warning of material diversion or plant misuse, it also might raise the issue of who verifies the Agency-operator and ascertains that there is' no conspiracy. Additionally, this approach assumes adoption by the operator of a near-real-time accounting system and acquiescence to rather pervasive Agency involvement in plant activities--a rather large political assumption. Thus, while this approach might meet verification concerns, it would raise a host of other complex issues. 
considered a realistic alternative. However, a partial measure designed to reform the stringent constraints on facility access, while representing a departure from current practice in Agency-operator interface, could offer a significant improvement relative to materials measurement and verification. This is particularly true in throughputdominated facilities where even highly sensitive detection capability will not, because of inherent measurement uncertainty, fully assure that a diversion will be detected.

Nothing in INFCIRC/153, of course, prevents a State from negotiating liberal access arrangements with the IAEA if it so desires. Even liberal-minded States might be reluctant to do so, however, for reasons of protecting proprietary and commercial information that could bear on their compelitive position as a supplier of reprocessing services, especially if competitors were not submitting their facilities to the same conditions.

One element, the continuous presence of IAEA inspectors in the facility, does not appear to present a problem. The formula for defining the maximum routine inspection effort in para. 80 of INFCIRC-153 would seem sufficient to accommodate continuous inspection at both the small and large-scale reprocessing plants. Thus, any modification in safeguards agreements involves principally the scope of access available to the inspector.

In sum, it would appear that independent verification of near-real-time materials accounting (or of any other identified accounting system) requires broader access by Agency inspectors in the facility under safeguards than is current practice. This would entail a change of philosophy regarding the level of detail at which materials accounting is verified by the IAEA. At first approximation, it seems that this is as much a matter of practice coupled to some modification in Subsidiary Arrangements between States and the IAEA as it is a matter of revision of basic documents. Optimally, the IAEA should not only have broad access rights to observe plant operations and to undertake independent verification activities on a random basis in large throughput-dominated facilities, but also early involvement in facility design and verification of the construction of those facilities so as to ensure inter alia the integrity of its containment characteristics. These measures could contribute significantly to enhancing Agency, and presumably clientele, confidence in the reliability and integrity of safeguards as applied to reprocessing plants. In the last analysis, States and operators must feel persuaded of the value of the system to them for internal materials accounting purposes, and that the costs incurred in terms of increased Agency presence in sensitive facilities are justified by their nonproliferation benefits. 


\section{E. International Management Strategies}

Whether States will be persuaded of the materials management merits of near-real-time accounting and move to adopt such a system is another matter. So also is the question of whether and to what extent near-real-time accounting meets nonproliferation concerns associated with the presence, under national control, of sensitive NM such as plutonium.

The technical capabilities of near-real-time accounting systems to meet sensitivity and timeliness criteria are dealt with in Sec. $V$. It should be noted here, however, that materials accounting, whether conventional or more sophisticated, has inherent limitations as a safeguards measure. While materials accounting methodology can be improved, and the magnitude of the absolute uncertainties in the materials balance of spent-fuel reprocessing plants reduced, the inherent limits in measurement methodology cannot be completely eliminated either through subdividing the facility into smaller and rnore discrete units (unit process areas) or through the application of more sophisticated statistical techniques.

Those holding such a view may be concerned lest the international community be lulled into a false sense of security as a result of interpreting improved accounting as tantamount to resolving the sensitive materials problem. Others may conclude that whatever merits real-time accounting may have for domestic materials management, alternatives such as enhanced containment and survejllance, in conjunction with conventional materials accounting, offer an equally sound or even preferred safeguarts approach for international purposes. INFCIRC/153, of course, ascribes to containment and surveillance an important complementary safeguards role; it does not, however, regard them as substitutes for materials accounting (Ref. 9, para. 29). Just what will be the balance between these methods will depend on evolving political decisions regarding the nature of the proliferation risk and the consequent definition that ought to be given to particular safeguards goals and objectives. This in turn probably will depend on the characteristics of the institutional arrangements applied to plutonium production and stockpile facilities.

Even if near-real-time accounting were to be widely accepted as a significant improvement for reliable international safeguards for reprocessing plants, safeguardsrelated proliferation problems would remain. Plutonium and plutonium-producing facilities are vulnerable to conversion to illicit uses. Diversion of plutonium from a fuel-cycle facility is only one pathway that might be followed. Others that raise questions regarding the efficacy of safeguards include (1) the diversion from, or seizure of, stockpiles of separated plutonium by national authorities or by subnational thieves or 
terrorists; (2) the seizure by national authorities of a safeguarded reprocessing plant for the purpose of converting it to provide material for a nuclear weapons program; (3) the decision by national authorities to abrogate or withdraw from commitments to place national facilities and stocks of material under international safeguards and to adhere to international commitments regarding the use of such facilities and materials either to pursue a weapons development program directly (as noted above) or to maintain the option eventually to do so. 97,104

International safeguards cannot, and were not, intended to cope with such problems. Yet the improvement of diversion-detection sensitivity and timeliness could lead to pressures toward widespread dissemination of sensitive nuclear facilities and materials on the ground that effective (i.e., sensitive and timely) safeguards are in place. These other risks (abrogation, withdrawal, seizure) must be recognized as distinct from the diversion risk and in need of being dealt with other than through the application of improved diversion-detection capability. But the two types of problems must be recognized as inextricably related to one another, as reflecting the highly interdependent nature of nuclear fuel-cycle risks, and as requiring compatible and mutually reinforcing responses.

The problem really is one of plutonium management, not just reprocessing safeguards. Even improved diversion-detection safeguards, while necessary, are not alone sufficient for maintaining the traditional barrier between peaceful and military explosive applications of nuclear energy where large-scale presence and use of plutonium and plutonium-producing facilities are involved. The adequacy of this barrier depends partly on strengthened and improved safequards, and partly on additional institutional measures. The question is what are the measures that usefully or appropriately might reinforce deployment of near-real-time accounting diversion safeguards in spent-fuel reprocessing plants.

Two kinds of institutional measures are relevant here: those involving structural arrangements related to the back end of the nuclear fuel cycle and those establishing normative rules of the game with respect to the development, dissemination, and use of sensitive facilities and materials.*

\footnotetext{
*The discussion that follows is not intended as a detailed analysis of alternative strategies, but only to point up certain potentially useful and promising institutional arrangements that might reinforce conventional institutional safeguards. It is beyond the scope of this discussion to deal with economic or managerial considerations that would need to be satisfactorily resolved for certain institutional arrangements to be widely accepted.
} 
If we assume (1) that some reprocessing will be carried out at some meaningful level of activity in the context of the global nuclear fuel cycle, and (2) that there is widespread recognition that, although not the optimal path to nuclear explosives, diversion from the commercial fuel cycle does pose a significant proliferation risk, then we can identify certain potentially important measures and rules that might supplement advanced diversion safeguards and provide added nonproliferation protection.

In particular, it would seem appropriate (1) to link spent-fuel reprocessing to the development of an international plutonium storage arrangement and (2) to consider multinational ownership and management for reprocessing plants as a means of reinforcing safeguards and minimizing the risk of abrogation or national seizure by the host state. At the same time this measure could reduce the perceived need for the spread of nationally owned and operated facilities by providing added assurance of supply and service, and take advantage of state-of-the-art technology and of the economies of scale associated with large-scale activities. In this context, it is possible (3) to visualize an extension of the functions of the reprocessing facility to include other responsibilities ranging from spent-fuel storage to conversion and fuel-fabrication activities and integrally linked to an international plutonium storage regime, although other less comprehensive arrangements might also represent important nonproliferation contributions.

1. International Plutonium Storage. Under the assumptions specified above, an international plutonium storage regime is perhaps the most relevant institutional measure in support of nonproliferation goals. Ideally, all plutonium produced in the global peacefuI nuclear fuel cycle would, from the moment of its separation from spent fuel, come within the purview of the regime. Basically, the regime would consist of rules regarding deposit, release, use, and disposition of the plutonium; include physical storage sites under appropriate international safeguards and physical security arrangements; and establish rules regarding the handling and transport of released plutonium.

To be meaningful in nonproliferation terms an international plutonium storage regime would have to be comprehensive. This means not only international confidence in the integrity of the storage sites and administration of the regime, but also systematically applied rigorous rules regarding the release of plutonium to national use. Release criteria, therefore, would have to cover such matters as how much material is released at any given time, to whom it is released, the purposes for which it is released, the safeguards and physical security arrangements that would apply to the reieased material, and the manner in which such material, once used, would be disposed of. To avoid 
build-up of national plutonium stockpiles, rules might have to be evolved to the effect that release must be timed to actual need for insertion in a research or power reactor and that both insertion and reactor startup must take place under the scrutiny of international officials. Rules also would have to be evolved to ensure that the requested releases were de facto legitimate and that the use of plutonium was keyed to an on-going, visible and credible peaceful research or power reactor program. This in turn means achieving some consensus on when in the State's fuel-cycle development, taking account of the size of the electrical grid, the role assigned to nuclear power, and the scope of the research and development effort, plutonium-based fuel cycles are appropriate. States seeking release of material would have to ensure the regime that materials would not be used for developing nuclear explosive devices, would be subject to international diversion-detection safeguards, and would be disposed of under conditions agreed with the regime authorities.

To be acceptable to the international community, an international plutonium storage regime would have to be structured to give confidence that legitimate peaceful activities would not be impaired and that material would be availahle under agreed terms and conditions on a timely basis consistent with actual operating and research needs of the national program. Acceptability would be enhanced to the degree that such a regime encompassed both existing and to-be-produced stocks of plutonium. Universal, or near-universal application of the regime would help dispel concern about discrimination in the peaceful uses of nuclear energy. The possibility for maximum regine coverage might be increased if clear and concise understandings were reached and if some of the advanced nuclear technology States were to consider internationalization of some plutonium research reactor facilities. This would provide less sophisticated States an opportunity to participate in nuclear research under favorable technological circumstances and without having to replicate on a national basis existing research activities.

Certain normative rules of conduct should accompany the development of an international plutonium storage regime. If plutonium presents problems that can be managed, but not eliminated other than through global forsaking of plutonium-related activities, then the establishment of an international storage regime should be regarded as an important contribution to, but not a complete solution for, the proliferation problem. In addition, it should be generally agreed that the existence of a regime should not justify unnecessary reprocessing activity, should not be used as an excuse for the premature deployment of new facilities or the expansion of existing ones, and should not encourage unnecessary accumulations of stockpiled plutonium. Rather, plutonium separation should 
be explicitly related to legitimate research and power reactor needs. These principles apply as well to both the multinational and extended scope concepts discussed below.

2. Multinational Ownership. Multinational ownership and management of reprocessing facilities represents an institutional arrangement with potential for helping to reconcile energy security and nonproliferation values. See, for example, the papers on multinational ownership in Ref. 105. While not panaceas, multinational arrangements do have some important and attractive features: they offer the possibility of rencing the risk of seizure of sensitive facilities or abroqation of agreements for operation of the facilities by considerably increasing the cost of doing so to the host country. Furthermore, they contribute to the goal of reducing national control of, and direct access to, plutonium by removing the justification for widespread national facilities by offering access on potentially attractive terms to large-scale facilities employing advanced technologies and capitalizing on the associated economies of scale. If integrally related to an international plutonium storage regime, they have added nonproliferation significance.

Multinational alternatives might, of course, stimulate demands for larger-scale reprocessing and might facilitate a broader dissemination of sensitive technology, particularly with regard to plutonium handling. On the other hand, they would appear to represent a reasonable mid-point between (a) nationally owned and operated facilities subject to international safeguards and possibly part of an international plutonium storage regime, and (b) more far-reaching efforts to internationalize sensitive fuel-cycle activities, for example, by charging the IAEA or a newly created international agency with responsibility for owning, operating, and safeguarding reprocessing plants on behalf of the international community. The multinational approach, by offering countries an opportunity to share directly in management and/or operation, would ensure those in need of access to required services on a timely and assured basis while removing the dependency that would result from reliance solely on negotiating for services on the international market. It also would enable these countries to play a role in basic policy, e.g., determining the price to be charged for the services or negotiating terms and conditions with an international plutonium storage regime. These measures, while substantially reducing concerns about discrimination and dependence, would help limit the number and location of reprocessing facilities and thus contribute to nonproliferation goals.

Multinational participation in a reprocessing plant would have safeguards value as well. Even if a multinationally owned and managed plant were to have near-real-tims 
accounting safeguards, the presence of several nationalities, presumably with nonproliferation interests and strong nonproliferation commitments, would help reinforce the credibility of the safeguards system. It would, of course, be important that the multinational facility be composed of countries with a genuine adversity of interest with respect to the acquisition of nuclear explosives by any of them. 106 This is important not only to the performance of proliferation functions but to global perceptions of the institution's assurances as well. It has been suggested that an alternative might be to lodge all materials accounting and safeguards functions in the IAEA as mentioned earlier, but this would seem less important in the case of a multinational plant and probably would be more difficult to implement than some operator-based multinational materials management. 103

Like most potential measures to strengthen nonproliferation, the multinational approach leaves something to be desired. There is rio assurance, for example, that a participant might not decide to withdraw after gaining operational experience and build a national (possibly unsafeguarded) reprocessing facility. Nor, unless the multinational charter so provided, would anything a priori prevent a participant from building a parallel national facility while maintaining membership in the multinational consortium. If not linked to some kind of international regime for plutonium management, the multinational approach might only succeed in broadening the arena of States in control of sensitive material. It is for such reasons that normative rules of the game such as those mentioned earlier would have to be an integral part of any arrangement to which the international community agreed.

3. International Fuel-Cycle Centers. The third possibility mentioned above is the extension of the functions of the reprocessing facility to include other responsibilities such as fuel fabrication and possibly spent-fuel storage. Conceptually, this arrangement could be either a national facility under international safeguards, or a national facility under an international regime crafted to accommodate the existence of some national reprocessing facilities, or a multinational facility of the type just discussed. Its distinguishing feature would not be the scope of its membership, but the range of its functional responsibilities. If an international plutonium storage regime were to exist, such a facility might be designated as a storage site subject to all the terms and conditions required by the regime for storage, access, withdrawal, use, final disposition, transportation, safeguards, and the like. 
The notion of extended functional scope has a number of nonproliferation advantages. First, it helps reduce the risk of the misuse of material. Fabricated fuel elements represent a lower proliferation risk than does separated plutonium. While a recipient of fabricated fuel could process the fuel elements to extract the contained plutonium, there is a high probability of timely detection of such an event. Furthermore, shipment of fabricated fuel elements could be timed to rieet actual needs for identified legitimate peaceful activities thus avoiding the possibility of substantial stockpiles of material with contained plutonium coming under the direct jurisdiction and control of a State. Second, by including fuel fabrication among facility responsibilities the risks associated with the shipment of plutonium in a form highly attractive to a potential divertor would be eliminated. Transportation is one of the weaker safeguards links in the international nuclear fuel cycle, and steps that would reduce those risks will become increasingly important as and when a plutonium commerce on a significant scale emerges. Finally, this approach supports the idea of reducing proliferation risks through the reduction in the number and dispersion of sensitive fuel-cycle activities.

The concept of reqional international fuel-cycle centers to minimize proliferation risks has been studied by the IAEA, ${ }^{34}$ and contributions to safeguards have been a consideration in US studies of nuclear fuel-cycle centers. ${ }^{107}$ An important feature of collocation of reprocessing, conversion, and fuel-fabrication facilities is the potential for using the conversion facility, with enhanced safeguards, as a "buffer" between the supply-driven reprocessing plant and the demand-driven fabrication facility (Fig. 24), ${ }^{2,8}$ referred to as the BCF concept. The conversion facility could be expanded to include product storage from the reprocessing plant and oxide storage for the fabrication plant. In this way, the safeguards controlling authority could more effectively monitor and verify production and consumption rates, and maintain cognizance of the disposition of all fissile materials produced by the complex.

The same kinds of caveats apply here as elsewhere: States must be persuaded of the security, political, and economic merits of such enterprises if they are to participate. It is, therefore, important to develop alternatives to national sensitive nuclear facilities in such a way that concerns about discriminatory treatment in the peaceful fuel cycle are allayed; the economic, commercial, and managerial merits of the arrangement remain identifiable, clear, and attractive; and the nonproliferation benefits are seen to outweigh the costs attached to proceeding with alternative institutional arrangements.

Each of the institutional arrangements identified here is amenable to such analysis but the detailed benefits and costs of each lie beyond our present needs and purpose. It 


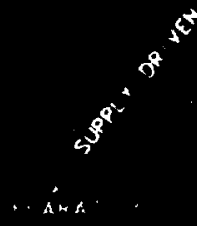

* Tha í stima, ANI, BI FNI : ${ }^{\prime}$.

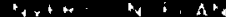 , wh It in it,}

$$
\begin{aligned}
& \text { 1. XIIf ', T/RA', } \\
& \text { ANf } \mathrm{H}_{1} \mid \mathrm{NP} ! \mathrm{Nr} \text {, }
\end{aligned}
$$

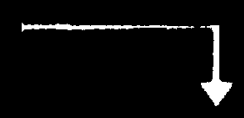

As.

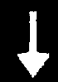

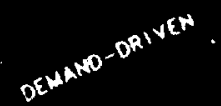

Fig. 24. The Bonded Crucial Facility (BCF). 
bears emphasis that none of the arrangements discussed relieves us of the responsibility to seek to improve international safeguards. Thus, the development of more sensitive and timely diversion-detection methodologies as represented by near-real-time accounting, and also through effective use of surveillance and containment techniques as mandated in INFCIRC/153, must be continued. 
VIII. RESULTS, RECOMMENDATIONS, CONCLLUSIONS

This report addresses the effectiveness of materials accounting in providing international safeguards for reprocessing and conversion facilities. The applicability of materials accounting to safeguarding future high-throughput (1500 MTHM/yr) and current small (210 MTHM/yr) reprocessing plants is evaluated. The role of the IAEA and of the State in the design and operation of the system is describer.

\section{A. International Safeguards Requirements}

The operator's NM accounting system and the Agency verification program described here are based on considerations of Agency requirements; the State's sovereignty, capabilities, and proprietary rights; and the technology available to the operator and to the Agency.

1. Agency Requirements. The basis for international safeguards arrangements is described in INFCIRC/153 (Ref. 9) for nations party to the NPT and in INFCIRC/66 (Ref. 35) for non-NPT nations, and is reviewed in Sec. IV for the operator's system and Sec. VI for Agency verification.

The objective of international safeguards, as declared by these documents, is the "...timely detection of diversion of significant quantities of nuclear material from peaceful nuclear activities..." The emphasis is on "...the use of materials accountancy as a safeguards measure of fundamental importance, with containment and surveillance as important complementary measures..." ${ }^{13}$ The manner and frequency of inspections for compliance are negotiated between the IAEA and the host nation on a case-by-case basis and are documented in the so-called "Subsidiary Arrangements" and "Facility Attachments."

By materials accounting the IAEA seeks to obtain to a satisfactory degree of confidence (now accepted as $95 \%$ ) that a significant amount of NM is not diverted from a materials balance area over a specified period. INFCIRC/153, para. 31 also requires that the IAEA "shall make full use of the State's system of accounting for and control of all nuclear material subject to safeguards under the Agreement, and shall avoid unnecessary duplication of the State's accounting and control activities." This statement and para. 7 set the tone of international safeguards: the IAEA shall verify findings of the State's system. At the same time, para. 6 requires that the Agency "take full account of technological developments in the field of safeguards, ..." The phrase most descriptive of 
the IAEA safeguards ideal seems to be "simultaneously effective and nonintrusive through technological sophistication."

These documents do not specify significant quantities or detection times. Values of $8 \mathrm{~kg}$ of plutonium with a detection time of 1-3 wks for $\mathrm{PuO}_{2}$ have been proposed for detecting abrupt diversion, and $8 \mathrm{~kg}$ in $1 \mathrm{yr}$ for protracted diversion. The requirements for low-enriched uranium are $75 \mathrm{~kg}$ of contained ${ }^{235} \mathrm{U}$ in 1 yr. ${ }^{36}$

The IAEA's accounting activities depend fundamentally on the State's system of accounting; the MMAS is owned and operated by the State or a licensee of the State. The IAEA is required to verify independently the State's system and interacts with the State in a negotiated but well-defined manner.

2. The State's Requirements. The State's safeguards system must meet IAEA requirements; however, the Agency does not specify a standard form for the State's materials accounting system in INFCIRC/153 or INFCIRC/66. The Agency's verification procedures for the State's safeguards system are negotiated on a facility-specific basis between the IAEA and the State, and are defined for that facility in the safeguards Agreement. Under the safeguards Agreement the State provides facility design information to the Agency relevant to NM accounting, including descriptions of existing and proposed procedures for accounting.

Because information provided by the State under these agreements may be proprietary, the IAEA is bound to maintain the confidentiality of this information. Additionally, it is conceded that the safeguards system cannot intrude unduly on process operations or provide economic hardships to the State. The State's safeguards system should meet IAEA criteria that are consistent with applications in other States.

3. Institutional Arrangements. Agency requirements for timely detection of diversion activities and the State's insistence on equal treatment, retaining proprietary information, noninterference with process operations, and maintaining a competitive position in international commerce frequently give rise to conflicting opinions on what constitutes effective safequards.

International requirements for prohibiting or minimizing the spread of nuclear weapons should, in principle, override national claims of sovereignty concerning process operations, but they cannot always be successfully negotiated. Criteria for safeguards effectiveness must be based on realistic technical measures so that the Agency can verify rapidly and with a high degree of assurance the results from the State's NM accounting system. In turn, the State's accounting system must incorporate up-to-date equipment 
and technical measures. The requirement that international safeguards be applied without prejudice to weapons or non-weapons States anr not provide a competitive advantage to one State over another is a further complication that may be difficult to satisfy in practice.

\section{B. The Operator's Safeguards System}

1. Safeguards System Structure. The structure of the State's advanced safeguards system is desciibed in Sec. IIl. The safeguards system comprises several subsystems such as safeguards coordination (including safeguards management, data collection, and data analysis), materials measurement and accounting, physical protection, and process monitoring. These stsbsystems and their interfaces with each other and the related facility operations of process control and plant management are described in Sec. IIl.

2. The Materials Measurement and Accounting System. The conceptual design of the advanced MMAS for the reference facilities is hased on a combination of conventional and near-real-time (dynamic) accounting techniques incorporating state-of-the-art measurement methods. Conventional MBA accounting methods are augmenter by unit process accounting, where the MBAs are partitioned into discrete accounting areas called UPAAs. The proposed measurements and estimates of their precisions and accuracies are hased on experience with currently avajlable instrumentation or on modest extrapolations of current measurement technology (Apps. K, L). Conventional process cleanoust and physical inventory are performed periodically to establish fiducials or reference points for the dynamic accounting system.

Flow and inventory KMPs for the large and small reprocessing plants and the conversion plant are identified in Sec. IV. Conventional accounting relies on proesess shutdown for inventory measurement. Dynamic accounting adds at-line and on-line NDA measurements to draw more timely materials balances.

The basic accounting strategy is to partition the facility into MBAs. For this study the MBAs in the large reference facility are:

MBA 1: fuel receiving, storage, chop, and leach;

MBA 2: chemical separations process;

MBA 3: uranium nitrate storage;

MBA 4: plutonium nitrate storage;

MBA 5: conversion process; and

MBA 6: plutonium oxide storage. 
The MBAs in the small reference facility are similar to those of the large facility but include only MBAs 1-4 because a conversion process has not been selected for the reference facility.

Under dynamic materials accounting, a UPAA can include the entire MBA or portions of the MBA. The distinguishing feature of a UPAA is that materials balances are closed in near-real-time by measuring all significant materials flows and in-process inventories. By comparison, conventional materials balances are closed once each shutdown, cleanout physical inventory.

3. Effectiveness of the Materials Measurement and Accounting System. Table $X \times X I$ lists ${ }^{235} \cup$ materials balance standard deviations in the process MBAs of the reference facilities. The materials balance standard deviations are based on a shutdown and cleanout physical inventory and were calculated using state-of-the-art measurement techniques reviewed in the report. A range of these materials accounting sensitivities will be degraded if high-quality measurements cannot be obtained. Conversely, the sensitivities could be irnproved if measurement errors can be controlled more effectively by identifying the dominant error sources and establishing effective measurement control procedures. Note that the diversion-detection sensitivity is $\sim 3.3$ times the materials balance standard deviation for a $95 \%$ detection probability and a FAP of $5 \%$. From our analysis, we conclude that:

- For ${ }^{235} \mathrm{U}$ the proposed IAEA criteria for diversion sensitivity and timeliness probably are attainable by conventional materials accounting if rigorous materials measurement control programs are instituted.

TABLE XXXI

URANIUM-235 MATERIALS ACCOUNTING IN THE REFERENCE FACILITIES

\begin{tabular}{|c|c|c|}
\hline Accounting & $\begin{array}{c}\text { Materials Balance St } \\
\text { Large Reference } \\
\text { Facility }\end{array}$ & $\begin{array}{c}\text { dard Deviations }(\mathrm{kg}) \\
\text { Small Reference } \\
\text { Facility }\end{array}$ \\
\hline $\begin{array}{l}\text { Period } \\
\text { (months) }\end{array}$ & $\begin{array}{c}\text { Chemical Separations } \\
\text { Area }\end{array}$ & $\begin{array}{c}\text { Chemical Separations } \\
\text { Area }\end{array}$ \\
\hline 3 & $6.3-10.4$ & $0.8-1.3$ \\
\hline 6 & $11.6-20.3$ & $1.5-2.6$ \\
\hline 12 & $22.3-40.1$ & $2.8-5.1$ \\
\hline
\end{tabular}


Table $X X X I I$ summarizes plutonium materials balance standard deviations for the process MBAs of the reference facilities. Additional accounting strategies are discussed in Sec. $V$. Materials balance standard deviations for accounting periods $\leq 1$ month are based on in-process inventory measurements while the process is operating. In each case, a range of uncertainties is given for the entire process area. The cases considered range from best-case estimates of contactor in-process inventories with 2-day recalibrations of feed and product flow and concentration measurements to worst-case estimates of in-process inventories and no recalibrations within the accounting periods. Note that the diversion-detection sensitivity is 23.3 times the materials balance standard deviation for a 95\% detection probability and a FAP of $5 \%$.

In examining the materials accounting sensitivities we further conclude that for plutonium:

- In the large chemical separations process area the proposed IAEA criteria for detecting abrupt diversion probably can be met if a rigorous measurement control program is undertaken.

- In the large chemical separations process area the proposed IAEA criteria for detecting protracted diversion cannot be met by any known system because the goal quantity is only $0.05 \%$ of the annual plant throughput.

- In the conversion process area the proposed IAEA criteria for detecting abrupt diversion probably can be met.

- In the conversion process area the proposed IAEA criteria for detecting protracted diversion cannot be met by any known system because the goal quantity is only $0.05 \%$ of the annual plant throughput.

- In the small chemical separations process area proposed IAEA criteria for abrupt diversion probably can be met.

- In the sinall chemical separations process area the proposed IAEA criteria for protracted diversion may be achievable.

\section{Design Criteria and Identified Problem Areas}

The safeguards materials accounting systems described in this report were established for existing or designed facilities; therefore, safeguards criteria did not influence facility design. This study has identified several areas where modifications in the plant or process design could improve the State's materials accounting system and the Agency's verification system (App. $H$ and Sec. VI). These areas are summarized below. 
TABLE XXXII

PLUTONIUM MATERIALS ACCOUNTING IN THE REFERENCE FACILITIES ${ }^{a}$

Large Reference Facility

\begin{tabular}{|c|c|}
\hline $\begin{array}{l}\text { Materials Balance } \\
\text { Frequency } \\
\end{array}$ & $\mathrm{g}(\mathrm{kg} \mathrm{Pu})$ \\
\hline $1 / 2$ days & $2 . i-2.4$ \\
\hline$-\infty$ & --- \\
\hline $1 / 2$ days & $2.5-2.8$ \\
\hline $1 / 2$ days & $3.0-3.6$ \\
\hline $1 / 2$ days & $4.0-5.7$ \\
\hline--- & -- \\
\hline $1 / 3$ months & $7.5-14.0$ \\
\hline $1 / 6$ months & $13.0-26.8$ \\
\hline $1 / y r$ & $23.8-52.7$ \\
\hline
\end{tabular}

Conversion Area

\begin{tabular}{c} 
Materials Balance \\
Frequencyc \\
\hline
\end{tabular}

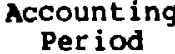

1 balance

1 day

1 wk

2 wk

1 month

2 months

3 months

6 months

1 yr
$1 / 2.88 \mathrm{~h}$

$1 / 2.88 \mathrm{~h}$

$1 / 2.8 ; \mathrm{h}$

$1 / 2.88 \mathrm{~h}$

$1 / 2.89 \mathrm{~h}$

$1 / 2$ months

$1 / 3$ months

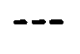

g ( $\mathrm{kg} \mathrm{Pu}) \mathrm{d}$

0.40

0.43

$0.70-0.85$

$1.1-1.4$

2.0-2.4

4. $0-4.9$

$5.9-7.2$

$--$

$--$
Small Reference Facility Chemical Separations Area Materials Balance Frequencye

O (kg Pu)

$1 /$ day

$0.25-0.38$

$0.25-0.38$

$0.30-0.43$

$0.36-0.52$

$0.48-0.77$

$1 /$ day

1/day

$-\infty$

$$
---
$$

$0.94-1.9$

$1 / 3$ months

1.7-3.7

$1 / y r$

dMaterials balance standard deviations for accounting periods sl month are based on in-process inventory measurements while the process is operating. Materials balance standard deviations for accounting periods $>1$ month are based on a shutdown and cleanout physical inventory. Ranges are given for the cases that are considered in Sec. V. Unless otherwise noted, the accounting strategies shown here use chemical analysis techniques for the feed and product batches.

bynamic materials balances taken every 2 days include five input accountability batches and two product batches.

CDynamic materials balances taken every $2.88 \mathrm{~h}$ include one input accountability batch and three product batches.

$d_{\text {An }}$ on-line measurement technique for the product batches is used in the accounting strategy shown here. This measurement is replaced by the result of chemical analysis of a sample $8 \mathrm{~h}$ after the batch is produced.

edynamic materials balances taken every day (immediately after the product evaporator is drained) include two feed accountabllity batches and one product batch. 
1. NDA on Spent Fuel. Nondestructive assay methods should be considered for verifying fuel burnup and/or fissile content of irradiated fuel received at or stored ir, the fuel receiving and storage area (App. I).

2. Input Accountability. The accountability tank and accounting procedures should be designed to provide the most accurate analysis and verification of NM input to the accountability tank. If accountability tank heels and recycle material degrade the quality of isotopic correlation analyses (App. M), provision should be made for obtaining samples directly from the dissolver. Recycle nitric acid $\left(\mathrm{HNO}_{3}\right)$ containing plutonium should not be used in the dissolver or accountability tank.

To minimize the effect of contained particulates, the centrifuge should be located ahear of the accountability tank.

3. Solvent-Extraction Contactors. Uncertainties in contactor inventory have been identified as a limiting factnr in short-term detection of diversion from the process area of reprocessing plants. Improved models of contactor operation would upgrade in-process inventory estimates (App. J). Where practical, pulsed columns and mixer-settlers should he replaced with centrifugal contactors to minimize uncertainties in in-process inventory and to decrease the time required for obtaining a drain-down inventory.

4. Codecontamination Cycle. Codecontamination can be improved by increasing the number of stages in the HA contactor or by providing an additional decontamination cycle. The reduced radinactivity would facilitate plutonium concentration measurements at the input to the PPP.

5. Process Tanks. All process tanks containing significant quantities of NM should be instrumented for liquid level, density, acidity, and temperature measurements, and feed tanks should include flow-measurement devices. These process data facilitate estimating in-process inventories.

6. Process Buffer Tanks. Installing appropriately sized buffer tanks between major process areas decouples and thereby assists in defining UPAAs. Decoupling could allow process interruption in the plutonium purification area without disrupting headend operations. 
7. Product Concentration. Collocation of the reprocessing and conversion facilities eliminates the need for the plutonium concentrator at the output of the reprocessing plant. The plutonium nutput concentration of the final plutonium purification cycle could be tailored to the requirements of the conversion process.

8. Process Stream Measurements. Flow meters capable of measuring flow rates to $1 \%$ or better in major process streams and $5-10 \%$ in waste streams should be installer. In-line or at-line $c$ - isctors should be incorporated to measure plutonium concentrations to $1 \%$ in process streams and $5-20 \%$ in waste streams.

9. Instrument Accessibility. All instruments that are required for conventional and dynamic accounting should be accessible for maintenance and recalibration. All sensors should be tamper resistant or tamper indicating.

10. Redundant Instrumentation. Redundant flow, volume, and concentration instruments should be considered at KMPs.

11. Computer Data Handling. All data acquisition and reduction should be performed by computer, and all in-line and laboratory instruments should be linked to the computer.

\section{Recommendations and Conclusions}

As a result of this study we propose recommendations that could improve safeguards for reprocessing and conversion facilities operated under an international inspection and verification program.

1. Institutional Arrangements. International agreements for the application of safeguards to reprocessing and conversion facilities should take into consideration requirements for improved diversion detection as well as national rights and prerogatives. This is particularly true in the high-throughput facilities that are expected to be on stream in the latter part of this century. Improved technology for international inspection and verification activities must be provided to all facilities equitably and without prejudice.

2. Process Design. Safeguards design considerations for new facilities should be incorporated at the facility design stage and must rank with health, safety, and economic 130 
considerations. Process design features that could improve materials accounting are discussed in App. $C$ and Ser. VIII.C and emphasize minimal unmeasured in-process inventories and an adequate measurement system.

3. Materials Accounting. The materials accounting system for any facility should be designed by using a systematic and detailed analysis of process design and operating parameters (App. F). The MMAS should be as simple as possible, but capable of meeting IAEA criteria for sensitivity and timeliness.

Dur analysis shows that an extensive measurement control program will be required to meet some of the proposed IAEA diversion-detection criteria. Conventional accounting probably can meet proposed accounting criteria for low-enriched uranium. Near-realtime accounting is required to meet the criteria for detection of abrupt diversion of plutonium. No known system will meet the criteria for detecting protracted diversion of plutonium in large facilities if the same goal quantity is extended over an entire year's operatjon.

4. Reactor-Reprocessing Plant Correlations. Isotopic correlation techniques should be considered as a verification aid between the reactor and reprocessing plant. The techniques and theory of these techniques require further refinement (App. $M$ ).

5. Verification. Continuous verification involving on-site inspectors will be required for future high-throughput facilities, and continuous or hiqh-frequency inspection is recommended for the smaller present-day plants. Verification activities may vary from checking seals and reports and monitoring NM movement in item control areas such as the fuel receiving and storage area and the product storage area to performing independent. analyses of random samples from process areas. Agency inspectors should have some limited on-site analytical capability (conventional and/or NDA) to perform rapid verification analyses. The measurement control program, including the maintenance and selection of standards, should be under the quidance of Aqency inspectors. Analytical and NDA instruments should be coupled to Agency computers with verification that data have not been altered (App. H, I). All instruments should be tamper resistant or tamper indicating.

The Agency should have its own on-site computer for analyzing the verification data. The Agency computer may share data with the operator's computer system, but the operator may not have access to the Agency's programs. 
5. Integration of Materials Accounting with Containment and Surveillance. The design of the materials accounting system should take into consideration capabilities and limitations of containment and surveillance systems (App. O). Conventional accounting, supported by improved containment and surveillance techniques probably will be required in item control areas such as the fuel receiving and storage, the plutonium nitrate, and the plutonium oxide product storage areas. An improved MMAS, protected by an improved surveillance system, will be required for the separations process and the conversion process.

7. Demonstration. The concepts and techniques described in this report should be implemented in existing facilities to demonstrate their applicability and to quantify their effectiveness. The development of the near-real-time NM accounting system at the BNFP should be continued, and the study should be extended to incorporate systems and verification concepts discussed in this report. 


\section{ACKNOWLEGMENTS}

The authors gratefully acknowledge the helpful suggestions and criticisms of R. G. Gutmacher, C. A. Ostenak, D. Stirpe, C. C. Thomas, Jr., and W. J. Whitty of the $Q-4$ staff. A. L. Baker and E. P. Schelonka contributed to the system reliability evaluations. A. L. Baker and D. P. Martinez assisted in development of the modeling and simulation computer programs. The staff of AGNS kindly provided details of the BNFP not available in the cited literature and critically reviewed the draft of the report. Information on the Tokai-mura facility was obtained from K. Ikawa of JAERI and K. Nakajima of PNC. Typing and correcting of numerous revisions was performed by Sharon Klein. The report could not have been assembled without the capable assistance of Margaret Scott, Kay Eccleston, Lucille Bonner, Mary Judy Roybal, and R. M. Tisinger.

The authors thank the members of the AGNS staff; $K$. Ikawa of JAERI; K. Nakajima of PNC; W. A. Higinbotham and E. V. Weinstock of BNL; P. J. Persiani of ANL; C. A. Bennett, T. McSweeney, 5. W. Heaberlin, R. Schuller, and F. Morris of BNML; W. V. Goeddel of General Atomic Company; D. F. Bowersox and S. T. Hsue of LASL; J. E. Lovett of the IAEA; R. Erickson of the Savannah River Office of DOE; and G. A. Hammond of DOE/OSS for the critical reviews and comments that led to improvements in the final draft. The work was supported by the Office of Safeguards and Security of the Department of Energy. 


\section{REFERENCES}

1. E. A. Hakkila, D. D. Cobb, H. A. Dayem, R. J. Dietz, E. A. Kern, E. P. Schelonka, J.P. Shipley, D. B. Smith, R. H. Augustson, and J. W. Barnes, "Coordinated Safeguards for Materials Management in a Fuel Reprocessing Plant," Los Alamos Scientific Laboratory report LA-6881 (September 1977).

2. H. A. Dayem, D. D. Cobb, R. J. Dietz, E. A. Hakkila, E. A. Kern, J. P. Shipley, D. B. Smith, and D. F. Bowersox, "Coordinated Safeguards for Materials Management in a Nitrate-to-Oxide Conversion Facility," Los Alamos Scientific Laboratory report LA-7011 (April 1978).

3. J. P. Shipley, D. D. Cobb, R. J. Dietz, M. L. Evans, E. P. Schelonka, D. B. Smith, and R. B. Walton, "Coordinated Safeguards for Materials Management in a Mixer-Oxide Fuel Facility," Los Alamos Scientific Laboratory report LA-6536 (February 1977).

4. J. P. Shipley, M. E. Bleck, C. P. Cameron, J. L. Darby, R. J. Dietz, and E. A. Hakkila, "Preliminary Concepts: International Safeguards for a Light-Water Reactor Fuels Reprocessing Plant," L_os Alamos Scientific Laboratory report LA-7551-MS (March 1979).

5. "Barnwell Nuclear Fuels Plant Separations Facility--Final Safety Analysis Report," Docket 50-332, Allied-General Nuclear Services, Barnwell, South Carolina (October 10, 1973).

6. Savannah River Laboratory document DPSTP-LWR-76-5 (Novernber 1976).

7. Savannah River Plant document DPSP-LWR-77-29 (March 1977).

8. H. A. Dayem, D. D. Cobb, R. J. Dietz, E. A. Hakkila, E. A. Kern, E. P. Schelonka, J.P. Shipley, and D. B. Smith, "Coordinated Safeguards for Materials Management in a Uranium-Plutonium Nitrate-to-Oxide Coconversion Facility: Coprecal," Los Alamos Scientific Laboratory report LA-7521 (February 1979).

9. "The Structure and Content of Agreements Between the Agency and States Required in Connection with the Treaty on the Non-Proliferation of Nuclear Weapons," International Atomic Energy Agency document INFCIRC/153 (June 1972).

10. "Treaty on the Non-Proliferation of Nuclear Weapons," International Atomic Energy Agency document INFCIRC/140 (April 1970).

11. IAEA Safeguards Technical Manual, International Atomic Energy Agency technical document IAEA-174 (Vienna, 1976).

12. V. Sukhoruchkin, "Safeguarding of Reprocessing Facilities," International Atomic Energy Agency report STR-77 (January 1979).

13. J. R. Clark, "Modifying the West Valley Reprocessing Plant," Nucl. Eng. Int. 21 (239), 27-31 (February 1976).

14. L. L. Thomas, "Separation Facility Baseline Descriptions," Allied-General Nuclear Services report NMS-9 (September 1977). 
15. "Background, Material, Summaries, and General Information on BNFP Programs and Nuclear Fuel Reprocessing," BNFP Journal (September 22, 1978).

16. S. Rippon, 'Windscale--Now to Get On and Build It," Nucl. News, 45-48 (December 1978).

17. W. Schuller, K. L. Huppert, R. von Ammon, G. Baumgartel, F. Baumgartner, H. J. Bleyl, D. Ertel, J. Furrer, H. Goldacker, P. Groll, E. Heinrich, G. Koch, R. Kroebel, W. Ochsenfeld, H. Schmieder, L. Stieglitz, W. Weinlander, and J. G. Wilhelm, "Fuel Reprocessing and Waste Treatment at Karlsruhe Nuclear Research Centre," in Nuclear Power and Its Fuel Cycle (International Atomic Energy Agency, Vienna, 1977), Vol. 3, pp. 579-592.

18. S. Rippon, "Prospects Look Good for Gorleben Center," Nucl. News, 48-53 (February 1978).

19. R. Curillon and J. Viennot, "Japanese Fuel-Reprocessing Plant Described," Energ. Nucl. 10, 160-168 (1968).

20. K. Nakajima, "Development of Safeguards Procedures for a Reprocessing Plant with Mechanical Head-End and Mixer-Settler Contactors Using a Purex Flow Sheet," International Atomic Energy Agency report IAEA/R-796-F (February 1971).

21. T. Amanuma and K. Vematsu, "Plutonium Utilization in Thermal and Fast Reactors in Japan," in Nuclear Power and Its Fuel Cycle (International Atomic Energy Agency, Vienna, 1977), Vol. 2, pp. 21-35.

22. J. Couture, J. Mameile, and P. Auchapt, "Conception, Construction, Exploitation et Entretien des Usines de Retraitement," in Nuclear Power and Its Fuel Cycle (International Atomic Energy Agency, Vienna, 1977), Vol. 3, pp. 529-545.

23. S. Cao, H. Dworschak, G. Rolandi, and R. Simonetta, "Italian Experience with Pilot Reprocessing Plants," in Nuclear Power and Its Fuel Cycle (International Atomic Energy Agency, Vienna, 1977), Vol. 3, pp. 547-559.

24. S. Rippon, "Reprocessing--What Went Wrong," Nucl. Eng. Int. 21 (239), $21-27$ (February 1976).

25. A. N. Prasad and S. V. Kumar, "Indian Experience in Fuel Reprocessing," in Nuclear Power and Its Fuel Cycle (International Atomic Energy Agency, Vienna, 1977), Vol. 3, pp. 571-578.

26. G. Koch, W. Ochsenfeld, and H. Schmieder, "Uberlegungen Zum Fliessschema Einer Wiederaufarbeitungs-Grossanlage," Atomwirtschaft 20, 123-127 (1975).

27. "Nuclear Fuel Recovery and Recycling Center, Preliminary Safety Analysis Report," Docket 50-564, EXXON Nuclear Company.

28. "Pakistan Still Wants Reprocessing Plant, Despite French Refusal," Nucleonics Week 19(39), 6 (September 28, 1978).

29. "Pakistan is Becoming Impatient with France over the Reprocessing Plant Deal," Nucleonics Week 19(32), 7 (August 10, 1978). 
30. G. Kaiser, E. Merz, F. Zimmer, H. Pirk, and P. Vygen, "Reprocessing Technology in the HTGR Fuel Cycle," in Nuclear Power and Its Fuel Cycle (International Atomic Energy Agency, Vienna, 1977), Vol. 3, pp. 661-671.

31. R. H. Allardice, C. Buck, and J. Williams, "Fast-Reactor Fuel Reprocessing in the United Kingdom," in Nuclear Power and Its Fuel Cycle (International Atomic Energy Agency, Vienna, 1977), Vol. 3, pp. 615-631.

32. "Fue! Cycle Activities of the CEA," Nucl. Eng. Int. 17, 692-695 (1972).

33. W. D. Burch and A. L. Lotts, "Developments in Reprocessing Technology for High-Temperature and Fast-Breeder Fuels," in Nuclear Power and Its Fuel Cycle (International Atomic Energy Agency, Vienna, 1977), Vol. 3, pp. 673-691.

34. "Regional Nuclear Fuel Cycle Centres," STI/PUB/445, IAEA, V ienna (1977).

35. "The Agency's Safeguards System," International Atomic Energy Agency Information Circular INFC.IRC 66, Rev. 2 (September 16, 1968).

36. C. Hough, T. Shea, and D. Tolchenkov, "Technical Criteria for the Application of IAEA Safeguards," in Nuclear Safeguards Technology 1978, Proc. Symp., Vienna, October 2-6, 1978 (International Atomic Energy Agency, Vienna, 1979), IAEA-5M-231/112, Vol. I, pp. 25-35.

37. K. Ikawa, H. Ihara, H. Sakuragi, H. Nishimura, and M. Hirata, "Study of the Application of Dymac Principles to Safequarding Spent Fuel Reprocessing Plants," Japan Atomic Energy Research Institute report JAERI-Memo-B241 (April 1979).

38. G. Lefort, P. Miguel, and M. DeRubercy, "Investigations and Testing of the Ext!action Procedure Used in the Japanese Plant," Energ. Nucl. 10, 169-180 (1968).

39. R. Rometsch, F. Lopez-Menchero, M. M. Ryzhov, C. G. Hough, and Yu. Panitkov, "Safeguards: 1975-1985," in Safeguarding Nuclear Materials, Proc. Symp., Vienna, October 20-24, 1975 (International Atomic Energy Agency, Vienna, 1976), Vol. I, pp. 3-15.

40. B. Sanders and R. Rometsch, "Safeguards Against Using Nuclear Material for Weapons," Nucl. Eng. Int. 20, 682-685 (1975).

41. R. Rometsch and G. Hough, "The Position of IAEA Safeguards Relative to Nuclear Material Control and Accountancy by States," in Nuclear Power and Its Fuel Cycle (International Atomic Energy Agency, Vienna, 1977), Vol. 7, pp. 441-454.

42. "IAEA Contribution to INFCE: The Present Status of IAEA Safeguards in Nuclear Fuel Cycle Facilities," International Atomic Energy Agency INFCE/SEC/11 (February 1979).

43. K. Nakajima, T. Koizumi, T. Yamanouchi, S. Watanabi, and N. 5uyama, "Development and Demonstration of Safeguards Techniques in the Tokai Fuel Reprocessing Plant," in Nuclear Safegue is Technology 1978, Proc. Symp., Vienna, Oc tober 2-6, 1978 (International Atomic Energy Agency, Vienna, 1979), IAEA-SM-231/34, Vol. II, pp. 701-732. 
44. Title 10 Code of Federal Regulations, Part 70.51.

45. T. 1. McSweeney, J. W. Johnston, R. A. Schneider, and D. P. Granquist, "Improved Material Accounting for Plutonium Processing Facilities and a 235-U-HTGR Fuel Fabrication Facility," Battelle-Pacific Northwest Laboratories report BMM_-2098 (October 1975).

46. R. A. Schneider and D. P. Granquist, "Capability of a Typical Material Balance Accounting System for a Chemical Processing Plant," Battelle Pacific Northwest Laboratories report BNM-1384 (May 1970).

47. "The Physical Protection of Nuclear Material," International Atomic E.nergy Agency INFCIRC/225/Rev. I (June 1977).

48. T. Shea and D. Tolohenkov, "The Role of Containment and Surveillance in IAEA Safeguards," in Nurlear Safeguards Technology 1978, Proc. Symp., Vienna, October 2-6, 1978 (International Atomic Energy Agency, Vienna, 1979), IAEA-SM-231/110, Vol. I, pp. 547-559.

49. V. Sukhoruchkin, L. Thorne, D. Perricos, D. Tolchenkov, J. Lovett, and T. Shea, "Development of the Safequards Approach for Reprocessing Plants," in Nuclear Safeguards Technology 1978, Proc. Symp., Vienna, October 2-6, 1978 (International Atomic Energy Agency, Vienna, 1979), IAEA-SM-231/1113, Vol. 1, pp. 583-59?.

50. J. E. Lovett, M. Hirata, and R. H. Augustson, "Application of the Basic Concepts of Dynamic Materials Accountancy to the Tokai Spent Fuel Reprocessing Facility: A Feasibility Study," in Proc. Symp. Safeguards and Nucl. Mater. Manage., 1st, (European Safeguards Research and Development Association, ESARDA In, April 1979), pp. $432-436$.

51. E. A. Hakkila, R. J. Dietz, J. P. Shipley, "The Role of Near-Real-Time Accounting in International Safeguards for Reprocessing Plants," Nucl. Mater. Manage. VIII, 654-665 (1979).

52. D. Gupta and J. Heil, "International Safequards in Large-Scale Nuclear Facilities," in Nuclear Power and the Fuel Cycle (Interrational Atomic Energy Agency, Vienna, 1977), Vol. 7, pp. 465-484.

53. H. A. Dayem, D. D. Cobb, R. J. Dietz, E. A. Hakkila, J. P. Shipley, and D. B. Smith, "Dynamic Materials Accounting in the Back End of the LWR Fuel Cycle," Nucl. Technol., 43, 222-243 (1979).

54. F. Brown and P. T. Good, "Increasing Importance of Containment and Surveillance in International Safequards," Nucl. Mater. Manage. VIII, 48-53 (1979).

55. J. M. Crawfard, M. H. Ehinger, C. Joseph, and M. L. Madeen, "Development of a Computerized Nuclear Materials Control and Accounting System for a Fuel Reprocessing Plant," Nucl. Mater. Manage. VIll, 405-415 (1979).

56. J. M. de Mantmollin and R. B. Walton, "The Design of Integrated Safeguards Systems

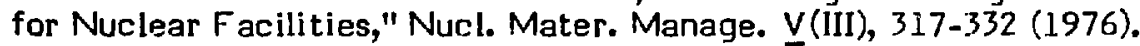


57. L. D. Chapman, J. M. de Montmollin, J. F. Deveney, W. C. Fienning, J. W. Hickman, L. D. Watkins, and A. F. Winblad, "Development of an Engineered Safeguards System Concept for a Mixed-Oxide Fuel Fabrication Facility," Sandia Laboratories report SAND76-0180 (August 1976).

58. W. C. Fienning, A. E. Winblad, and J. P. Shipley, "A Preliminary Concept Definition of a Combined Safeguards System for a Mixed-Oxide Fuel Fabrication Facility," Sandia Laboratories report SAND77-0224 (October 1977).

59. W. D. Chadwick, G. E. Rochau, W. C. Fienning, R. B. McKnight, and A. E. Winblad, "A Concept Definition of an Engineered Safeguards System for a Spent Fuel Reprocessing Facility," Sandia Laboratories report SAND77-1539 (March 1979).

60. J. P. Shipley, "The Structure of Safeguards Systems," Los Alamos Scientific L_aboratory report LA-7337-MS (May 1978).

6.l. J. H. Radke, Savannah River Plant, personal communication, 1977-1978.

62. D. D. Cobb and H. A. Dayem, "Preliminary Concepts: Safeguards for Light-Water Reactor Fuels," Los Alamos Scientific Laboratory report LA-7730-MS (June 1979).

63. T. D. Reilly, "The Measurement of Leached Hulls," Los Alamos Scientific I. ahoratory report LA-7784-MS (July 1979).

64. D. D. Cobb and D. B. Smith, "Modeling and Simulation in the Design and Evaluation of Conceptual Safeguards Systems," Nucl. Mater. Manage. VI (3) 171-184 (1977).

65. T. Naylor, J. L. Balintfy, D. S. Burdick, and K. Chu, Computer Simulation Techniques (John Wiley and Sons, New York, 1966).

66. J. Kleijnen, Statistical Techniques in Simulation (Marcel Dekker, New York, 1974).

67. A. Pritsker, The GASP IV Simulation Language (Wiley-Interscience, 1976).

68. 3. P. Shipley, "Decision Analysis for Nuclear Safeguards," in Nuclear Safeguards Analysis - Nondestructive and Analytical Chemical Techniques, E. A. Hakkila, Ed. (Am. Chem. Soc., Washington, DC, 1978), pp. 34-64.

69. James F. Shipley, "Decision Analysis for Dynamic Accounting of Nuclear Material," in Analytical Methods for Safeguards and Accountability Measurement of Special Nuclear Material, H. T. Yolken and J. E. Bullard, Eds., NBS Special Publication 528 (November 1978), pp. 83-97.

70. J. P. Shipley, "Efficient Analysis of Materials Accounting Data," Nucl. Mater. Manage. VII (3), 355-366 (1978).

71. R. E. Kalman, "A New Approach to Linear Filtering and Prediction Problems," Trans. ASME J. Basic Eng. 82D, 34-45 (March 1960).

72. R. E. Kalman and R. S. Bucy, New Results in Linear Filtering and Prediction Theory," Trans. ASME J. Basic Eng. 83D, 95-108 (March 1961). 
73. J. L. Jaech, "Statistical Methods in Nuclear Material Control," TID-26298, Technical Information Cenier, Oak Ridge, Tennessee (1973).

74. A. J. Duncan, Quality Control and Industrial Statistics, Third Edition (Richard D. Irwin, Inc., Homewood, Illinois, 1965).

75. D. H. Pike, G. W. Morrison, and C. W. Holland, "Linear Filtering Applied to Safeguards of Nuclear Material," Trans. Am. Nucl. Soc. 22, 143-144 (1975).

76. D. H. Pike, G. W. Morrison, and C. W. Holland, "A Comparison of Several Kalman Filter Models for Establishing MUF," Trans. Am. Nucl. Soc. 23, 267-268 (1976).

77. D. H. Pike and G. W. Morrison, "A New Approach to Safeguards Accounting," Oak Ridge National Laboratory report ORNL/CSD/ TM-25 (March 1977).

78. D. H. Pike and G. W. Morrison, "A New Approach to Safeguards Accounting," Nucl. Mater. Manage. VI(3), 64l-658(1977).

79. K. B. Stewart, "B-PID and Inventory Estimates with Minimum Variance," Hanford Laboratories report HN-56536 (July 1958).

80. D. D. Cobb and J. P. Shipley, "Performance Analysis of Nuclear Materials Accounting Systems," Nucl. Mater. Manage. VIII (2), 81-92 (1979).

81. K. B. Stewart, "The Loss Detection Fowers of Four Loss Estimators," Nucl. Mater. Manage. VII(3), 74-80 (1978).

82. K. Ikawa, H. Ihara, H. Nishimura, M. Hirata, H. Sakuragi, M. Iwanaga, N. Suyama, and K. Matsumoto, "Study of the Application of Semi-Dynamic Material Control Concepts to Saferuarding Spent Fuel Reprocessing Plants," presented at the ANS-INMM Conference on Measurement Technology for Safeguards and Materials Control, Kiawah Island, South Carolina, November 27-30, 1979; proceedings to be published.

83. D. Tolchenkov, A. Bilyk, and M. Honami, "Study on Estimation of Nuclear Material, Facilities Under Safeguards and Inspection Manpower Requirements for 1978-1984," International Atomic Energy Agency report STR-74 (October 197?).

84. C.P. Cameron and M. E. Bleck, "International Safeguards for a Light-Water Reactor Fuels Reprocessing Plant: Containment and Surveillance Concepts," Sandia Laboratories draft report SAND-80-0160.

85. J. P. Holmes, "Conceptual Design of a System for Detecting National Diversion of LWR Spent Fuel," Sandia Laboratories, Albuquerque report SAND 78-0192 (September 1978).

B6. S. J. Crutzen, C. J. Vinche, W. H. Burgers, M. R. Combet, "Remote-Controlled and Long-Distance Unique Identification of Reactor Fuel Elements or Assemblies" in Nuclear Safeguards Technology 1978, Proc. Symp., Vienna, October 2-6, 1978 (International Atomic Energy Agency, Vienna, 1979), IAEA-SM-231/24, Vol. 1, pp. 561-571. 
87. R. Nilson, J. F. Patterson, T. A. Sellers, 3. M. McKenzie, and S. Crutzen, "Recent Developments on a Fuel Assembly Identification System for LWR Fuel Assemblies," in Proc. Symp. Safeguards and Nucl. Mater. Manage., 1st, (European Safeguards Research and Development Association, ESARDA 10, April 1979), pp. 100-105.

88. E. J. Dowdy, A. A. Robba, R. D. Hastings, and S. W. France, "A New Instrument for the Confirmation of Declared Power Histories of Central Station Nuclear Power Plants," Nucl. Mater. Manage. VIII, 689-707 (1979).

89. F. J. Dowdy and J. T. Caldwell, Eds., "Irradiated Fuel Monitors-Preliminary Feasibility Study," Los Alamos Scientific Laboratory report LA-7699 (ISPO-51) (May 1979).

90. F. J. Dowdy, N. Nicholson, and J. Caldwell, "Irradiated Fuel Monitors by Cerenkov Glow Intensity Measurements," Los Alamos Scientific Laboratory report LA-7838-MS (September 1979).

91. D. D. Cobb, J. L. Sapir, E. A. Kern, and R. J. Dietz, "Concepts for Inventory Verification in Critical Facilities," Los Alamos Scientific Laboratory report LA-7315 (December 1978). Technical appendixes provided by $H$. O. Menlove, $N$. Ensslin, M. S. Krick, S. T. Hsue, J. T. Caldwell, P. E. Fehlau, S. W. France, and A. A. Robba of LASL Safeguards; and J. F. Ney, SLA.

92. L. Scheinman, "International Safeguards Objective - Status and Unresolved Issues: The United States View," Proc. ANS Executive Conf. on Safeguards, Hyannis, Massachusetts, October 1977.

93. F. Houck, "IAEA Safeguards from US Perspective," Nucl. Mater. Manage. VIII, 391-397 (1979).

94. L. Wh, "The Baruch Plan," Library of Congress Congressional Reference Service.

95. P. Szasz, "IAEA Safeguards," in International Safeguards at Nuclear Industries, $M$. Willrich, Ed. (Johns Hopkins Press, Baltimore, 1978), pp. 73-141.

96. L. Scheinman and R. Pendley, "International Safeguarding as Institutionalized Collective Behavior," International Organization 29, No. 3 (1975).

97. J. S. Nye, "Nonproliferation: A Long-Term Strategy," Foreign Affairs 56, 601-623 (1978).

98. L. Scheinman, "Political Implications of Safeguards," in International Safeguards at Nuclear Industries, M. Willrich, Ed. (Johns Hopkins Press, Baltimore, 1978), pP. 224-246.

99. B. Saunders, Safeguards Against Nuclear Proliferation, SEPRI Monograph (MIT Press, Cambridge, 1975).

100. C. Bennett, Battelle Human Affairs Institute, personal communication to $L$. Scheinman, July 1979. 
101. G. R. Keepin and 3. E. Lovett, "The Potential Value of Dynamic Materials Control in International Safeguards," in Nuclear Safequards Technology 1978, Proc. Symp., Vienna, October 2-6, 1978 (International Atomic Energy Agency, Vienna, 1979), IAEA-SM-231/133, Vol. II, pp. 430-434.

102. Congress of the United States, Office of Technology Assessment, Nuclear Proliferation and Safeguards (Praeger Publishers, New York, 1977).

103. E. V. Weinstock, "Some Ideas on Multinational Facilities," Brookhaven National Laboratory memorandum (Aprii 29, 1978).

104. L. Scheinman, "Towards a New Non-Proliferation Regime," Nucl. Mater. Manage. 7(1), 25-29 (1978).

105. A. Chayes and W. B. Lewis, International Arrangements for Nuclear Fuel Reprocessing (Ballinger Publishing Co., Cambridge, Massachusetts, 1976).

106. L. Scheinman, "Safeguarding Reprocessing Facilities: The Impact of Multinationalization," in International Arrangements for Nuclear Fuel Reprocessing, A. Chayes and W. B. Lewis, Eds. Gallinger Publishing Co., Cambridge, Massachusetts, 1976), pp. 65-77.

107. S. H. Smiley and K. M. Black, "Large-Scale Fuel Cycle Centres," in Nuclear Power and Its Fuel Cycle (International Atomic Energy Agency, Vienna, 1977), Vol. 3, pp. 709-722. 